\title{
Class I and Class II methanol masers in high-mass star-forming regions ${ }^{\star}$
}

\author{
F. Fontani ${ }^{1,2}$, R. Cesaroni ${ }^{3}$, and R. S. Furuya ${ }^{4}$
}

\author{
1 ESO, Karl Schwarzschild Str. 2, 85748 Garching bei München, Germany \\ 2 Institut de Radio-Astronomie Millimétrique, 300 rue de la Piscine, Domaine Universitaire, 38406 Saint Martin d'Hères, France \\ e-mail: fontani@iram.fr \\ 3 INAF-Osservatorio Astrofisico di Arcetri, L.go E. Fermi 5, 50125 Firenze, Italy \\ ${ }^{4}$ Subaru Telescope, National Astronomical Observatory of Japan, 650 North A'ohoku Place, Hilo, HI 96720, USA \\ Received 16 November 2009 / Accepted 20 April 2010
}

\section{ABSTRACT}

\begin{abstract}
Context. Among the tracers of the earliest phases in the massive star formation process, methanol masers have gained increasing importance. The phenomenological distinction between Class I and II methanol masers is based on their spatial association with objects such as jets, cores, and ultracompact HII regions, but is also believed to correspond to different pumping mechanisms: radiation for Class II masers, collisions for Class I masers.

Aims. We surveyed a large sample of massive star-forming regions in Class I and II methanol masers. The sample consists of 296 sources, divided into two groups named high and low according to their [25-12] and [60-12] IRAS colours. Previous studies indicate that the two groups may contain similar sources in different evolutionary stages, with the high sources representing the more evolved stages. Therefore, the sample can be used to assess a sequence for the occurrence of Class I and II methanol masers during the evolution of a massive star-forming region.

Methods. We observed the $6 \mathrm{GHz}$ (Class II) $\mathrm{CH}_{3} \mathrm{OH}$ maser with the Effelsberg 100-m telescope, and the $44 \mathrm{GHz}$ and $95 \mathrm{GHz}$ (Class I) $\mathrm{CH}_{3} \mathrm{OH}$ masers with the Nobeyama 45-m telescope.

Results. We detected 55 sources in the Class II line (39 high and 16 low, 12 new detections); 27 sources in the $44 \mathrm{GHz}$ Class I line (19 high and 8 low, 17 new detections); 11 sources in the $95 \mathrm{GHz}$ Class I line (eight high and three low, all except one are new detections). The detection rate of Class II masers decreases with the distance of the source (as expected), whereas that of Class I masers peaks at $\sim 5 \mathrm{kpc}$. This could be due to the Class I maser spots being spread over a region $\lesssim 1 \mathrm{pc}$, comparable to the telescope beam diameter at a distance of $\sim 5 \mathrm{kpc}$. We also find that the two Class I lines have similar spectral shapes at $44 \mathrm{GHz}$ and $95 \mathrm{GHz}$, which confirms that they have the same origin.

Conclusions. Our statistical analysis shows that the ratio between the detection rates of Class II and Class I methanol masers is basically the same in high and low sources. Therefore, both maser types seem to be equally associated with each evolutionary phase. In contrast, all maser species (including $\mathrm{H}_{2} \mathrm{O}$ ) have about three times higher detection rates in high than in low sources. This could indicate that the phenomena from which all masers originate become progressively more active with time during the earliest evolutionary phases of a high-mass star-forming region.
\end{abstract}

Key words. stars: formation - ISM: molecules - masers

\section{Introduction}

Maser lines of water $\left(\mathrm{H}_{2} \mathrm{O}\right)$, hydroxyl $(\mathrm{OH})$, and methanol $\left(\mathrm{CH}_{3} \mathrm{OH}\right)$ are commonly detected towards regions of high-mass star-formation (e.g. Comoretto et al. 1990; Menten 1991; Kurtz et al. 2000; Pestalozzi et al. 2005). Among these, methanol masers are the most recently discovered, and their place in the star-formation process is still not well understood. Menten (1991) suggested to classify methanol masers into two groups, Class I and Class II. The latter typically coincide in position with hot molecular cores, ultracompact (UC) HII regions, $\mathrm{OH}$ masers and near-IR sources (e.g. Minier et al. 2001; Ellingsen et al. 2006) and are believed to be radiatively pumped (Sobolev et al. 2007, and references therein; Cragg et al. 2005). In contrast, Class I masers are also found in massive star-forming regions, but usually offset $(\sim 0.1-1 \mathrm{pc})$ from other masers, UC HII regions, and bright infrared sources. They seem to be collisionally pumped (Cragg et al. 1992) at the interface between molecular

^ Appendices are only available in electronic form at http://www . aanda.org outflows/jets and the quiescent ambient material (Plambeck \& Menten 1990). This scenario is supported by observations that reveal a coincidence between Class I methanol masers at $44 \mathrm{GHz}$ and molecular shock tracers (Kurtz et al. 2004; Voronkov et al. 2006).

Even though both species are believed to trace the earliest phases of the massive star-formation process, it is still not clear whether any physical relation exists among them. Slysh et al. (1994) claim an anticorrelation between the intensity of Class I and II methanol masers in the same star-forming region. On the other hand, Ellingsen (2005) searched for Class I masers at $95 \mathrm{GHz}$ towards a sample of known $6 \mathrm{GHz}$ Class II masers and could not find any (anti)correlation between the two. It is also poorly understood whether a relationship exists between the occurrence of Class I and II masers and the evolution of the corresponding massive star-forming region. Van der Walt (2005) estimated a lifetime of the $6 \mathrm{GHz}$ Class II methanol maser of a few $10^{4} \mathrm{yrs}$, thus covering a consistent part of the early life of a massive star. Ellingsen (2006) compared the infrared (GLIMPSE) colours of sources containing Class II methanol masers with or without a Class I methanol maser, and found 
that those associated with Class I masers have redder GLIMPSE colours, suggesting that the sources hosting Class I masers are less evolved (see also Breen et al. 2010). However, until now an evolutionary sequence of methanol masers occurence has not been well established, partly because Class I masers are less studied and models for some Class I lines show that their excitation is very sensitive to the physical properties of the environment (Pratap et al. 2008).

To investigate a sequence for the occurrence of Class I and II methanol masers along the evolution of a massive star-forming region, one needs to study large samples of high-mass young stellar objects (YSOs) believed to be in different evolutionary stages. A large sample of massive YSO candidates with this property was identified by Palla et al. (1991): the sources, all with $\delta \geq-30^{\circ}$, were selected on the basis of their high luminosities $\left(>10^{3} L_{\odot}\right)$ and far-infrared (FIR) colours typical of dense molecular clumps. These have been divided into two subsamples based on the IRAS colours ${ }^{1}$ : sources with [25 - 12] $>0.57$ and $[60-12]>1.3$ were named high, the others low. The threshold was taken from Wood \& Churchwell (1998), who suggested that UC HII regions have IRAS colours above these limits. Palla et al. (1991) searched for $22 \mathrm{GHz} \mathrm{H_{2 }} \mathrm{O}$ masers towards high and low sources, and found a higher detection rate in high sources. In the last decade a series of studies aimed at investigating the environment associated with these sources (association with ammonia cores, centimetre and (sub-)millimetre continuum emission, ${ }^{12}$ CO outflows: Molinari et al. 1996, 1998a, 2000; Brand et al. 2001; Zhang et al. 2001, 2005) indicated that low and high sources are massive stars in a very early evolutionary stage, with the low group dominated by the youngest sources. Two prototypical examples of high and low objects are IRAS 20126+4104 (Cesaroni et al. 1997, 1999) and IRAS 23385+6053, respectively (Molinari et al. 1998b; Fontani et al. 2004; Molinari et al. 2008).

We have searched for $6 \mathrm{GHz}$ (Class II), $44 \mathrm{GHz}$ (Class I) and $95 \mathrm{GHz}$ (Class I) $\mathrm{CH}_{3} \mathrm{OH}$ maser emission in the high and low sources of the Palla et al. (1991) sample with the aim to find a possible evolutionary sequence for the occurrence of the different masers. The observations were made with the Effelsberg 100-m telescope (at $6 \mathrm{GHz}$ ) and Nobeyama 45-m telescope (at 44 and $95 \mathrm{GHz}$ ). In Sect. 2 we give an overview of the observations performed and of the data reduction procedure adopted. The results are presented in Sect. 3 and discussed in Sect. 4. A summary of the main findings is given in Sect. 5.

\section{Observations and data reduction}

\subsection{Effelsberg 100-m telescope observations and data reduction}

The $51_{1}-6_{0} \mathrm{~A}^{+}$Class II methanol maser line at $6.6685192 \mathrm{GHz}$ was observed with the Effelsberg 100-m antenna towards 296 sources (149 high and 147 low; see Table B.1) in May 2003. These consist of all the 260 sources selected by Palla et al. (1991), plus 36 sources with FIR colours characteristic of high and low sources but rejected by Palla et al. (1991) because associated with known HII regions. Data were obtained using two spectral windows corresponding to the right- (RCP) and left- (LCP) circular polarization. Each spectral window had a $\sim 500 \mathrm{~km} \mathrm{~s}^{-1}$ bandwidth with a spectral resolution of $\sim 0.11 \mathrm{~km} \mathrm{~s}^{-1}$ (4096 channels). For sources previously detected in ammonia by Molinari et al. (1996), we centred the windows at the local standard of rest (LSR) velocity, $V_{\mathrm{LSR}}$, obtained from the

\footnotetext{
${ }^{1}$ We define the IRAS colours as $\left[\lambda_{1}-\lambda_{2}\right]=\log _{10}\left(F_{\lambda_{1}} / F_{\lambda_{2}}\right)$.
}

$\mathrm{NH}_{3}$ observations. For the other sources the bandwidth was centred at $0 \mathrm{~km} \mathrm{~s}^{-1}$. The half power beam width at the frequency of the $\left(5_{1}-6_{0} \mathrm{~A}^{+}\right)$methanol line is $\sim 120^{\prime \prime}$. Because the two polarisations had remarkably different system temperatures ( $45 \mathrm{~K}$ for the LCP and $120 \mathrm{~K}$ for the RCP) due to a technical problem, we used only the LCP spectra in the analysis. The conversion factor between main beam brightness temperature and flux density is $1.45 \mathrm{Jy} / \mathrm{K}$. The spectra have a typical $3 \sigma \mathrm{rms}$ of $\sim 0.15 \mathrm{Jy}$, comparable to the high-sensitivity survey of $6 \mathrm{GHz}$ methanol masers performed by Caswell et al. (2010). The pointing was checked towards $\mathrm{W} 3 \mathrm{OH}$ and $3 \mathrm{C} 123$, and the pointing accuracy was always better than $20^{\prime \prime}$. The flux density scale was calibrated by observing NGC7027, whose flux was assumed equal to $5.9 \mathrm{Jy}$ and the flux calibration uncertainty is estimated to be of the order of $\pm 10 \%$.

The data were reduced and analysed by means of the CLASS software, which is part of the GILDAS package ${ }^{2}$ developed at IRAM and Observatoire de Grenoble.

\subsection{Nobeyama 45- $m$ telescope observations and data reduction}

Observations of the Class I $44.069476 \mathrm{GHz}\left(7_{0}-6_{1} \mathrm{~A}^{+}\right)$and $95.169489 \mathrm{GHz}\left(8_{0}-7_{1} \mathrm{~A}^{+}\right)$methanol lines towards 88 of the sources observed in the $6 \mathrm{GHz}$ line were performed with the Nobeyama Radio Observatory (NRO) 45-m telescope in April 2002. The 88 sources were randomly selected among the 260 sources of Palla et al. (1991), depending on the available observing time, and should not have introduced any bias in the sub-sample. We used two SIS receivers simultaneously, centred at the rest frequencies of the lines. The half power beam width was $\sim 38^{\prime \prime}$ at $44 \mathrm{GHz}$ and $\sim 18^{\prime \prime}$ at $95 \mathrm{GHz}$. The observations were made in position-switching mode. The telescope pointing was checked observing nearby $\mathrm{SiO}$ maser sources at $43 \mathrm{GHz}$; we estimated a pointing accuracy of $3^{\prime \prime}$. The main beam efficiencies were 0.75 and 0.53 at 44 and $95 \mathrm{GHz}$, respectively. As a backend, we used the AOS-H which provides velocity resolutions of $\sim 0.14 \mathrm{~km} \mathrm{~s}^{-1}$ at $44 \mathrm{GHz}$ and $\sim 0.06 \mathrm{~km} \mathrm{~s}^{-1}$ at $95 \mathrm{GHz}$. The AOS-H arrays had velocity coverages of $272 \mathrm{~km} \mathrm{~s}^{-1}$ at $44 \mathrm{GHz}$ and $126 \mathrm{~km} \mathrm{~s}^{-1}$ at $95 \mathrm{GHz}$, and were centred at the same velocity used for the $6 \mathrm{GHz}$ observations. The system temperature was $~ 300-500 \mathrm{~K}$ at $44 \mathrm{GHz}$, and $700-1300 \mathrm{~K}$ at $95 \mathrm{GHz}$. All the spectra were calibrated with the standard chopper wheel method. Assuming that the telescope beam is Gaussian, the conversion between the main-beam brightness temperature, $T_{\mathrm{MB}}$, and flux density, $F_{v}$, is $F_{v}(\mathrm{Jy})=2.23 T_{\mathrm{MB}}(\mathrm{K})$. We reduced the data using the NEWSTAR package developed by the NRO. Subsequently, the fully reduced spectra were converted into CLASS format for further scientific analysis.

Towards some of the sources observed in the $\mathrm{CH}_{3} \mathrm{OH}$ lines, we also obtained spectra of the ammonia $(1,1),(2,2)$, and $(3,3)$ inversion transitions. The details of these $\mathrm{NH}_{3}$ spectra are not presented in this work; we used these spectra only to derive the systemic LSR velocities, $V_{\text {sys }}$, of the sources whose $V_{\text {sys }}$ cannot be found in the literature (see Tables B.2 and B.3, and Sect. 4.3).

\section{Results}

In this section we present the detections in the three lines observed, and the parameters obtained from the fitting procedure described in Sects. 2.1 and 2.2. Spectra of all detected sources

\footnotetext{
2 The GILDAS software is available at http : //www . iram. fr/IRAMFR/GILDAS
} 
Table 1. Sources observed (O), detected (D) and corresponding detection rates (DR) of $\mathrm{CH}_{3} \mathrm{OH}$ masers, and $\mathrm{H}_{2} \mathrm{O}$ maser at $22 \mathrm{GHz}$ in high and low sources.

\begin{tabular}{|c|c|c|c|c|c|c|c|c|c|c|c|c|c|}
\hline & \multicolumn{3}{|c|}{$6 \mathrm{GHz}$} & \multicolumn{3}{|c|}{$44 \mathrm{GHz}$} & \multicolumn{3}{|c|}{$95 \mathrm{GHz}$} & \multirow{2}{*}{$\overline{\mathrm{H}_{2} \mathrm{O}}$} & \multirow{2}{*}{$44 \mathrm{GHz} / 6 \mathrm{GHz}$} & \multirow{2}{*}{$\overline{\mathrm{H}_{2} \mathrm{O} / 6 \mathrm{GHz}}$} & \multirow{2}{*}{$44 \mathrm{GHz} / \mathrm{H}_{2} \mathrm{O}$} \\
\hline & $\mathrm{O}$ & $\mathrm{D}$ & $\overline{\mathrm{DR}}$ & $\mathrm{O}$ & $\mathrm{D}$ & $\overline{D R}$ & $\mathrm{O}$ & $\mathrm{D}$ & $\overline{D R}$ & & & & \\
\hline high & 147 & 39 & $27 \pm 4 \%$ & 40 & 19 & $48 \pm 8 \%$ & 40 & 8 & $20 \pm 6 \%$ & $28 \pm 4 \%$ & $1.8 \pm 0.6$ & $1.0 \pm 0.3$ & $1.8 \pm 0.5$ \\
\hline low & 149 & 16 & $11 \pm 3 \%$ & 48 & 8 & $17 \pm 5 \%$ & 48 & 3 & $6 \pm 3 \%$ & $9 \pm 2 \%$ & $1.5 \pm 0.8$ & $0.8 \pm 0.4$ & $1.9 \pm 1.0$ \\
\hline total & 296 & 55 & $19 \pm 2 \%$ & 88 & 27 & $31 \pm 5 \%$ & 88 & 11 & $13 \pm 4 \%$ & & & & \\
\hline high/low & & & $2.9 \pm 1.3$ & & & $2.5 \pm 1.1$ & & & $3.3 \pm 1.4$ & $3.1 \pm 1.1$ & $1.2 \pm 1.0$ & $1.2 \pm 1.0$ & $0.9 \pm 0.7$ \\
\hline
\end{tabular}

are shown in Appendix A. The spectra are grouped as follows: sources detected in all three lines are shown in Fig. A.1; sources detected only in the $6 \mathrm{GHz}$ and $44 \mathrm{GHz}$ lines are shown in Fig. A.2; sources detected only in the $44 \mathrm{GHz}$ and $95 \mathrm{GHz}$ lines are shown in Fig. A.3; sources detected only in the $6 \mathrm{GHz}$ line are shown in Figs. A.4 and A.4; sources detected only in the $44 \mathrm{GHz}$ line are shown in Fig. A.5. The list of detection and non-detections as well as the main parameters of the lines are tabulated in Appendix B.

\subsection{New detections}

Our survey has been cross-correlated with catalogues and large surveys of both Class I and II methanol masers. For the $6.7 \mathrm{GHz}$ line, we used the catalogue of Pestalozzi et al. (2005), and the recent works of Cyganowski et al. (2009) and Caswell et al. (2010). For the Class I lines we used the catalogue of Val'tts \& Larionov (2007); Chen et al. (2009); Pratap et al. (2008); Cyganowski et al. (2009). We have found 12 new 6.7 GHz methanol masers, 17 new $44 \mathrm{GHz}$ methanol masers (of which three are marginal detections). To our knowledge, all the sources detected in the $95 \mathrm{GHz}$ methanol masers except IRAS $21391+5802$ (detected in Val'tts et al. 1995) are new detections.

The new detections are marked in italics in Table B.1.

\subsection{Observed sources and detection summary}

The observed sources are listed in Table B.1. The IRAS name, the type (high $=\mathrm{H}$; low $=\mathrm{L}$ ), and the corresponding equatorial coordinates are reported in Cols. 1 to 4 . In Col. 5 we give the velocities used for the observations (see Sect. 2.1). In Cols. 6 to 8 we give the following information: source detected (Y), undetected $(\mathrm{N})$, or not observed $(-)$ in the three $\mathrm{CH}_{3} \mathrm{OH}$ lines $(6 \mathrm{Ghz}$ in Col. 6, $44 \mathrm{GHz}$ in Col. 7, $95 \mathrm{GHz}$ in Col. 8). For the sake of completeness, we give in Col. 9 the same information for the $22 \mathrm{GHz} \mathrm{H} \mathrm{H}_{2} \mathrm{O}$ maser emission. For this, the information was taken from Palla et al. (1991), Valdettaro et al. (2001), Wouterloot et al. (1993), Henning et al. (1992), and Medicina archival data.

In Fig. 1 we plot a sketch summarising the number of sources in which one, two, or all three lines have been detected. Given that the sample observed in the Class $\mathrm{I} \mathrm{CH}_{3} \mathrm{OH}$ masers is much smaller than that observed in the other two lines, for the $\mathrm{H}_{2} \mathrm{O}$ and Class II $\mathrm{CH}_{3} \mathrm{OH}$ masers we also give the number of detected sources that have been observed also in the Class I maser (numbers in parentheses in Fig. 1).

The number of sources observed and detected in the three maser species, and the corresponding detection rates, are summarised in Table 1 . We also give the same information for the $22 \mathrm{GHz} \mathrm{H}_{2} \mathrm{O}$ maser (Col. 11) and some detection rate ratios: $44 \mathrm{GHz} / 6 \mathrm{GHz}$ (Col. 12), $\mathrm{H}_{2} \mathrm{O} / 6 \mathrm{GHz}$ (Col. 13) and $44 \mathrm{GHz} / \mathrm{H}_{2} \mathrm{O}$ (Col. 14). For the Class I $\mathrm{CH}_{3} \mathrm{OH}$ maser line, we consider the $44 \mathrm{GHz}$ line only because all sources detected at $95 \mathrm{GHz}$ have

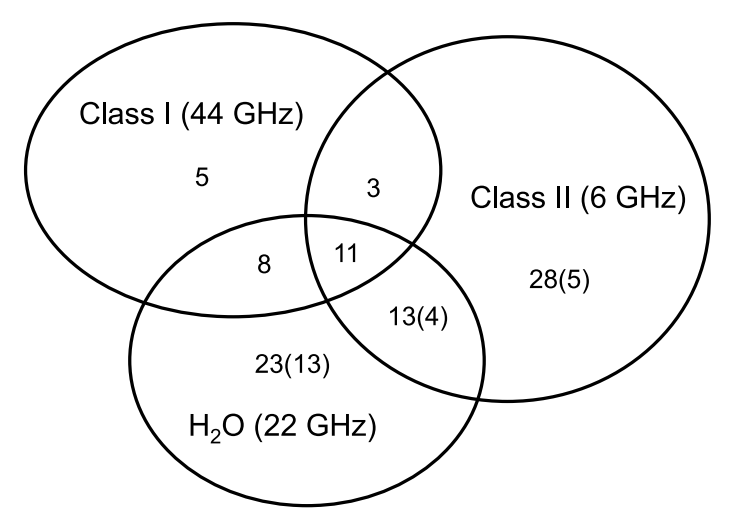

Fig. 1. Sketch showing the number of sources detected in the three maser lines. In parentheses we give the number of sources detected in the $22 \mathrm{GHz} \mathrm{H}_{2} \mathrm{O}$ maser and/or in the Class II $\mathrm{CH}_{3} \mathrm{OH}$ maser also observed in the Class $\mathrm{I}(44 \mathrm{GHz}) \mathrm{CH}_{3} \mathrm{OH}$ maser.

also been detected at $44 \mathrm{GHz}$. One can notice that the detection rates of the Class II masers are comparable to those of $\mathrm{H}_{2} \mathrm{O}$ masers both in high and low sources (respectively, 27\% and 28\% in high sources, $11 \%$ and $9 \%$ in low sources), whereas the Class I masers have a higher detection rate than Class II and $\mathrm{H}_{2} \mathrm{O}$ masers in both source types (48\% in high sources, $17 \%$ in low sources).

The high/low detection ratio given in Table 1 has the purpose to highlight possible differences between the relative occurrence of masers of Class I and II in high and low sources: The most evident result from Table 1 is that the detection rates in all the masers (Class I, Class II, $\mathrm{H}_{2} \mathrm{O}$ ) are greater in high than in low sources. On the other hand, their ratios seem to be independent of the distinction between high and low (Cols. 12-14). Therefore, our analysis does not reveal any significant difference in the relative occurrence of the different masers observed in high and low sources. We propose an interpretation of this result in Sect. 4.1.

The $95 \mathrm{GHz}$ Class I line has the lowest total detection rate $(13 \%)$ and all the sources detected in this line have been detected also in the Class I $44 \mathrm{GHz}$ line. We checked whether the different detection rates in the two Class I masers $(31 \%$ at $44 \mathrm{GHz}$ versus $13 \%$ at $95 \mathrm{GHz}$ ) could be due to worse signal-to-noise ratio $(\mathrm{S} / \mathrm{N})$ at $95 \mathrm{GHz}$ than at $44 \mathrm{GHz}$. For this purpose, we first estimated the noise level that one should have had in the $44 \mathrm{GHz}$ spectra to achieve the same average $\mathrm{S} / \mathrm{N}$ as in the $95 \mathrm{GHz}$ spectra: this is $0.7-0.8 \mathrm{Jy}$. Then we computed the detection rate that we would have achieved at $44 \mathrm{GHz}$ with this noise: this turns out to be $25 \%$, which is still significantly higher than the $13 \%$ obtained for the $95 \mathrm{GHz}$ line. Therefore the different detection rates in the two lines cannot be attributed only to the different noise level, but must be due to different intensities of the two masers. 


\subsection{Parameters of the $6 \mathrm{GHz}$ (Class II) $\mathrm{CH}_{3} \mathrm{OH}$ masers}

In Table B.2 we list the parameters obtained from Gaussian fits to the $6 \mathrm{GHz}$ maser lines for high sources. In Col. 2 we give the systemic velocity $\left(V_{\mathrm{LSR}}\right)$ of the sources. This was obtained mainly from $\mathrm{NH}_{3}$ observations ${ }^{3}$. The best-fit parameters are given in Cols. 3 to 6 as follows: integrated intensity (Col. 3); peak velocity (Col. 4); line width at half maximum (Col. 5); peak intensity (Col. 6). The same information is given for low sources in Table B.3. As can be seen from the spectra in Figs. A.1-A.4, in the large majority ( $85 \%)$ of the detected sources the emission consists in multiple peaks spread over a well defined velocity range rather than in a single line. Interestingly, only two out of the seven sources with only one line in the spectrum belong to the high group. Indeed, $94 \%$ of the detected high sources have multiple lines, while only $70 \%$ of low sources do. The line widths are between 0.2 and $0.9 \mathrm{~km} \mathrm{~s}^{-1}$ in the large majority $(\sim 95 \%)$ of the lines, and never exceed $1.5 \mathrm{~km} \mathrm{~s}^{-1}$ except in two cases: 18089-1732, and one line in the spectrum of 18048-2019. We believe that in these sources (especially 18089-1732, for which we derive a line width of $10 \mathrm{~km} \mathrm{~s}^{-1}$ ) the broad linewidths are due to blending of several narrow lines. This is suggested because that other surveys of this maser transition in similar IRAS sources (Szymczak \& Kus 2000) have revealed line widths narrower than $1 \mathrm{~km} \mathrm{~s}^{-1}$ in all cases.

In our survey we find a median flux density peak of $\sim 15 \mathrm{Jy}$ and a median number of lines per spectrum of 4 (see Tables B.2 and B.3). Among the new detections, only two sources have components with peak flux densities in excess of $6 \mathrm{Jy}$, IRAS $05480+2545$ and IRAS 18024-2119, and 10 out of 12 sources have less than five components.

Walsh et al. (1997) observed a sample of 535 IRAS sources

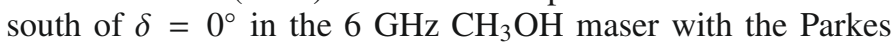
64-m telescope. They observed four sources that have also been observed in our survey (18159-1648, 18236-1205, 18265-1517 and 18316-0602), all belonging to the high group. We find a good agreement - both in the flux densities of the lines and in the velocity ranges - between the spectra taken with the two telescopes in all sources, except 18236-1205. In 18236-1205, the Parkes 64-m observations show more spectral features and an intensity more than twice the one observed by us with the Effelsberg 100-m telescope. This is likely due to the variability of the maser line. In the sources detected in the Parkes survey, the median value of the flux density peak is $\sim 13 \mathrm{Jy}$, and the median number of lines per spectrum (i.e. per source) is 5 (Walsh et al. 1997), consistent with our findings.

\subsection{Parameters of the 44 and $95 \mathrm{GHz}$ (Class I) $\mathrm{CH}_{3} \mathrm{OH}$ masers}

The parameters obtained from Gaussian fits to the spectra observed towards both high and low sources at $44 \mathrm{GHz}$, shown in Figs. A.1-A.3 and A.5, are given in Table B.4. The structure of the table is the same as Tables B.2 and B.3, but a letter has been added to the IRAS name to denote if the source belongs to the high $(\mathrm{H})$ or low $(\mathrm{L})$ sample. Thirteen of the 27 detected objects

\footnotetext{
${ }_{3}^{3}$ For most sources the velocity is taken from the $\mathrm{NH}_{3}$ survey by Molinari et al. (1996); for seven sources it is estimated from $\mathrm{NH}_{3}$ spectra obtained with the Nobeyama 45-m telescope during the same observing run allocated for the observations of the $\mathrm{CH}_{3} \mathrm{OH}$ masers (see Sect. 2.2); for the remaining sources we took the systemic velocities from Sridharan et al. (2002); Bronfman et al. (1996, from observations of the CS(2-1) line); Richards et al. (1987) from observations of $\mathrm{HCO}^{+}(1-0)$; Sunada et al. (2007) and references therein.
}

(i.e. $\sim 50 \%$ ) are undetected in the $6 \mathrm{GHz}$ line, among which is the brightest $44 \mathrm{GHz}$ source, 18018-2426. Contrary to the $6 \mathrm{GHz}$ lines, at $44 \mathrm{GHz}$ only eight sources out of the 27 detected show multiple components, and the line widths are generally broader than, or comparable to, $1 \mathrm{~km} \mathrm{~s}^{-1}$; only $31 \%$ of the sources show linewidths below this limit (see Table B.4). In addition, the lines are not very bright on average: except 18018-2426, for which the peak flux is $\sim 350 \mathrm{Jy}$, the others have intensities of the order of 1-10 Jy. We did not find any systematic differences between the old and new detections neither in the peak fluxes nor in the line widths.

The relatively broad linewidths suggest either that some of the lines are thermal or that they are the superposition of several blended components. We believe that the second possibility is more likely on the basis of the VLA observations of Kurtz et al. (2004). These authors observed some of our sources with better sensitivity and angular resolution revealing multiple components spread over a velocity range comparable to the line widths measured by us with the Nobeyama 45-m telescope. The sources in common with the survey of Kurtz et al. (2004) are 18144-1723, 18162-1612, 19092+0841, $21307+5049,21391+5802$ and $23385+6053$. All of them were also detected in our observations with the sole exception of $21307+5049$, which has an intensity peak of $\sim 1 \mathrm{Jy}$ in the observations of Kurtz et al. (2004). Because this value is higher than the $3 \sigma \mathrm{rms}$ in our observations, the intensity of this maser has probably decreased with time. In 18144-1723, 19092+0841 and $23385+6053$ we detect only one line, while Kurtz et al. (2004) detected multiple lines separated by about $2-3 \mathrm{~km} \mathrm{~s}^{-1}$. This can explain the line widths observed in our study $(\sim 1.5,5.7$ and $3.2 \mathrm{~km} \mathrm{~s}^{-1}$, respectively). We thus conclude that most of the line widths $>1 \mathrm{~km} \mathrm{~s}^{-1}$ are likely due to multiple components having small $\left(\leq 0.5 \mathrm{~km} \mathrm{~s}^{-1}\right)$ velocity separations. This is also supported by the study of Slysh et al. (1994), who detected the $44 \mathrm{GHz}$ line in 148 massive young stellar objects similar to those studied in this work, and derived linewidths $\lesssim 1 \mathrm{~km} \mathrm{~s}^{-1}$ in the large majority (87\%, against our $31 \%$ ) of the sources.

Finally, in Table B.5 we list the line parameters obtained from Gaussian fits to the spectra at $95 \mathrm{GHz}$. All sources detected in this line were also detected in the $44 \mathrm{GHz}$ transition (see Table B.1). At 95 GHz, as well as at 44 GHz, 18018-2426 is the brightest source. The line widths are distributed around $1-2 \mathrm{~km} \mathrm{~s}^{-1}$, and the peak intensities are of the order of $1 \mathrm{Jy}$, with the above mentioned exception of 18018-2426 ( 50 Jy), suggesting that some of the detected lines might be thermal. In the survey of Kalenskii et al. (1994), the linewidths are similar to those measured in our sources, but the intensities are comparable to or higher than $40 \mathrm{Jy}$, suggesting maser emission.

At first glance, the spectra of the $44 \mathrm{GHz}$ and $95 \mathrm{GHz}$ masers shown in Figs. A.1 and A.3 indicate that the shape of these two lines are similar in a given source, and clearly different from that of the corresponding $6 \mathrm{GHz}$ maser. To analyse this effect more quantitatively, we normalised each spectrum with respect to the peak intensity and then calculated the quantity $\left|f_{95 \mathrm{GHz}}-f_{44 \mathrm{GHz}}\right| / f_{44 \mathrm{GHz}}$, where $f_{v}$ indicates the integral under the lines of the normalised spectrum. In Fig. 2 we plot this quantity as a function of the flux integrated under the $44 \mathrm{GHz}$ lines, $F_{44 \mathrm{GHz}}$, for 9 out of the 11 sources detected in both lines. We did not include 18396-0431, because the detection at $44 \mathrm{GHz}$ is very doubtful. We also excluded $21391+5802$, for which the 95 and $44 \mathrm{GHz}$ lines have inconsistent velocity ranges. Figure 2 demonstrates that seven sources, i.e. $\sim 65 \%$ of the total, have relative deviations $\leq 0.3$. Even though the number of sources is very low, this result indicates that the two Class I masers have similar 


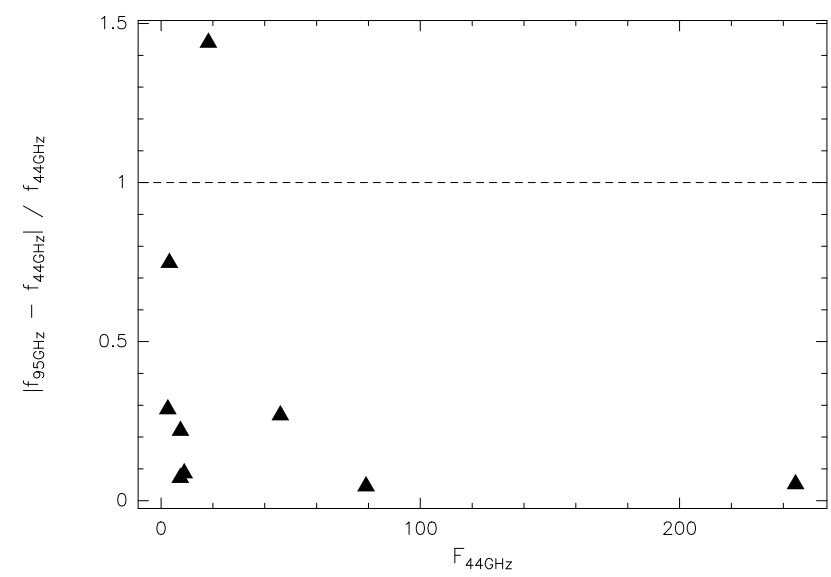

Fig. 2. Relative difference between the integrated intensity of the lines in the normalised spectra (see text) at $95 \mathrm{GHz}$ and $44 \mathrm{GHz}$, $\left|f_{95 \mathrm{GHz}}-f_{44 \mathrm{GHz}}\right| / f_{44 \mathrm{GHz}}$, as a function of the integrated flux $F_{44 \mathrm{GHz}}$ for 9 out of the 11 sources detected in both lines. We did not include $18396-0431$ because it is only marginally detected in the $44 \mathrm{GHz}$ line, and 21391+5802, for which the 95 and $44 \mathrm{GHz}$ lines have inconsistent velocity ranges.

shapes in the majority of the sources detected in both lines, thus confirming the findings of previous studies (e.g. Val'tts et al. 1995).

\section{Discussion}

An important caveat to be kept in mind when considering our results is that the angular resolution of our observations $\left(18^{\prime \prime}-120^{\prime \prime}\right)$ corresponds to a maximum linear scale of several parsecs. Regions that large contain a multiplicity of YSOs, possibly in different evolutionary stages, so that it is impossible to associate our findings for a given maser species with a single object. Nevertheless, our results have a statistical significance in the sense that they represent the mean properties of the whole star-forming region encompassed by the telescope beam. The validity of this approach is demonstrated by the distinction itself between high and low sources, which is based on the IRAS data, whose resolution is similar to that of our observations. In this regard, we also stress that such a similarity guarantees a consistent comparison between our findings and the source classification based on the IRAS colours.

For these reasons, it is not surprising that we do not find neither a correlation nor an anti-correlation between the intensity of Class I and that of Class II masers. While this might be expected for different maser types associated with single YSOs, any such effect is bound to disappear when multiple sources are observed altogether. On the other hand, one can still use the detection rates described in Sect. 3.2 to draw statistical conclusions on the relative evolutionary phase of the different maser types. This will be done in Sect. 4.1.

Below we will also illustrate and compare properties such as the typical line width and the line velocity dispersion for the different maser types.

\subsection{Detection rates: high versus low sources}

The most evident result of this work is that for all maser types the detection rates are a factor of $\sim 3$ greater in high sources than in low sources, which indicates that all types of maser emission in a high-mass star-forming region become more easily excited

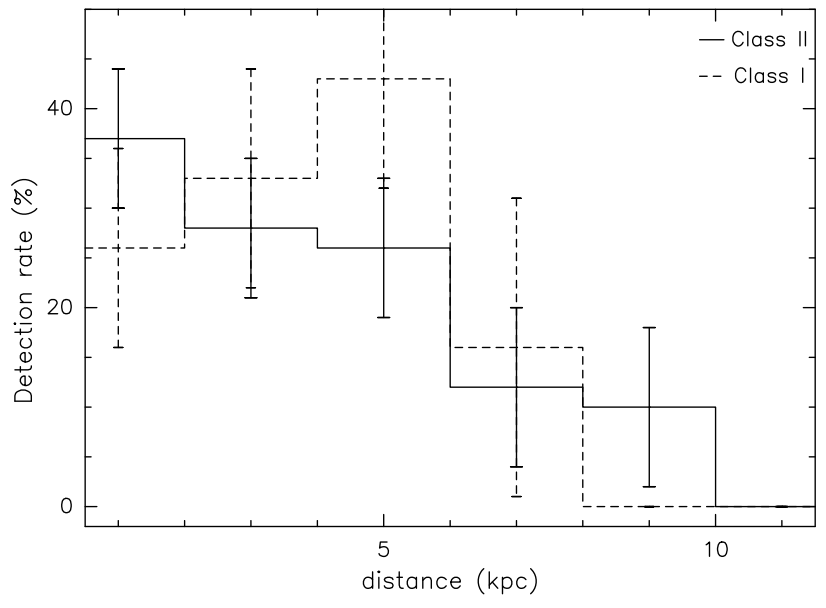

Fig. 3. Distributions of the detection rate for the Class II $6 \mathrm{GHz}$ maser (solid line) and Class I $44 \mathrm{GHz}$ maser (dashed line) as a function of the source distance.

as evolution proceeds. This conclusion is confirmed because, as noted in Sect. 3.2, the ratio between the detection rates of two different maser types does not change significantly from high to low sources. In other words, all masers appear to evolve in a similar way from the low to the high phase, because the proportion of detected masers remains the same in low and high sources.

A possible interpretation of these results is that all phenomena triggering population inversion and hence maser emission (outflow/accretion shocks, hot dust emission, etc.) become more and more prominent during the evolution. Therefore, as time goes on, the number of bipolar outflows, accretion disks, and luminous infrared sources increases in a given star-forming region, thus leading to a corresponding increase of the number of maser sources.

Our findings appear to contradict the suggestion by Ellingsen (2006) that Class I masers are associated with younger sources than those associated with $\mathrm{CH}_{3} \mathrm{OH}$ Class II and $\mathrm{H}_{2} \mathrm{O}$ masers. However, Ellingsen's claim is admittedly based on a low number of sources and, as stated by the author himself, is rather speculative. A larger number of data with better angular resolution for both methanol maser types will be needed before drawing any conclusion on this issue.

\subsection{Detection in Class I and II masers and source distance}

In Fig. 3 we plot the detection rates for the $\mathrm{CH}_{3} \mathrm{OH}$ masers at $6 \mathrm{GHz}$ (Class II) and $44 \mathrm{GHz}$ (Class I) as a function of the source distance. The kinematic distance was taken from the following papers: Molinari et al. (1996, 2008); Sridharan et al. (2002); Zhang et al. (2005); Sunada et al. (2007). The plot shows that most of the sources detected at $6 \mathrm{GHz}$ have distances between 1 and $5 \mathrm{kpc}$ and the detection rate rapidly decreases with increasing distance. This is an obvious consequence because the closer the source, the higher is the measured flux. However, while the Class II maser detection rate increases all the way to the smallest distances, that of the Class I masers attains a maximum at $\sim 5 \mathrm{kpc}$ ( $45 \%$ of the sources observed between 4 and $6 \mathrm{kpc}$ are detected) and then decreases for smaller distances, even though the distance distribution of the whole sample peaks at distances lower than $\sim 5 \mathrm{kpc}$ (see Fig. 3 in Molinari et al. 1996). Our interpretation is that in each source the Class I maser spots are spread over a significantly larger region than that of the Class II maser spots. Consequently, in the closest objects part (or all) of 


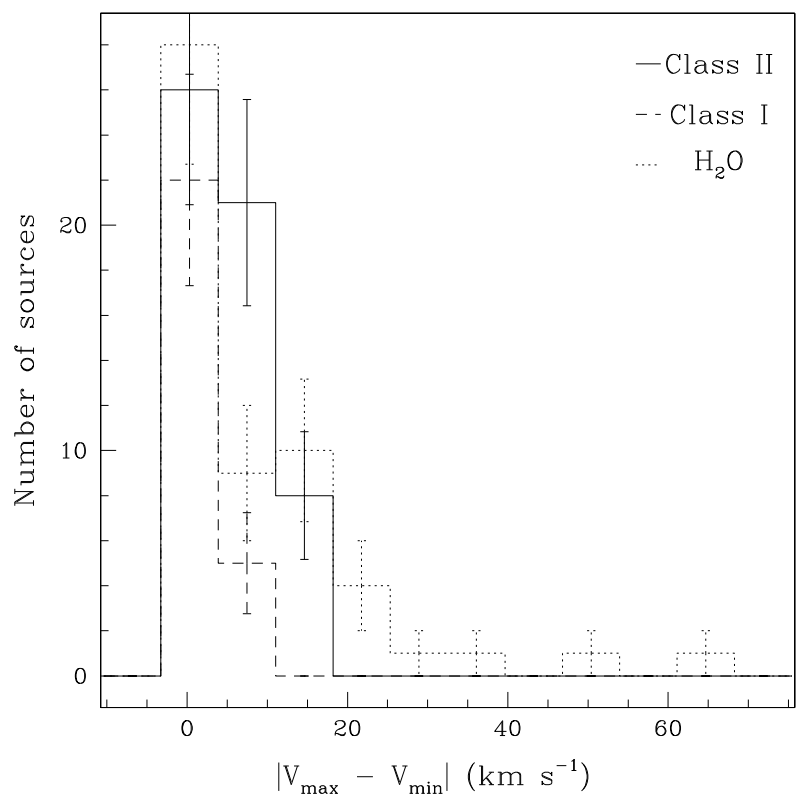

Fig. 4. Distribution of the difference between minimum and maximum line velocities for the Class II $6 \mathrm{GHz}$ (solid line), Class I $44 \mathrm{GHz}$ (dashed line) methanol masers, and of the $22 \mathrm{GHz} \mathrm{H}_{2} \mathrm{O}$ maser (dotted line). For spectra with a single line, we plot the measured full width at half maximum.

the Class I spots happen to fall outside the instrumental HPBW. This idea is supported by the fact that - as argued in Sect. 1 Class I masers are located typically $0.1-1 \mathrm{pc}$ away from the centre of star-formation activity, whereas Class II masers are found closer to it. At $44 \mathrm{GHz}$ the HPBW of the Nobeyama 45-m telescope is $\sim 38^{\prime \prime}$, which translates into a linear size of $\sim 0.9 \mathrm{pc}$ at a distance of $5 \mathrm{kpc}$, consistent with the maximum spread observed in Class I maser spots.

\subsection{Velocity ranges in Class I and Class II masers}

Figure 4 shows the distribution of the velocity range, derived as the difference between the minimum and maximum velocity peak of the different lines in each spectrum, $\left|V_{\max }-V_{\min }\right|$, for the Class II $6 \mathrm{GHz}$ and Class I $44 \mathrm{GHz} \mathrm{CH}_{3} \mathrm{OH}$ masers, and for the sources detected in the $22 \mathrm{GHz} \mathrm{H}_{2} \mathrm{O}$ masers by Palla et al. (1991, see their Table 2a) and Valdettaro et al. (2001, Table 1). Out of the 55 sources detected in the $\mathrm{H}_{2} \mathrm{O}$ maser line, 44 belong to the Palla et al. (1991) sample. For spectra with a single line we assumed as velocity range the measured full width at half maximum (Col. 5 of Tables B.2-B.4), to be consistent with Palla et al. (1991). The majority of the sources show maser emission of Class $\mathrm{I} \mathrm{CH}_{3} \mathrm{OH}$ spread over velocity ranges smaller than $6 \mathrm{~km} \mathrm{~s}^{-1}$ (93\%), while $60 \%$ and $~ 64 \%$ of the $\mathrm{H}_{2} \mathrm{O}$ and Class II maser emission, respectively, have a velocity range smaller than this value, suggesting once more that Class II masers originate from an environment different from that required to excite Class I masers. The distributions of the velocity ranges for Class II and $\mathrm{H}_{2} \mathrm{O}$ masers look more similar each other. However, that of the Class II masers extends up to velocity ranges of $\sim 12 \mathrm{~km} \mathrm{~s}^{-1}$, whereas the distributions of the Class I and $\mathrm{H}_{2} \mathrm{O}$ masers are clearly more peaked at small values: Fig. 4 shows that 21 out of 55 sources (38\%) detected in the Class II maser have velocity ranges between $\sim 6$ and $\sim 12 \mathrm{~km} \mathrm{~s}^{-1}$, wehreas only $16 \%$ and $19 \%$ of the sources detected in the $\mathrm{H}_{2} \mathrm{O}$ and Class I lines have velocity ranges in this interval. Finally,

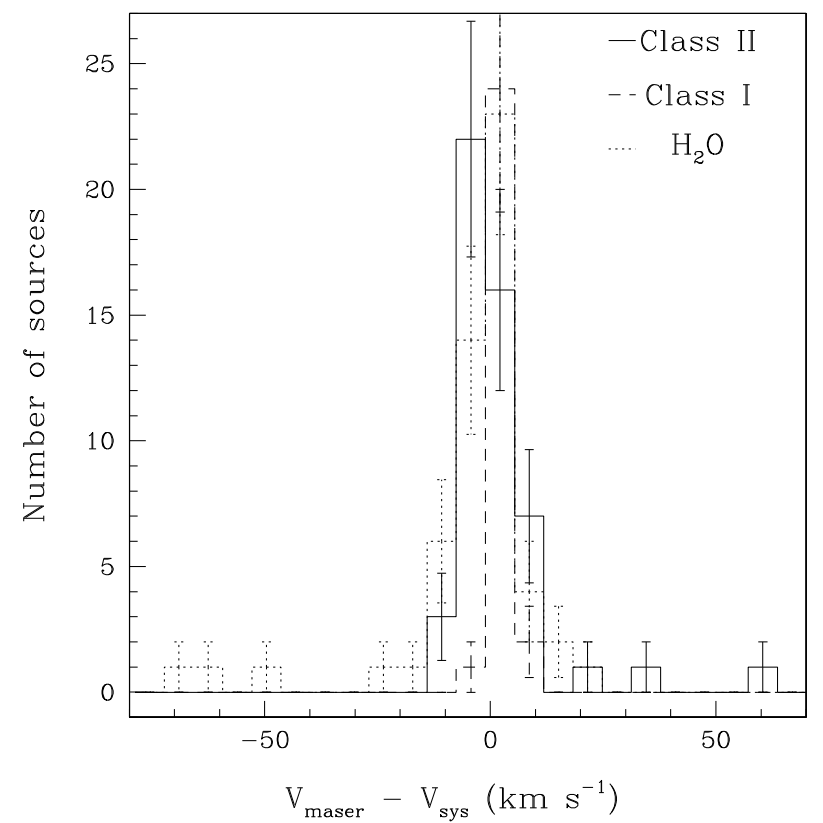

Fig. 5. Distribution of the difference between maser velocity and systemic velocity of the Class II $6 \mathrm{GHz}$ (solid line), Class I $44 \mathrm{GHz}$ (dashed line) methanol masers, and of the $22 \mathrm{GHz} \mathrm{H_{2 }} \mathrm{O}$ maser (dotted line). For sources with multiple lines, we have taken the velocity of the strongest one.

the largest difference between the maximum and minimum velocities is found in $\mathrm{H}_{2} \mathrm{O}$ masers. Indeed, six sources show $\mathrm{H}_{2} \mathrm{O}$ emission spread over a velocity range larger than $\sim 20 \mathrm{~km} \mathrm{~s}^{-1}$, whereas in all $\mathrm{CH}_{3} \mathrm{OH}$ masers the spread is below this limit. In summary, Fig. 4 indicates that there are no clear correlations among the velocity spreads of any of the three maser types.

In Fig. 5 we plot the distribution of the difference between the velocity of the maser, $V_{\text {maser }}$, and the systemic one, $V_{\text {sys }}$ once again for the three maser types. Obviously, we did not include sources without available measurements for $V_{\text {sys }}$ in Fig. 5 . These are: $06291+0421,17582-2234$ and $19045+0813$, among the sources detected in the $\mathrm{H}_{2} \mathrm{O}$ maser, and 17571-2328 and 19186+1440 (see Tables B.2 and B.3) among those detected in the $\mathrm{CH}_{3} \mathrm{OH}$ masers. $V_{\text {sys }}$ for the $\mathrm{H}_{2} \mathrm{O}$ maser detections was taken from ammonia measurements (Molinari et al. 1996; Valdettaro et al. 2001). For spectra with multiple lines we adopted as $V_{\text {maser }}$ that of the peak. The $6 \mathrm{GHz}$ masers show a distribution centred around zero, but the majority of the sources $(\sim 67 \%)$ have a separation of $\sim 5 \mathrm{~km} \mathrm{~s}^{-1}$ or more between the systemic and the peak velocity. On the other hand, for the $44 \mathrm{GHz}$ lines, the distribution is much more peaked around zero and only six sources (22\%) have a separation larger than $\sim 5 \mathrm{~km} \mathrm{~s}^{-1}$. The distribution of the $\mathrm{H}_{2} \mathrm{O}$ maser more closely resembles that of the Class II $\mathrm{CH}_{3} \mathrm{OH}$ line, and it shows the largest absolute difference between $V_{\text {maser }}$ and $V_{\text {sys. }}$. However, the sources with the largest velocity separation have $V_{\text {maser }}$ blue-shifted with respect to $V_{\text {sys }}$, while for Class II lines the largest difference is observed in redshifted lines.

Altogether, the results shown in Figs. 4 and 5 suggest that the $44 \mathrm{GHz}$ maser emission is originated in gas with smaller velocity spread and closer to the systemic velocity than the gas in which the other masers are produced. This finding appears in contrast with the belief that Class I masers could be associated with jets/outflow (Plambeck \& Menten 1990; Kurtz et al. 2004), unless the jet axis lies very close to the plane of the sky. Before drawing any conclusion, though, one must take into account the 
effect of the different noise at 44 and $6 \mathrm{GHz}$, which can play a significant role in shaping the distribution in Fig. 4. To take this into account, we proceeded as done in Sect. 3.2 for the comparison between the 44 and $95 \mathrm{GHz}$ spectra. The $3 \sigma \mathrm{rms}$ of the Effelsberg 100-m spectra is $\sim 0.03-0.04 \mathrm{Jy}$, whereas the one needed to achieve the same average signal to noise ratio as at $44 \mathrm{GHz}$ is $\sim 2.2 \mathrm{Jy}$. By inspecting Tables B.2 and B.3 one can see that several lines are below this limit, especially those at the edge of the velocity interval, i.e. those used to calculate $\left|V_{\max }-V_{\min }\right|$. Therefore, the different rms noise at the two frequencies plays an important role in the estimate of $\left|V_{\max }-V_{\min }\right|$. To quantify this effect, we recalculated the histogram in Fig. 4 for the $6 \mathrm{GHz}$ line, excluding the lines fainter than $\sim 2.2 \mathrm{Jy}$, and find that the histogram is still slightly wider than that at $44 \mathrm{GHz}$. In conclusion, we believe that the different distributions for the three maser types correspond to different formation environments, with Class I masers possibly forming in shocks slower than those generating e.g. $\mathrm{H}_{2} \mathrm{O}$ masers and/or propagating perpendicular to the line of sight.

\section{Summary and conclusions}

We have searched for three methanol maser lines $(6 \mathrm{GHz}$ Class II, $44 \mathrm{GHz}$ Class I, and $95 \mathrm{GHz}$ Class I) towards a large sample of massive YSOs divided into two groups (high and low) on the basis of their IRAS colours (Palla et al. 1991). Previous studies indicate that the two groups are in different evolutionary stages, with high sources being the more evolved. This work aims to use this sample to test a possible evolutionary sequence in the appearence of Class I and II methanol masers. The main findings of our study are:

- We detected 55 sources in the Class II line (39 high and 16 low, 12 new detections); 27 sources in the $44 \mathrm{GHz}$ Class I line (19 high and 8 low, 17 new detections); 11 sources in the $95 \mathrm{GHz}$ Class I line (eight high and three low, all are new detections except IRAS 21391+5802).

- The detection rates of all the masers observed are higher (by a factor $\sim 3$ ) in high than in low sources: the high/low detection rate ratios are $2.9 \pm 1.3$ for the Class I $44 \mathrm{GHz}$ line, $3.3 \pm 1.6$ for the $95 \mathrm{GHz}$ Class I line, and $2.5 \pm 1.1$ for the Class II line. All these values are similar to those found for $\mathrm{H}_{2} \mathrm{O}$ masers, i.e. $3.1 \pm 1.1$. Going from low to high sources, we do not find any statistically significant difference in the relative occurrence of Class I masers with respect to Class II masers. An analogous result holds for the ratio between the detection rates of $\mathrm{CH}_{3} \mathrm{OH}$ and $\mathrm{H}_{2} \mathrm{O}$ masers. A possible interpretation is that all maser species analysed in this work evolve similarly during the evolutionary phases corresponding to high and low sources.

- The detection rate of the Class II masers decreases with the distance of the source, as expected, whereas that of the Class I masers peaks at $\sim 5 \mathrm{kpc}$. We interpret this result with Class I maser spots being typically spread over a larger $(\lesssim 1 \mathrm{pc})$ region than Class II maser spots.

- The spectra in the two Class I masers appear to have similar shapes in seven out of the 11 sources detected in both lines, confirming a common physical origin. Their different detection rates cannot be explained only with the different noise levels at 44 and $95 \mathrm{GHz}$ and we thus conclude that the $95 \mathrm{GHz}$ line is intrinsically fainter.
Acknowledgements. We thank the anonymous referee for the constructive criticism that helped us to shorten, focus, and substantially improve the paper. We are grateful to the Effelsberg and Nobeyama staff for their help during the observations. For part of this work, F.F. acknowledges support by Swiss National Science Foundation grant (PP002 - 110504). The research leading to these results has received funding from the European Community's Seventh Framework Programme (FP7/2007-2013) under grant agreement No. 229517. This work is partially supported by a Grant-in-Aid from the Ministry of Education, Culture, Sports, Science and Technology of Japan (No. 20740113).

\section{References}

Brand, J., Cesaroni, R., Palla, F., \& Molinari, S. 2001, A\&A, 370, 230 Breen, S. L., Ellingsen, S. P., Johnston-Hollitt, M., et al. 2007, MNRAS, 377, 491

Breen, S. L., Ellingsen, S. P., Caswell, J. L., \& Lewis, B. E. 2010, 401, 2219 Bronfman, L., Nyman, L.-A., \& May, J. 1996, A\&AS, 115, 81 Caswell, J. L., Fuller, G. A., Green, J. A., et al. 2010, MNRAS, 404, 1029 Cesaroni, R., Felli, M., Testi, L., Walmsley, C. M., \& Olmi, L. 1997, A\&A, 325, 725

Cesaroni, R., Felli, M., Jenness, T., et al. 1999, A\&A, 345, 949

Chen, X., Ellingsen, S. P., \& Shen, Z.-Q. 2009, MNRAS, 396, 1609 Codella, C., \& Moscadelli, L. 2000, A\&A, 362, 723

Comoretto, G., Palagi, F., Cesaroni, R., et al. 1990, A\&AS, 84, 179

Cragg, D., Johns, K., Godfrey, P., \& Brown, R. 1992, MNRAS, 259, 203

Cragg, D. M., Sobolev, A. M., \& Godfrey, P. D. 2005, MNRAS, 360, 533

Cyganowski, C. J., Brogan, C. L., Hunter, T. R., \& Churchwell, E. 2009, ApJ, 702,1615

Ellingsen, S. P. 2005, MNRAS, 359, 1498

Ellingsen, S. P. 2006, ApJ, 638, 241

Fontani, F., Cesaroni, R., Testi, L., et al. 2004, A\&A, 414, 299

Henning, T., Cesaroni, R., Walmsley, M., \& Pfau, W. 1992, A\&AS, 93, 525

Kalenskii, S. V., Liljestroem, T., Val'tts, I. E., et al. 1994, A\&AS, 103, 129

Kurtz, S., Cesaroni, R., Churchwell, E., Hofner, P., \& Walmsley, C. M. 2000, Protostars and Planets IV, 299

Kurtz, S., Hofner, P., \& Alvarez, C. V. 2004, ApJS, 155, 149

Menten, K. M. 1991, in Atoms, ions and molecules: New results in spectral line astrophysics, ed. A. Haschick, \& P. T. P. Ho (San Francisco: ASP), 16, 119

Minier, V., Conway, J. E., \& Booth, R. S. 2001, A\&A, 369, 278

Molinari, S., Brand, J., Cesaroni, R., \& Palla, F. 1996, A\&A, 308, 573

Molinari, S., Brand, J., Cesaroni, R., Palla, F., \& Palumbo, G. G. C. 1998a, A\&A, 336, 339

Molinari, S., Testi, L., Brand, J., Cesaroni, R., \& Palla, F. 1998b, ApJ, 505, L39

Molinari, S., Brand, J., Cesaroni, R., \& Palla, F. 2000, A\&A, 355, 617

Molinari, S., Pezzuto, S., Cesaroni, R., et al. 2008, A\&A, 481, 345

Palla, F., Brand, J., Cesaroni, R., Comoretto, G., \& Felli, M. 1991, A\&A, 246, 249

Pestalozzi, M., Minier, V., \& Booth, R. S. 2005, A\&A, 432, 737

Plambeck, R. M., \& Menten, K. M. 1990, ApJ, 364, 555

Pratap, P., Shute, P. A., Keane, T. C., Battersby, C., \& Sterling, S. 2008, AJ, 135, 1718

Richards, P. J., Little, L. T., Heaton, B. D., \& Toriseva, M. 1987, MNRAS, 228, 43

Slysh, V. I., Kalenskii, S. V., Valtts, I. E., \& Otrupcek, R. 1994, MNRAS, 268, 464

Sobolev, A. M., et al. 2007, Astrophysical Masers and their Environments, Proc. IAU, IAU Symp., 242, 81

Sridharan, T. K., Beuther, H., Schilke, P., Menten, K. M., \& Wyrowski, F. 2002, ApJ, 566, 931

Sunada, K., Nakazato, T., Ikeda, N., et al. 2007, PASJ, 59, 1185

Szymczak, M., \& Kus, A. J. 2000, A\&A, 360, 311

Valdettaro, L., Palla, F., Brand, J., et al. 2001, A\&A, 368, 845

Val'tts, I. E., \& Larionov, G. M. 2007, ARep, 51, 519

Val'tts, I. E., Dzyura, A. M., Kalenskii, S. V., et al. 1995, AZh, 72, 22

van der Walt, J. 2005, MNRAS, 360, 153

Voronkov, M. A., Brooks, K. J., Sobolev, A. M., et al. 2006, MNRAS, 373, 411

Walsh, A. J., Hyland, A. R., Robinson, G., \& Burton, M. G. 1997, MNRAS, 291, 261

Wood, D. O. S., \& Churchwell, E. 1989, ApJ, 340, 265

Wouterloot, J. G. A., Brand, J., \& Fiegle, K. 1993, A\&AS, 98, 589

Zhang, Q., Hunter, T. R., Brand, J., et al. 2001, ApJ, 552, L167

Zhang, Q., Hunter, T. R., Brand, J., et al. 2005, ApJ, 625, 864 
Appendix A: Spectra of detected sources
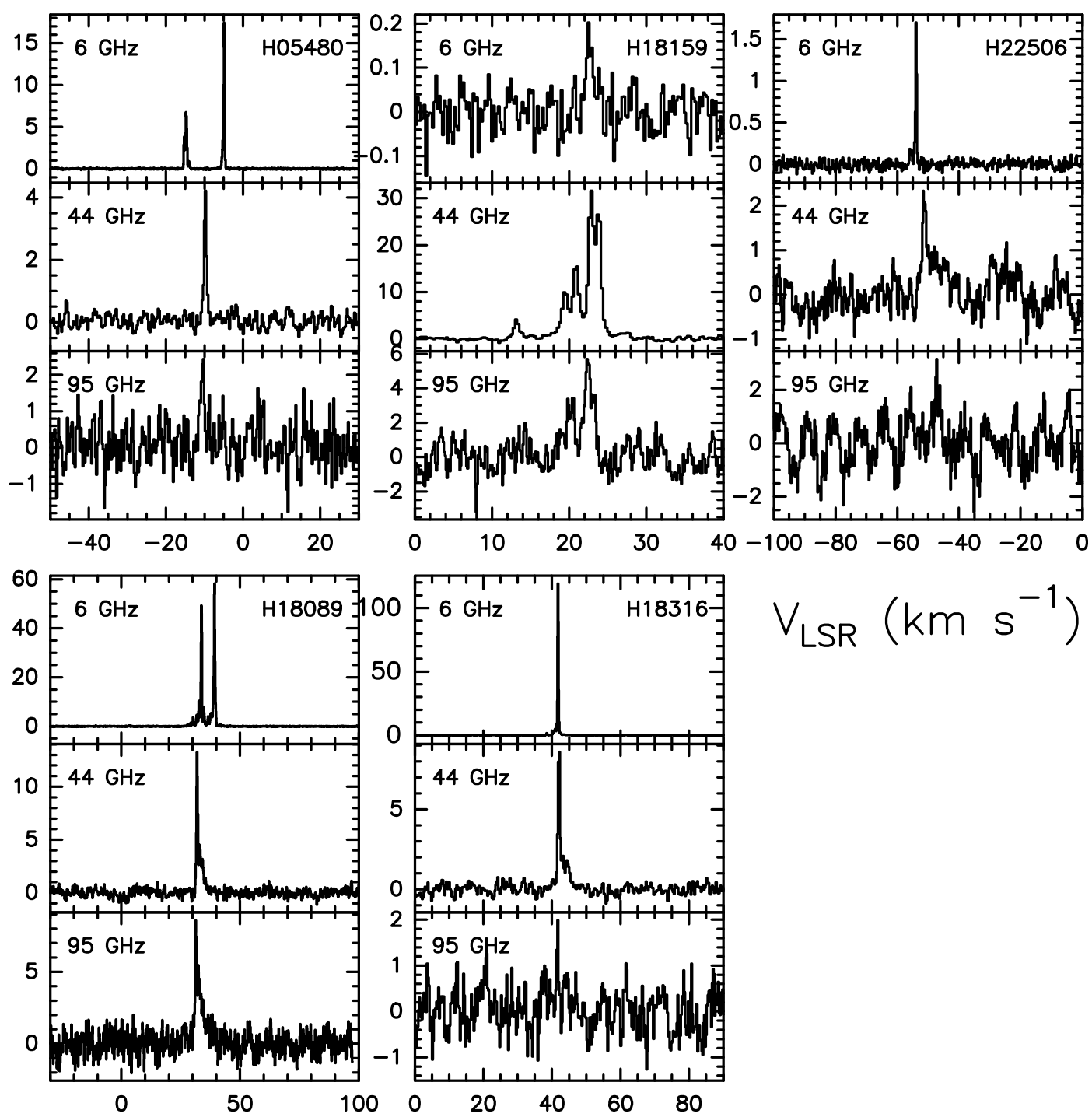

$V_{\text {LSR }}\left(\mathrm{km} \mathrm{s}^{-1}\right)$
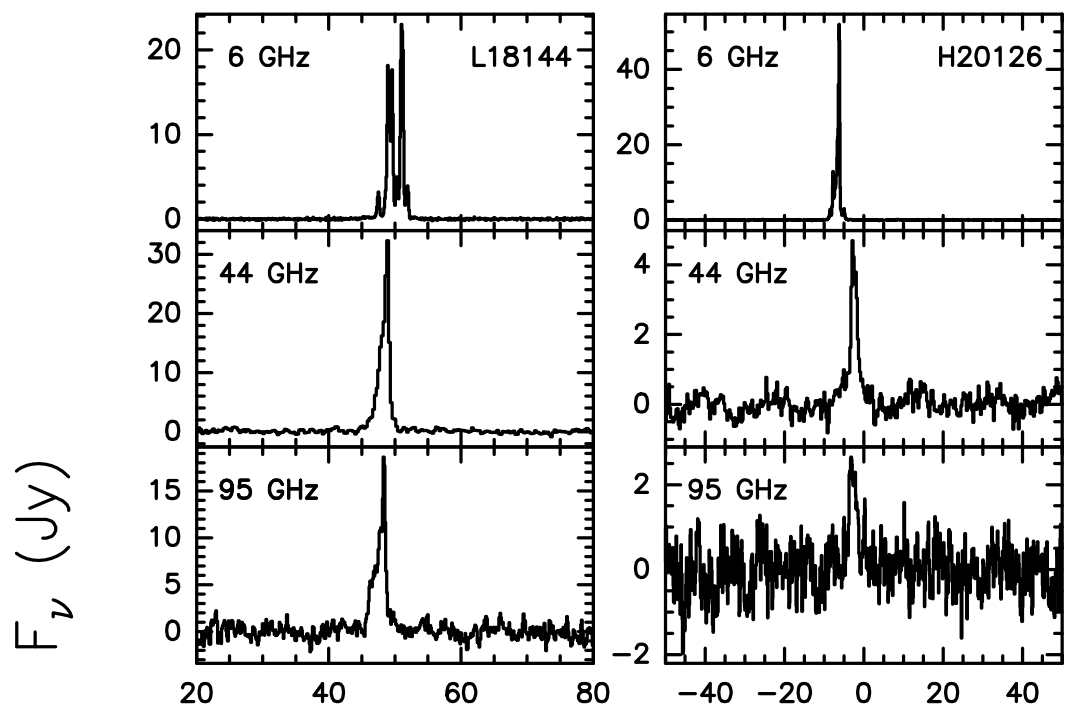

Fig. A.1. Spectra of the three $\mathrm{CH}_{3} \mathrm{OH}$ masers (from top to bottom: $6 \mathrm{GHz}, 44 \mathrm{GHz}$ and $95 \mathrm{GHz}$ ) observed towards the nine sources for which all masers have been detected. 
F. Fontani et al.: Methanol masers in high-mass star forming regions
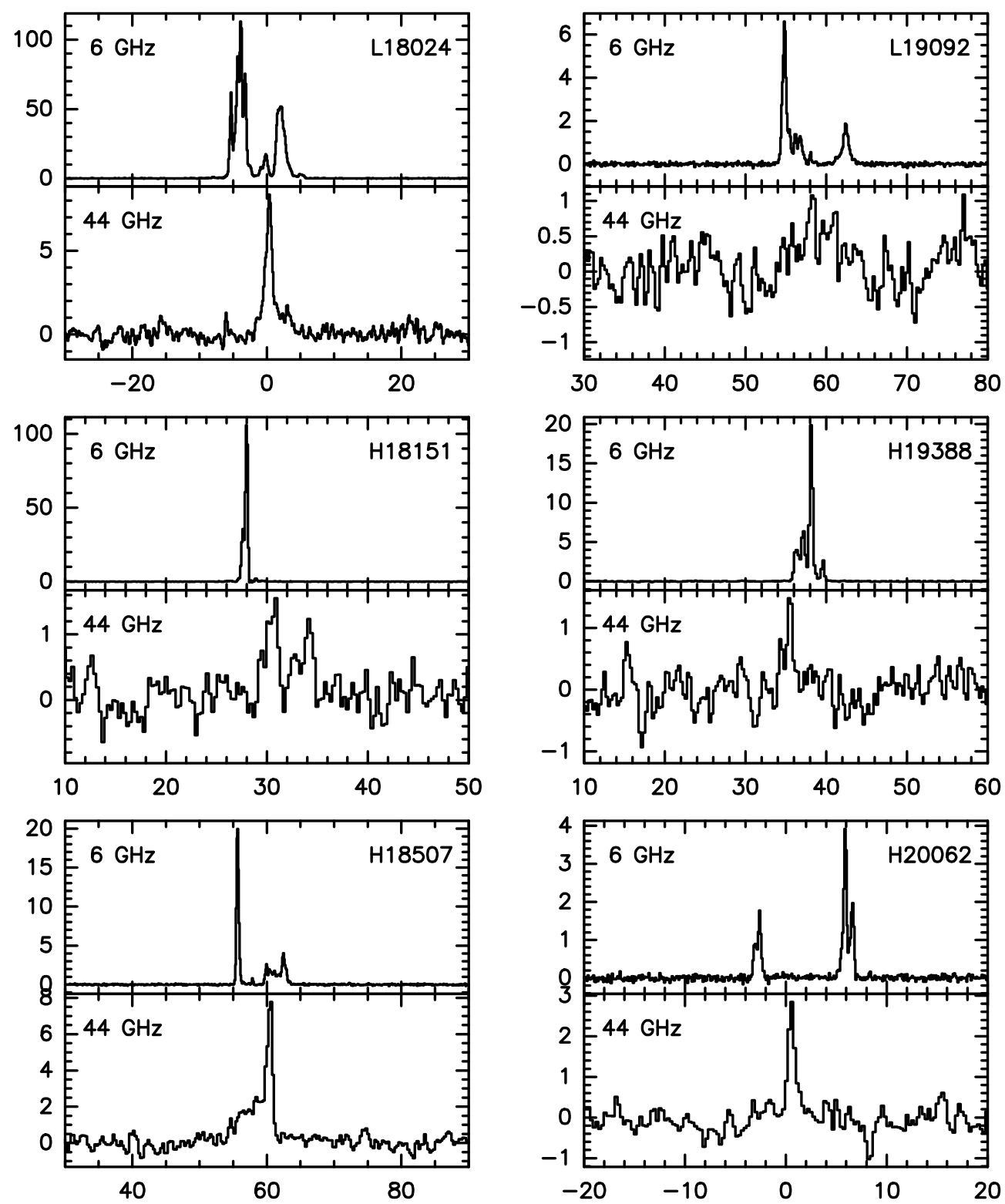

3

$L^{\lambda}$

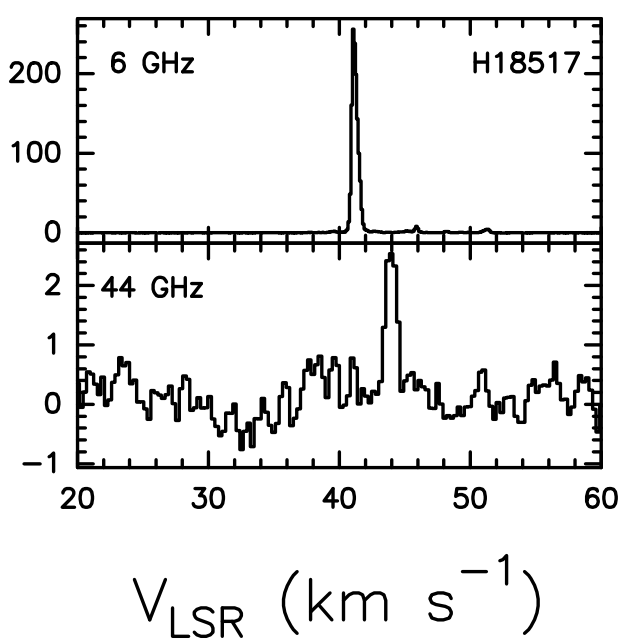

Fig. A.2. Same as Fig. A.1 for sources detected in the $6 \mathrm{GHz}$ and $44 \mathrm{GHz}$ masers. 


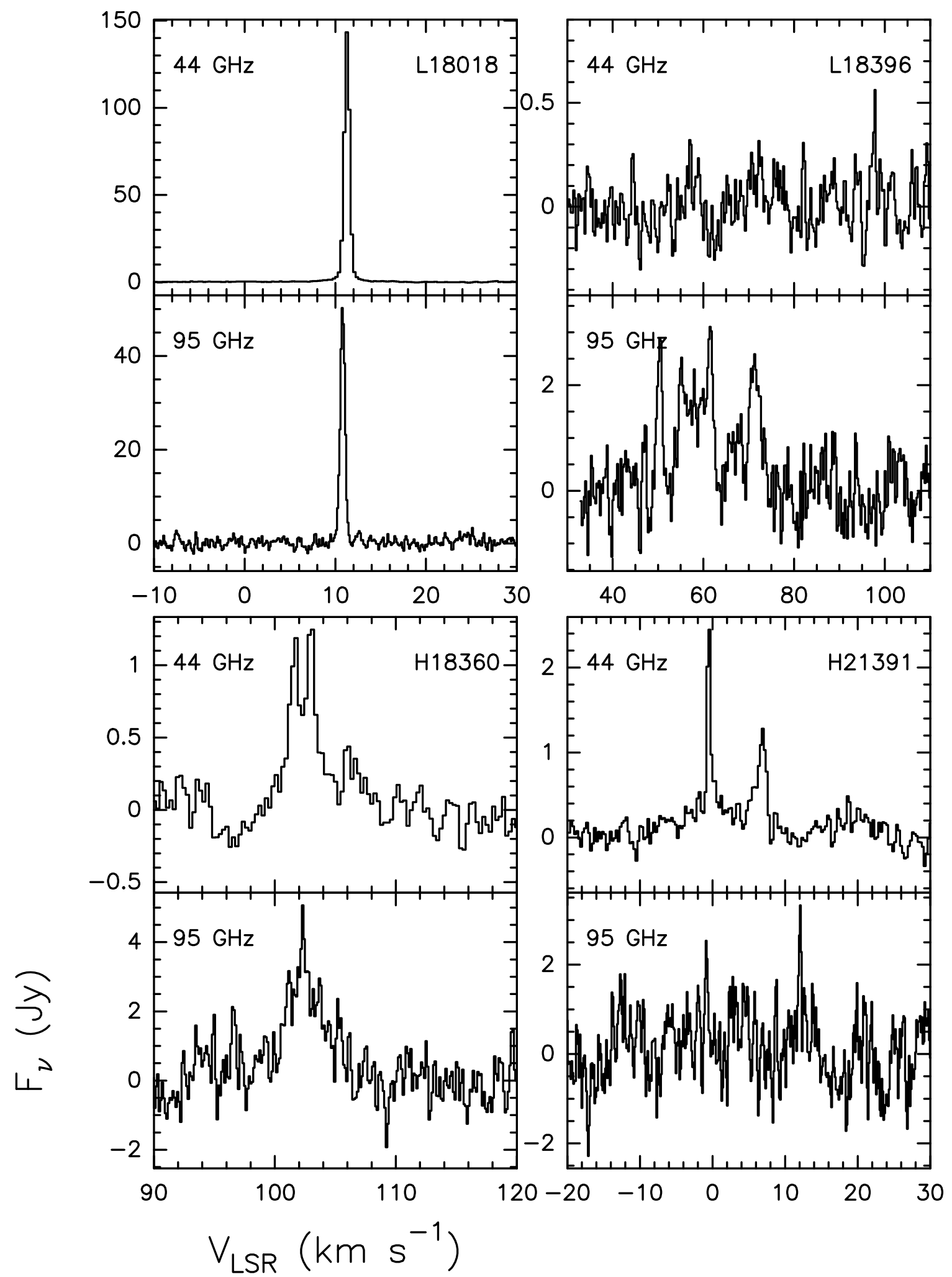

Fig. A.3. Same as Fig. A.1 for sources detected in the $44 \mathrm{GHz}$ and $95 \mathrm{GHz}$ masers. 
F. Fontani et al.: Methanol masers in high-mass star forming regions
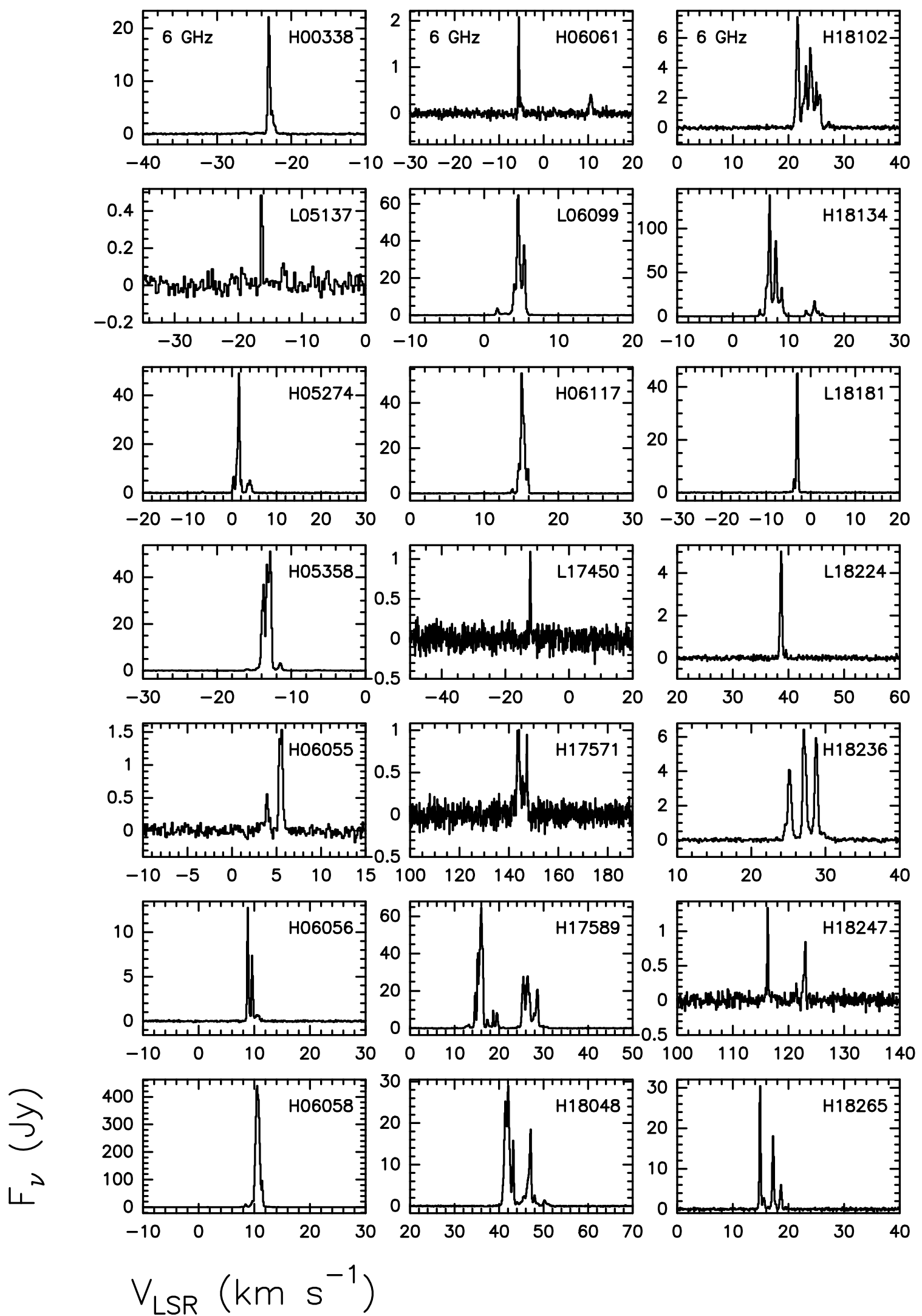

Fig. A.4. Same as Fig. A.1 for sources detected in the $6 \mathrm{GHz}$ maser only. 

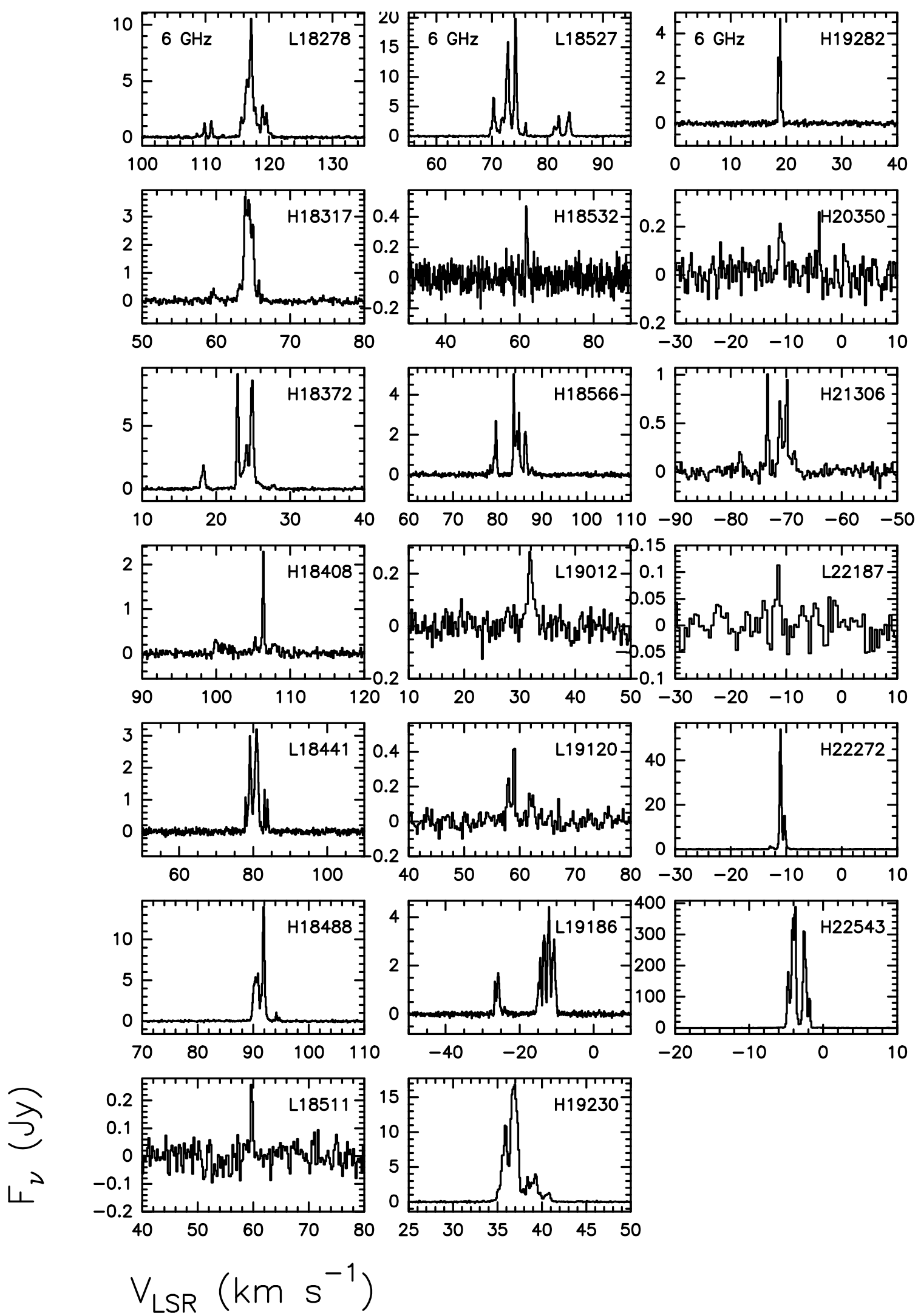

Fig. A.4. continued. 
F. Fontani et al.: Methanol masers in high-mass star forming regions

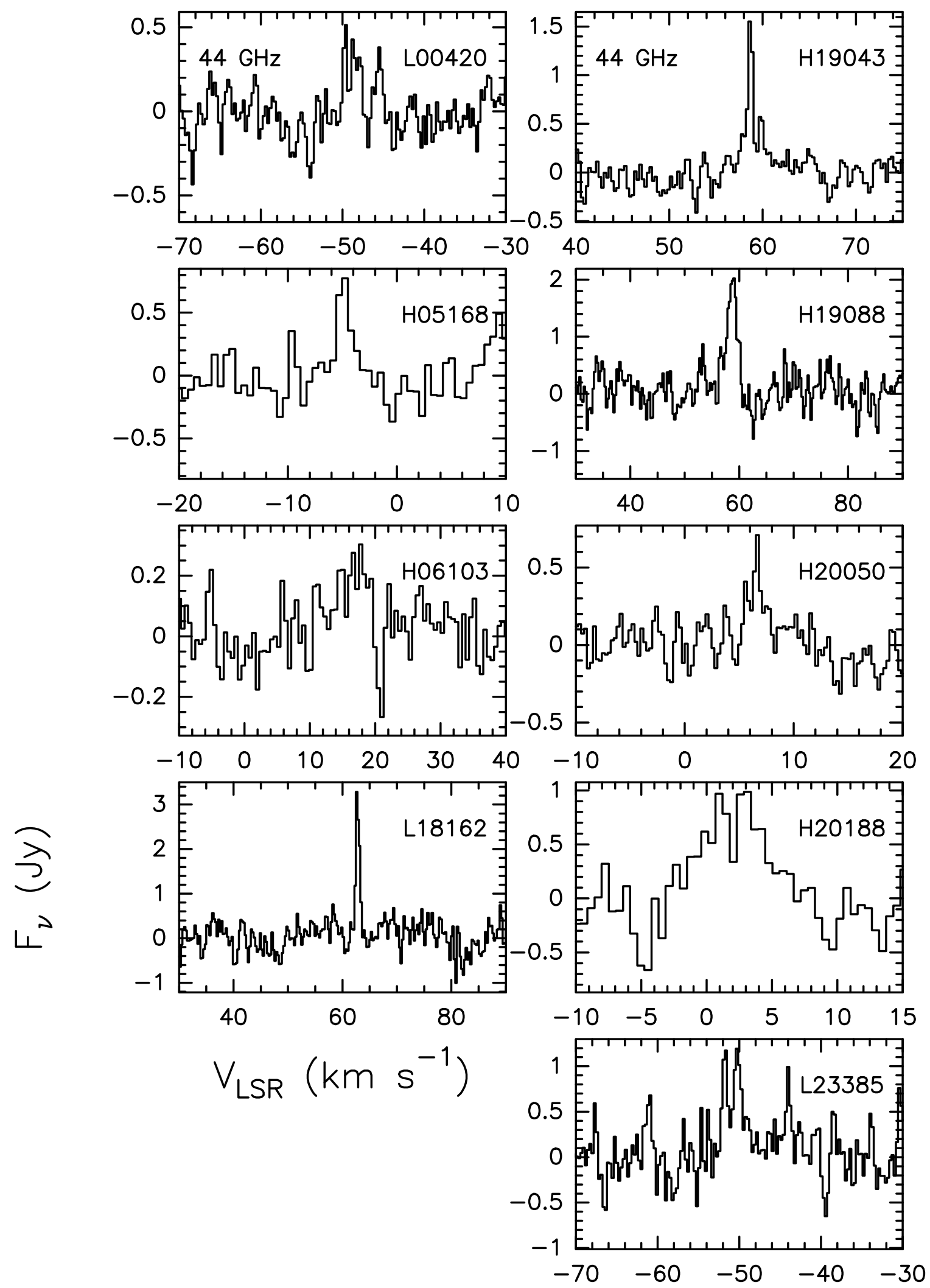

Fig. A.5. Same as Fig. A.1 for sources detected in the $44 \mathrm{GHz}$ line only. 


\section{Appendix B: Tables}

Table B.1. Source parameters used for the observations and detection summary.

\begin{tabular}{|c|c|c|c|c|c|c|c|c|}
\hline IRAS name & type & RA (J2000) & Dec (J2000) & $\begin{array}{c}V_{\mathrm{LSR}} \\
\mathrm{km} \mathrm{s}^{-1}\end{array}$ & $6 \mathrm{GHz}$ & $\begin{array}{l}\mathrm{CH}_{3} \mathrm{OH} \\
44 \mathrm{GHz}\end{array}$ & $95 \mathrm{GHz}$ & $\begin{array}{c}\mathrm{H}_{2} \mathrm{O}^{p} \\
22 \mathrm{GHz}\end{array}$ \\
\hline $00070+6503$ & $\bar{L}$ & $00: 09: 43.7$ & $+65: 20: 09$ & 0.0 & $\mathrm{~N}$ & - & - & $\mathrm{N}$ \\
\hline $00117+6412$ & $\mathrm{H}$ & $00: 14: 27.7$ & $+64: 28: 46$ & -36.3 & $\mathrm{~N}$ & - & - & $\mathrm{N}$ \\
\hline $00127+6058^{a}$ & $\mathrm{~L}$ & $00: 15: 29.1$ & $+61: 14: 41$ & 0.0 & $\mathrm{~N}$ & - & _- & $\mathrm{N}^{w}$ \\
\hline $00338+6312^{a}$ & $\mathrm{H}$ & $00: 36: 47.5$ & $+63: 29: 02$ & 0.0 & Y & - & - & $\mathbf{N}^{v}$ \\
\hline $00420+5530$ & $\mathrm{~L}$ & $00: 44: 57.6$ & $+55: 47: 18$ & -51.2 & $\mathrm{~N}$ & $Y$ & $\mathrm{~N}$ & Y \\
\hline $00484+6531$ & $\mathrm{~L}$ & $00: 51: 33.0$ & $+65: 47: 58$ & 0.0 & $\mathrm{~N}$ & $\mathrm{~N}$ & $\mathrm{~N}$ & $\mathrm{~N}$ \\
\hline $00554+6524$ & $\mathrm{~L}$ & $00: 58: 39.0$ & $+65: 40: 42$ & 0.0 & $\mathrm{~N}$ & $\mathrm{~N}$ & $\mathrm{~N}$ & $\mathrm{~N}$ \\
\hline $01056+6251^{a}$ & $\mathrm{~L}$ & 01:08:48.5 & $+63: 07: 19$ & 0.0 & $\mathrm{~N}$ & - & - & $\mathrm{N}^{w}$ \\
\hline $01420+6401$ & $\mathrm{~L}$ & $01: 45: 39.6$ & $+64: 16: 02$ & 0.0 & $\mathrm{~N}$ & - & - & $\mathrm{N}$ \\
\hline $02383+6241$ & $\mathrm{~L}$ & $02: 42: 20.1$ & $+62: 53: 51$ & 0.0 & $\mathrm{~N}$ & $\mathrm{~N}$ & $\mathrm{~N}$ & $\mathrm{~N}$ \\
\hline $02434+6018$ & $\mathrm{~L}$ & $02: 47: 15.8$ & $+60: 30: 44$ & 0.0 & $\mathrm{~N}$ & $\mathrm{~N}$ & $\mathrm{~N}$ & $\mathrm{~N}$ \\
\hline $02593+6016^{a}$ & $\mathrm{H}$ & 03:03:17.9 & $+60: 27: 52$ & 0.0 & $\mathrm{~N}$ & - & - & $\mathbf{N}^{v}$ \\
\hline $03064+5638$ & $\mathrm{~L}$ & $03: 10: 15.2$ & $+56: 50: 18$ & 0.0 & $\mathrm{~N}$ & $\mathrm{~N}$ & $\mathrm{~N}$ & $\mathrm{~N}$ \\
\hline $03211+5446$ & $\mathrm{~L}$ & 03:24:59.1 & $+54: 57: 25$ & 0.0 & $\mathrm{~N}$ & - & - & $\mathrm{N}$ \\
\hline $03353+5550$ & $\mathrm{~L}$ & $03: 39: 15.6$ & $+55: 59: 48$ & 0.0 & $\mathrm{~N}$ & $\mathrm{~N}$ & $\mathrm{~N}$ & $\mathrm{~N}$ \\
\hline $03448+5545$ & $\mathrm{~L}$ & $03: 48: 47.9$ & $+55: 54: 45$ & 0.0 & $\mathrm{~N}$ & $\mathrm{~N}$ & $\mathrm{~N}$ & $\mathrm{~N}$ \\
\hline $04000+5052$ & $\mathrm{~L}$ & 04:03:49.3 & +51:00:48 & 0.0 & $\mathrm{~N}$ & $\mathrm{~N}$ & $\mathrm{~N}$ & $\mathrm{~N}$ \\
\hline $04034+5116$ & $\mathrm{H}$ & 04:07:11.9 & $+51: 24: 45$ & 0.0 & $\mathrm{~N}$ & - & - & $\mathrm{N}$ \\
\hline $04156+5251^{a}$ & $\mathrm{~L}$ & $04: 19: 32.7$ & $+52: 58: 36$ & 0.0 & $\mathrm{~N}$ & - & - & $\mathrm{N}^{w}$ \\
\hline $04269+3510^{a}$ & $\mathrm{~L}$ & $04: 30: 14.4$ & $+35: 16: 30$ & 0.0 & $\mathrm{~N}$ & - & - & $\mathbf{N}^{v}$ \\
\hline $04579+4703$ & $\mathrm{H}$ & $05: 01: 39.7$ & $+47: 07: 23$ & -16.5 & $\mathrm{~N}$ & - & - & Y \\
\hline $05100+3723^{a}$ & $\mathrm{H}$ & $05: 13: 25.4$ & $+37: 27: 04$ & 0.0 & $\mathrm{~N}$ & - & - & $\mathrm{N}^{w}$ \\
\hline $05137+3919$ & $\mathrm{~L}$ & $05: 17: 13.3$ & $+39: 22: 14$ & -25.4 & $Y$ & $\mathrm{~N}$ & $\mathrm{~N}$ & $\mathrm{Y}$ \\
\hline $05168+3634$ & $\mathrm{H}$ & $05: 20: 16.1$ & $+36: 37: 21$ & -15.1 & $\mathrm{~N}$ & $Y^{m}$ & $\mathrm{~N}$ & Y \\
\hline $05197+3355$ & $\mathrm{~L}$ & $05: 23: 04.4$ & $+33: 58: 27$ & 0.0 & $\mathrm{~N}$ & $\mathrm{~N}$ & $\mathrm{~N}$ & $\mathrm{~N}$ \\
\hline $05236+3828$ & $\mathrm{~L}$ & 05:27:06.6 & $+38: 31: 18$ & 0.0 & $\mathrm{~N}$ & $\mathrm{~N}$ & $\mathrm{~N}$ & $\mathrm{~N}$ \\
\hline $05274+3345$ & $\mathrm{H}$ & $05: 30: 45.6$ & $+33: 47: 52$ & -3.8 & $\mathrm{Y}$ & - & - & Y \\
\hline $05334+3149$ & $\mathrm{H}$ & $05: 36: 41.1$ & $+31: 51: 14$ & 0.0 & $\mathrm{~N}$ & $\mathrm{~N}$ & $\mathrm{~N}$ & $\mathrm{~N}$ \\
\hline $05345+3157$ & $\mathrm{~L}$ & $05: 37: 47.8$ & $+31: 59: 24$ & -18.4 & $\mathrm{~N}$ & $\mathrm{~N}$ & $\mathrm{~N}$ & Y \\
\hline $05351+3549^{a}$ & $\mathrm{H}$ & $05: 38: 28.1$ & $+35: 51: 15$ & 0.0 & $\mathrm{~N}$ & - & - & $\mathrm{N}^{w}$ \\
\hline $05355+3039$ & $\mathrm{~L}$ & $05: 38: 47.2$ & $+30: 41: 27$ & 0.0 & $\mathrm{~N}$ & $\mathrm{~N}$ & $\mathrm{~N}$ & $\mathrm{~N}$ \\
\hline $05358+3543^{a}$ & $\mathrm{H}$ & 05:39:10.4 & $+35: 45: 19$ & 0.0 & $\mathrm{Y}$ & - & - & $\mathrm{Y}^{v}$ \\
\hline $05373+2349$ & $\mathrm{~L}$ & $05: 40: 24.4$ & $+23: 50: 54$ & 2.3 & $\mathrm{~N}$ & $\mathrm{~N}$ & $\mathrm{~N}$ & $\mathrm{Y}$ \\
\hline $05382+3547$ & $\mathrm{~L}$ & $05: 41: 37.4$ & $+35: 48: 49$ & 0.0 & $\mathrm{~N}$ & - & - & $\mathrm{N}$ \\
\hline $05480+2545$ & $\mathrm{H}$ & $05: 51: 10.6$ & $+25: 46: 14$ & 0.0 & $Y$ & $Y$ & $Y$ & $\mathrm{~N}$ \\
\hline $05490+2658$ & $\mathrm{H}$ & $05: 52: 12.8$ & $+26: 59: 32$ & 0.0 & $\mathrm{~N}$ & $\mathrm{~N}$ & $\mathrm{~N}$ & $\mathrm{~N}$ \\
\hline $05553+1631$ & $\mathrm{H}$ & 05:58:13.9 & $+16: 32: 00$ & 6.1 & $\mathrm{~N}$ & $\mathrm{~N}$ & $\mathrm{~N}$ & $\mathrm{Y}$ \\
\hline $05554+2013$ & $\mathrm{H}$ & $05: 58: 24.5$ & $+20: 13: 57$ & 0.0 & $\mathrm{~N}$ & $\mathrm{~N}$ & $\mathrm{~N}$ & $\mathrm{~N}$ \\
\hline $05588+2625$ & $\mathrm{~L}$ & 06:01:55.2 & $+26: 24: 59$ & 0.0 & $\mathrm{~N}$ & $\mathrm{~N}$ & $\mathrm{~N}$ & $\mathrm{~N}$ \\
\hline $06001+3014^{a}$ & $\mathrm{~L}$ & 06:03:22.9 & $+30: 14: 11$ & 0.0 & $\mathrm{~N}$ & - & - & $\mathrm{Y}^{v}$ \\
\hline $06013+3030$ & $\mathrm{~L}$ & 06:04:34.2 & $+30: 30: 39$ & 0.0 & $\mathrm{~N}$ & $\mathrm{~N}$ & $\mathrm{~N}$ & $\mathrm{~N}$ \\
\hline $06055+2039^{a}$ & $\mathrm{H}$ & 06:08:32.8 & $+20: 39: 16$ & 0.0 & $\mathrm{Y}$ & - & - & $\mathrm{Y}^{v}$ \\
\hline $06056+2131$ & $\mathrm{H}$ & 06:08:40.9 & $+21: 31: 01$ & 2.6 & $\mathrm{Y}$ & $\mathrm{N}$ & $\mathrm{N}$ & $\mathrm{N}$ \\
\hline $06058+2138^{a}$ & $\mathrm{H}$ & 06:08:54.1 & $+21: 38: 25$ & 0.0 & $\mathrm{Y}$ & - & - & $\mathrm{Y}^{v}$ \\
\hline $06061+2151$ & $\mathrm{H}$ & 06:09:07.8 & $+21: 50: 39$ & -0.6 & $\mathrm{Y}$ & $\mathrm{N}$ & $\mathrm{N}$ & Y \\
\hline $06063+2040$ & $\mathrm{H}$ & 06:09:21.9 & $+20: 39: 28$ & 0.0 & $\mathrm{~N}$ & - & - & $\mathrm{N}$ \\
\hline $06068+2030$ & $\mathrm{~L}$ & 06:09:51.7 & $+20: 30: 04$ & 0.0 & $\mathrm{~N}$ & - & - & $\mathrm{N}$ \\
\hline $06084+1727^{a}$ & $\mathrm{H}$ & $06: 11: 24.5$ & $+17: 26: 26$ & 0.0 & $\mathrm{~N}$ & - & - & $\mathrm{N}^{w}$ \\
\hline $06099+1800^{a}$ & $\mathrm{~L}$ & $06: 12: 53.3$ & $+17: 59: 22$ & 0.0 & $\mathrm{Y}$ & - & - & $\mathrm{Y}^{v}$ \\
\hline $06103+1523$ & $\mathrm{H}$ & 06:13:15.1 & $+15: 22: 36$ & 15.6 & $\mathrm{~N}$ & $Y^{m}$ & $\mathrm{~N}$ & $\mathrm{~N}$ \\
\hline $06104+1524$ & $\mathrm{H}$ & $06: 13: 21.3$ & $+15: 23: 57$ & 0.0 & $\mathrm{~N}$ & - & - & $\mathrm{N}$ \\
\hline $06105+1756$ & $\mathrm{H}$ & $06: 13: 28.3$ & $+17: 55: 29$ & 8.0 & $\mathrm{~N}$ & $\mathrm{~N}$ & $\mathrm{~N}$ & Y \\
\hline $06114+1745^{a}$ & $\mathrm{H}$ & $06: 14: 23.7$ & $+17: 44: 36$ & 0.0 & $\mathrm{~N}$ & - & - & $\mathrm{N}^{v}$ \\
\hline $06117+1350^{a}$ & $\mathrm{H}$ & $06: 14: 36.6$ & $+13: 49: 35$ & 0.0 & $\mathrm{Y}$ & - & - & $\mathrm{Y}^{v}$ \\
\hline $06155+2319$ & $\mathrm{H}$ & $06: 18: 35.2$ & $+23: 18: 11$ & 0.0 & $\mathrm{~N}$ & - & - & $\mathrm{N}$ \\
\hline $06158+1517^{a}$ & $\mathrm{~L}$ & 06:18:44.8 & $+15: 16: 43$ & 0.0 & $\mathrm{~N}$ & - & - & $\mathbf{N}^{w}$ \\
\hline $06291+0421$ & $\mathrm{~L}$ & 06:31:48.1 & $+04: 19: 31$ & 0.0 & $\mathrm{~N}$ & - & - & Y \\
\hline 06299+1011 & $\mathrm{L}$ & $06: 32: 41.3$ & +10:09:34 & 0.0 & $\mathrm{~N}$ & - & - & $\mathrm{N}$ \\
\hline $06303+1021$ & $\mathrm{~L}$ & 06:33:04.4 & $+10: 19: 21$ & 0.0 & $\mathrm{~N}$ & - & - & $\mathrm{N}$ \\
\hline $06308+0402$ & $\mathrm{~L}$ & 06:33:31.1 & $+04: 00: 07$ & 0.0 & $\mathrm{~N}$ & - & - & $\mathrm{N}$ \\
\hline $06314+0427$ & $\mathrm{~L}$ & 06:34:05.5 & $+04: 24: 54$ & 0.0 & $\mathrm{~N}$ & $\mathrm{~N}$ & $\mathrm{~N}$ & $\mathrm{~N}$ \\
\hline $06382+0939$ & $\mathrm{~L}$ & 06:41:02.7 & $+09: 36: 10$ & 5.2 & $\mathrm{~N}$ & $\mathrm{~N}$ & $\mathrm{~N}$ & $\mathrm{~N}$ \\
\hline 06568-0411 & $\mathrm{L}$ & 06:59:22.4 & $-04: 15: 45$ & 0.0 & $\mathrm{~N}$ & - & - & $\mathrm{N}$ \\
\hline
\end{tabular}


Table B.1. continued.

\begin{tabular}{|c|c|c|c|c|c|c|c|c|}
\hline IRAS name & type & RA (J2000) & $\operatorname{Dec}(\mathrm{J} 2000)$ & $\begin{array}{c}V_{\mathrm{LSR}} \\
\mathrm{km} \mathrm{s}^{-1}\end{array}$ & $6 \mathrm{GHz}$ & $\begin{array}{l}\mathrm{CH}_{3} \mathrm{OH} \\
44 \mathrm{GHz}\end{array}$ & $95 \mathrm{GHz}$ & $\begin{array}{c}\mathrm{H}_{2} \mathrm{O}^{p} \\
22 \mathrm{GHz}\end{array}$ \\
\hline $06584-0852$ & $\mathrm{~L}$ & $07: 00: 51.5$ & $-08: 56: 29$ & 41.3 & $\mathrm{~N}$ & $\mathrm{~N}$ & $\bar{N}$ & $\bar{Y}$ \\
\hline $07029-1215^{a}$ & $\mathrm{~L}$ & $07: 05: 16.9$ & $-12: 20: 02$ & 0.0 & $\mathrm{~N}$ & - & - & $\mathrm{N}^{h}$ \\
\hline 07069-1045 & $\mathrm{H}$ & 07:09:20.5 & $-10: 50: 25$ & 0.0 & $\mathrm{~N}$ & $\mathrm{~N}$ & $\mathrm{~N}$ & $\mathrm{~N}$ \\
\hline $07284-1511^{a}$ & $\mathrm{H}$ & $07: 30: 42.5$ & $-15: 17: 40$ & 0.0 & $\mathrm{~N}$ & - & - & $\mathbf{N}^{b}$ \\
\hline 07295-1915 & $\mathrm{L}$ & $07: 31: 47.6$ & $-19: 21: 48$ & 0.0 & $\mathrm{~N}$ & - & - & $\mathrm{N}$ \\
\hline $07333-1838^{a}$ & $\mathrm{H}$ & $07: 35: 34.3$ & $-18: 45: 32$ & 0.0 & $\mathrm{~N}$ & - & - & $\mathbf{N}^{v}$ \\
\hline $07429-2523^{a}$ & $\mathrm{~L}$ & $07: 45: 01.4$ & $-25: 31: 10$ & 0.0 & $\mathrm{~N}$ & - & - & $\mathrm{N}^{w}$ \\
\hline $17417-2851$ & $\mathrm{H}$ & $17: 44: 53.4$ & $-28: 52: 20$ & -5.6 & $\mathrm{~N}$ & - & - & $\mathrm{N}$ \\
\hline $17450-2742$ & $\mathrm{~L}$ & $17: 48: 09.3$ & $-27: 43: 21$ & -16.9 & Y & - & - & $\mathrm{N}$ \\
\hline $17456-2850$ & $\mathrm{H}$ & $17: 48: 47.1$ & $-28: 51: 49$ & 0.0 & $\mathrm{~N}$ & - & - & $\mathrm{N}$ \\
\hline $17495-2624$ & $\mathrm{H}$ & $17: 52: 41.9$ & $-26: 25: 32$ & 17.3 & $\mathrm{~N}$ & - & - & $\mathrm{N}$ \\
\hline $17504-2519$ & $\mathrm{H}$ & $17: 53: 35.1$ & $-25: 19: 56$ & 12.4 & $\mathrm{~N}$ & - & - & $\mathrm{N}$ \\
\hline $17527-2439$ & $\mathrm{H}$ & $17: 55: 49.1$ & $-24: 40: 20$ & 13.2 & $\mathrm{~N}$ & $\mathrm{~N}$ & $\mathrm{~N}$ & Y \\
\hline $17571-2328$ & $\mathrm{H}$ & 18:00:14.2 & $-23: 28: 57$ & 0.0 & $Y$ & - & - & $\mathrm{N}$ \\
\hline $17580-2215$ & $\mathrm{~L}$ & 18:01:02.2 & $-22: 15: 45$ & 0.0 & $\mathrm{~N}$ & - & - & $\mathrm{N}$ \\
\hline $17582-2234$ & $\mathrm{~L}$ & 18:01:18.0 & $-22: 34: 57$ & 0.0 & $\mathrm{~N}$ & - & - & Y \\
\hline $17589-2312$ & $\mathrm{H}$ & 18:01:57.1 & $-23: 12: 36$ & 0.0 & Y & - & - & $\mathrm{N}$ \\
\hline $18014-2428$ & $\mathrm{~L}$ & 18:04:29.6 & $-24: 28: 47$ & 12.5 & $\mathrm{~N}$ & $\mathrm{~N}$ & $\mathrm{~N}$ & $\mathrm{~N}$ \\
\hline $18018-2426$ & $\mathrm{~L}$ & 18:04:53.9 & $-24: 26: 41$ & 10.5 & $\mathrm{~N}$ & Y & $Y$ & $\mathrm{~N}$ \\
\hline $18024-2119$ & $\mathrm{~L}$ & $18: 05: 25.4$ & $-21: 19: 41$ & 0.5 & Y & Y & $\mathrm{N}$ & Y \\
\hline $18024-2231$ & $\mathrm{~L}$ & 18:05:30.6 & $-22: 31: 35$ & 16.2 & $\mathrm{~N}$ & - & - & $\mathrm{N}$ \\
\hline $18026-2145$ & $\mathrm{~L}$ & $18: 05: 37.9$ & $-21: 45: 06$ & 0.0 & $\mathrm{~N}$ & - & - & $\mathrm{N}$ \\
\hline $18027-2202$ & $\mathrm{H}$ & $18: 05: 46.2$ & $-22: 01: 57$ & 0.0 & $\mathrm{~N}$ & - & - & $\mathrm{N}$ \\
\hline $18039-2052$ & $\mathrm{~L}$ & 18:06:56.7 & $-20: 51: 51$ & 0.0 & $\mathrm{~N}$ & - & - & $\mathrm{N}$ \\
\hline $18043-2153$ & $\mathrm{~L}$ & $18: 07: 23.2$ & $-21: 53: 00$ & 0.0 & $\mathrm{~N}$ & - & - & $\mathrm{N}$ \\
\hline $18048-2019$ & $\mathrm{H}$ & $18: 07: 51.5$ & $-20: 18: 36$ & 49.1 & Y & $\mathrm{N}$ & $\mathrm{N}$ & Y \\
\hline $18054-1818$ & $\mathrm{~L}$ & 18:08:24.0 & $-18: 17: 35$ & 0.0 & $\mathrm{~N}$ & - & - & $\mathrm{N}$ \\
\hline 18078-1928 & $\mathrm{H}$ & 18:10:48.7 & $-19: 27: 42$ & 0.0 & $\mathrm{~N}$ & - & - & $\mathrm{N}$ \\
\hline $18079-1756$ & $\mathrm{H}$ & $18: 10: 50.3$ & $-17: 55: 52$ & 0.0 & $\mathrm{~N}$ & - & - & $\mathrm{N}$ \\
\hline $18081-2138$ & $\mathrm{~L}$ & 18:11:10.5 & $-21: 38: 15$ & 0.0 & $\mathrm{~N}$ & - & - & $\mathrm{N}$ \\
\hline 18089-1732 & $\mathrm{H}$ & 18:11:51.3 & $-17: 31: 29$ & 32.9 & Y & Y & $Y$ & Y \\
\hline $18102-1800$ & $\mathrm{H}$ & 18:13:12.1 & $-17: 59: 34$ & 0.0 & Y & - & - & $\mathrm{N}$ \\
\hline $18115-1701$ & $\mathrm{~L}$ & $18: 14: 25.6$ & $-17: 00: 53$ & 0.0 & $\mathrm{~N}$ & - & - & $\mathrm{N}$ \\
\hline $18122-1751$ & $\mathrm{~L}$ & $18: 15: 12.2$ & $-17: 49: 60$ & 0.0 & $\mathrm{~N}$ & - & - & $\mathrm{N}$ \\
\hline $18123-1203$ & $\mathrm{~L}$ & $18: 15: 07.3$ & $-12: 02: 42$ & 0.0 & $\mathrm{~N}$ & - & - & $\mathrm{N}$ \\
\hline 18131-1606 & $\mathrm{L}$ & 18:16:01.9 & $-16: 05: 05$ & 0.0 & $\mathrm{~N}$ & - & - & $\mathrm{N}$ \\
\hline $18132-1638$ & $\mathrm{~L}$ & 18:16:08.8 & $-16: 37: 07$ & 0.0 & $\mathrm{~N}$ & - & - & $\mathrm{N}$ \\
\hline 18134-1942 & $\mathrm{H}$ & 18:16:22.2 & $-19: 41: 20$ & 10.5 & Y & $\mathrm{N}$ & $\mathrm{N}$ & Y \\
\hline $18136-1347$ & $\mathrm{~L}$ & $18: 16: 28.6$ & $-13: 46: 33$ & 0.0 & $\mathrm{~N}$ & - & - & $\mathrm{N}$ \\
\hline $18144-1723$ & $\mathrm{~L}$ & $18: 17: 24.4$ & $-17: 22: 13$ & 47.3 & Y & Y & $Y$ & Y \\
\hline $18145-1557$ & $\mathrm{H}$ & 18:17:26.7 & $-15: 56: 19$ & 0.0 & $\mathrm{~N}$ & - & - & $\mathrm{N}$ \\
\hline $18151-1208$ & $\mathrm{H}$ & 18:17:57.1 & $-12: 07: 22$ & 32.8 & Y & Y & $\mathrm{N}$ & $\mathrm{N}$ \\
\hline $18153-1651$ & $\mathrm{H}$ & 18:18:15.9 & $-16: 50: 37$ & 0.0 & $\mathrm{~N}$ & - & - & $\mathrm{N}$ \\
\hline $18156-1343$ & $\mathrm{~L}$ & 18:18:28.6 & $-13: 42: 22$ & 0.0 & $\mathrm{~N}$ & - & - & $\mathrm{N}$ \\
\hline $18159-1550$ & $\mathrm{H}$ & 18:18:47.6 & $-15: 48: 54$ & 59.7 & $\mathrm{~N}$ & - & - & $\mathrm{N}$ \\
\hline 18159-1648 & $\mathrm{H}$ & 18:18:53.0 & $-16: 47: 39$ & 22.1 & Y & Y & $Y$ & $\mathrm{~N}$ \\
\hline $18160-1641$ & $\mathrm{~L}$ & 18:18:57.3 & $-16: 40: 15$ & 0.0 & $\mathrm{~N}$ & - & - & $\mathrm{N}$ \\
\hline $18162-1612$ & $\mathrm{~L}$ & 18:19:07.5 & $-16: 11: 21$ & 61.8 & $\mathrm{~N}$ & Y & $\mathrm{N}$ & $\mathrm{N}$ \\
\hline $18167-1614$ & $\mathrm{~L}$ & 18:19:37.7 & $-16: 13: 11$ & 0.0 & $\mathrm{~N}$ & - & - & $\mathrm{N}$ \\
\hline $18171-1548$ & $\mathrm{H}$ & 18:20:04.6 & $-15: 46: 47$ & 0.0 & $\mathrm{~N}$ & - & - & $\mathrm{N}$ \\
\hline $18181-1534$ & $\mathrm{~L}$ & 18:20:58.9 & $-15: 33: 10$ & 0.0 & $\mathrm{Y}$ & - & - & $\mathrm{N}$ \\
\hline 18195-1407 & $\mathrm{L}$ & $18: 22: 24.4$ & $-14: 05: 33$ & 0.0 & $\mathrm{~N}$ & - & - & $\mathrm{N}$ \\
\hline $18197-1351$ & $\mathrm{H}$ & $18: 22: 36.7$ & $-13: 50: 11$ & 0.0 & $\mathrm{~N}$ & - & - & $\mathrm{N}$ \\
\hline $18198-1429$ & $\mathrm{H}$ & $18: 22: 41.7$ & $-14: 27: 35$ & 0.0 & $\mathrm{~N}$ & - & - & $\mathrm{N}$ \\
\hline $18212-1320$ & $\mathrm{H}$ & $18: 24: 04.7$ & $-13: 19: 16$ & 0.0 & $\mathrm{~N}$ & - & - & $\mathrm{N}$ \\
\hline $18224-1228$ & $\mathrm{~L}$ & $18: 25: 12.6$ & $-12: 27: 09$ & 0.0 & Y & - & - & $\mathrm{N}$ \\
\hline $18230-1248$ & $\mathrm{~L}$ & $18: 25: 51.7$ & $-12: 46: 15$ & 0.0 & $\mathrm{~N}$ & - & - & $\mathrm{N}$ \\
\hline $18236-1205$ & $\mathrm{H}$ & $18: 26: 24.3$ & $-12: 03: 47$ & 26.2 & Y & - & - & Y \\
\hline $18247-1147$ & $\mathrm{H}$ & 18:27:31.1 & $-11: 45: 56$ & 55.9 & $Y$ & - & - & $\mathrm{N}$ \\
\hline $18248-1218$ & $\mathrm{~L}$ & $18: 27: 37.9$ & $-12: 16: 27$ & 0.0 & $\mathrm{~N}$ & - & - & $\mathrm{N}$ \\
\hline $18256-0742$ & $\mathrm{~L}$ & $18: 28: 20.5$ & $-07: 40: 22$ & 36.7 & $\mathrm{~N}$ & $\mathrm{~N}$ & $\mathrm{~N}$ & $\mathrm{~N}$ \\
\hline $18258-0737$ & $\mathrm{H}$ & $18: 28: 34.1$ & $-07: 35: 31$ & 37.9 & $\mathrm{~N}$ & - & - & $\mathrm{N}$ \\
\hline $18265-1517$ & $\mathrm{H}$ & $18: 29: 24.8$ & $-15: 15: 49$ & 0.0 & Y & - & - & $\mathrm{N}$ \\
\hline 18278-1009 & $\mathrm{L}$ & $18: 30: 35.2$ & $-10: 07: 12$ & 93.7 & Y & $\mathrm{N}$ & $\mathrm{N}$ & $\mathrm{N}$ \\
\hline $18288-0158$ & $\mathrm{~L}$ & 18:31:26.6 & $-01: 56: 35$ & 5.8 & $\mathrm{~N}$ & $\mathrm{~N}$ & $\mathrm{~N}$ & $\mathrm{~N}$ \\
\hline
\end{tabular}


Table B.1. continued.

\begin{tabular}{|c|c|c|c|c|c|c|c|c|}
\hline IRAS name & type & RA (J2000) & Dec (J2000) & $\begin{array}{c}V_{\mathrm{LSR}} \\
\mathrm{km} \mathrm{s}^{-1}\end{array}$ & $6 \mathrm{GHz}$ & $\begin{array}{l}\mathrm{CH}_{3} \mathrm{OH} \\
44 \mathrm{GHz}\end{array}$ & $95 \mathrm{GHz}$ & $\begin{array}{c}\mathrm{H}_{2} \mathrm{O}^{p} \\
22 \mathrm{GHz}\end{array}$ \\
\hline $18310-0825$ & $\mathrm{H}$ & $18: 33: 47.2$ & $-08: 23: 34$ & 0.0 & $\mathrm{~N}$ & - & - & $\mathrm{N}$ \\
\hline 18311-0701 & $\mathrm{L}$ & $18: 33: 52.8$ & $-06: 58: 44$ & 0.0 & $\mathrm{~N}$ & - & - & $\mathrm{N}$ \\
\hline $18314-0820$ & $\mathrm{H}$ & 18:34:08.9 & $-08: 17: 52$ & 0.0 & $\mathrm{~N}$ & - & - & $\mathrm{N}$ \\
\hline 18314-0517 & $\mathrm{L}$ & $18: 34: 05.9$ & $-05: 14: 49$ & 0.0 & $\mathrm{~N}$ & - & - & $\mathrm{N}$ \\
\hline $18316-0602$ & $\mathrm{H}$ & $18: 34: 19.8$ & $-05: 59: 44$ & 42.2 & Y & $Y$ & $Y^{m}$ & Y \\
\hline 18317-0845 & $\mathrm{H}$ & $18: 34: 29.9$ & $-08: 43: 22$ & 0.0 & Y & - & - & $\mathrm{N}$ \\
\hline $18317-0513$ & $\mathrm{H}$ & $18: 34: 25.9$ & $-05: 10: 59$ & 42.2 & $\mathrm{~N}$ & - & - & $\mathrm{N}$ \\
\hline 18318-0741 & $\mathrm{L}$ & $18: 34: 30.8$ & $-07: 38: 54$ & 0.0 & $\mathrm{~N}$ & - & - & $\mathrm{N}$ \\
\hline $18355-0550$ & $\mathrm{~L}$ & 18:38:13.6 & $-05: 48: 17$ & 0.0 & $\mathrm{~N}$ & - & - & $\mathrm{N}$ \\
\hline $18358-0647$ & $\mathrm{H}$ & 18:38:31.3 & $-06: 44: 29$ & 0.0 & $\mathrm{~N}$ & - & - & $\mathrm{N}$ \\
\hline 18360-0537 & $\mathrm{H}$ & $18: 38: 40.3$ & $-05: 35: 06$ & 102.3 & $\mathrm{~N}$ & $Y$ & $Y$ & Y \\
\hline 18363-0554 & $\mathrm{L}$ & 18:39:03.7 & $-05: 52: 15$ & 65.2 & $\mathrm{~N}$ & $\mathrm{~N}$ & $\mathrm{~N}$ & $\mathrm{~N}$ \\
\hline $18372-0541$ & $\mathrm{H}$ & $18: 39: 56.0$ & $-05: 38: 49$ & 22.8 & Y & - & - & $\mathrm{N}$ \\
\hline 18396-0431 & $\mathrm{L}$ & $18: 42: 18.8$ & $-04: 28: 37$ & 97.3 & $\mathrm{~N}$ & $Y^{m}$ & $Y$ & $\mathrm{~N}$ \\
\hline 18408-0353 & $\mathrm{H}$ & $18: 43: 28.8$ & $-03: 50: 20$ & 0.0 & $Y$ & - & - & $\mathrm{N}$ \\
\hline $18408-0348$ & $\mathrm{H}$ & $18: 43: 31.1$ & $-03: 44: 57$ & 0.0 & $\mathrm{~N}$ & - & - & $\mathrm{N}$ \\
\hline 18411-0312 & $\mathrm{L}$ & $18: 43: 46.4$ & $-03: 09: 54$ & 0.0 & $\mathrm{~N}$ & - & - & $\mathrm{N}$ \\
\hline 18424-0329 & $\mathrm{L}$ & $18: 45: 03.3$ & $-03: 26: 49$ & 47.9 & $\mathrm{~N}$ & $\mathrm{~N}$ & $\mathrm{~N}$ & $\mathrm{~N}$ \\
\hline 18441-0134 & $\mathrm{L}$ & $18: 46: 44.2$ & $-01: 30: 55$ & 0.0 & Y & - & - & $\mathrm{N}$ \\
\hline $18445-0222$ & $\mathrm{H}$ & $18: 47: 10.7$ & $-02: 19: 06$ & 86.9 & $\mathrm{~N}$ & - & - & $\mathrm{N}$ \\
\hline 18463-0052 & $\mathrm{L}$ & $18: 48: 52.8$ & $-00: 49: 02$ & 0.0 & $\mathrm{~N}$ & - & - & $\mathrm{N}$ \\
\hline $18488+0000$ & $\mathrm{H}$ & $18: 51: 24.8$ & $+00: 04: 19$ & 83.2 & $\mathrm{Y}$ & - & - & $\mathrm{N}$ \\
\hline $18507+0121$ & $\mathrm{H}$ & 18:53:17.4 & $+01: 24: 55$ & 57.1 & $\mathrm{Y}$ & $Y$ & $\mathrm{~N}$ & Y \\
\hline $18511+0146$ & $\mathrm{~L}$ & 18:53:38.1 & $+01: 50: 27$ & 56.8 & $Y$ & - & - & $\mathrm{N}$ \\
\hline $18517+0437$ & $\mathrm{H}$ & 18:54:13.8 & $+04: 41: 32$ & 43.7 & Y & $Y$ & $\mathrm{~N}$ & Y \\
\hline $18527+0301$ & $\mathrm{~L}$ & 18:55:16.5 & $+03: 05: 07$ & 76.0 & Y & $\mathrm{N}$ & $\mathrm{N}$ & $\mathrm{N}$ \\
\hline $18532+0047$ & $\mathrm{H}$ & 18:55:50.8 & $+00: 51: 22$ & 58.6 & $Y$ & - & - & $\mathrm{N}$ \\
\hline $18537+0145$ & $\mathrm{~L}$ & 18:56:15.0 & $+01: 49: 03$ & 0.0 & $\mathrm{~N}$ & - & - & $\mathrm{N}$ \\
\hline $18544+0112$ & $\mathrm{~L}$ & 18:56:59.8 & $+01: 16: 20$ & 0.0 & $\mathrm{~N}$ & - & - & $\mathrm{N}$ \\
\hline $18551+0302$ & $\mathrm{H}$ & 18:57:42.1 & $+03: 06: 04$ & 57.5 & $\mathrm{~N}$ & - & - & $\mathrm{N}$ \\
\hline $18565+0349$ & $\mathrm{~L}$ & 18:59:03.4 & $+03: 53: 22$ & 91.6 & $\mathrm{~N}$ & $\mathrm{~N}$ & $\mathrm{~N}$ & $\mathrm{~N}$ \\
\hline $18566+0408$ & $\mathrm{H}$ & 18:59:09.8 & $+04: 12: 14$ & 85.1 & $\mathrm{Y}$ & - & - & $\mathrm{N}$ \\
\hline $18567+0700$ & $\mathrm{~L}$ & 18:59:13.6 & $+07: 04: 47$ & 29.4 & $\mathrm{~N}$ & $\mathrm{~N}$ & $\mathrm{~N}$ & $\mathrm{~N}$ \\
\hline $18571+0326$ & $\mathrm{~L}$ & 18:59:40.2 & $+03: 30: 29$ & 0.0 & $\mathrm{~N}$ & - & - & $\mathrm{N}$ \\
\hline $18571+0349$ & $\mathrm{~L}$ & 18:59:40.1 & $+03: 53: 35$ & 56.2 & $\mathrm{~N}$ & - & - & $\mathrm{N}$ \\
\hline $18586+0106$ & $\mathrm{~L}$ & 19:01:10.6 & $+01: 11: 16$ & 37.9 & $\mathrm{~N}$ & $\mathrm{~N}$ & $\mathrm{~N}$ & $\mathrm{~N}$ \\
\hline $18596+0536$ & $\mathrm{H}$ & 19:02:06.5 & $+05: 40: 33$ & 0.0 & $\mathrm{~N}$ & - & - & $\mathrm{N}$ \\
\hline $19001+0402$ & $\mathrm{H}$ & $19: 02: 36.2$ & $+04: 06: 58$ & 50.7 & $\mathrm{~N}$ & - & - & $\mathrm{N}$ \\
\hline $19002+0454$ & $\mathrm{H}$ & 19:02:42.0 & $+04: 58: 49$ & 69.2 & $\mathrm{~N}$ & - & - & $\mathrm{N}$ \\
\hline $19012+0505$ & $\mathrm{~L}$ & 19:03:43.5 & $+05: 09: 49$ & 40.4 & Y & - & - & $\mathrm{N}$ \\
\hline $19023+0538$ & $\mathrm{~L}$ & 19:04:49.0 & $+05: 42: 40$ & 0.0 & $\mathrm{~N}$ & - & - & $\mathrm{N}$ \\
\hline $19043+0726$ & $\mathrm{H}$ & 19:06:47.6 & $+07: 31: 38$ & 58.9 & $\mathrm{~N}$ & $Y$ & $\mathrm{~N}$ & $\mathrm{~N}$ \\
\hline $19045+0518$ & $\mathrm{H}$ & 19:06:59.3 & $+05: 22: 57$ & 53.6 & $\mathrm{~N}$ & - & - & $\mathrm{N}$ \\
\hline $19045+0813$ & $\mathrm{H}$ & 19:06:59.8 & $+08: 18: 43$ & 0.0 & $\mathrm{~N}$ & - & - & Y \\
\hline $19077+0839$ & $\mathrm{~L}$ & 19:10:09.6 & $+08: 44: 11$ & 0.0 & $\mathrm{~N}$ & - & - & $\mathrm{N}$ \\
\hline $19088+0902$ & $\mathrm{H}$ & 19:11:15.9 & $+09: 07: 27$ & 59.6 & $\mathrm{~N}$ & $Y$ & $\mathrm{~N}$ & Y \\
\hline $19092+0841$ & $\mathrm{~L}$ & 19:11:37.4 & $+08: 46: 30$ & 58.0 & $\mathrm{Y}$ & Y & $\mathrm{N}$ & Y \\
\hline $19094+0944$ & $\mathrm{H}$ & 19:11:52.0 & $+09: 49: 46$ & 65.3 & $\mathrm{~N}$ & - & - & $\mathrm{N}$ \\
\hline $19118+0945$ & $\mathrm{~L}$ & 19:14:14.7 & $+09: 50: 40$ & 0.0 & $\mathrm{~N}$ & - & - & $\mathrm{N}$ \\
\hline $19120+1148$ & $\mathrm{~L}$ & 19:14:22.1 & $+11: 53: 39$ & 0.0 & $Y$ & - & - & $\mathrm{N}$ \\
\hline $19124+1106$ & $\mathrm{H}$ & $19: 14: 45.3$ & $+11: 11: 57$ & 0.0 & $\mathrm{~N}$ & - & - & $\mathrm{N}$ \\
\hline 19139+1137 & $\mathrm{L}$ & 19:16:18.7 & $+11: 42: 46$ & 0.0 & $\mathrm{~N}$ & - & - & $\mathrm{N}$ \\
\hline $19183+1556$ & $\mathrm{~L}$ & 19:20:37.6 & $+16: 02: 31$ & 0.0 & $\mathrm{~N}$ & - & - & $\mathrm{N}$ \\
\hline $19186+1440$ & $\mathrm{~L}$ & 19:20:56.9 & $+14: 46: 40$ & 0.0 & $\mathrm{Y}$ & - & - & $\mathrm{N}$ \\
\hline $19198+1423$ & $\mathrm{H}$ & 19:22:07.7 & $+14: 29: 20$ & 58.9 & $\mathrm{~N}$ & - & - & $\mathrm{N}$ \\
\hline $19202+1412$ & $\mathrm{~L}$ & $19: 22: 31.5$ & $+14: 18: 30$ & 0.0 & $\mathrm{~N}$ & - & - & $\mathrm{N}$ \\
\hline $19213+1723$ & $\mathrm{H}$ & $19: 23: 37.0$ & $+17: 28: 59$ & 41.7 & $\mathrm{~N}$ & $\mathrm{~N}$ & $\mathrm{~N}$ & Y \\
\hline $19214+1458$ & $\mathrm{H}$ & 19:23:46.1 & $+15: 04: 51$ & 0.0 & $\mathrm{~N}$ & - & - & $\mathrm{N}$ \\
\hline $19230+1341$ & $\mathrm{H}$ & $19: 25: 22.1$ & $+13: 47: 19$ & 0.0 & Y & - & - & $\mathrm{N}$ \\
\hline $19282+1814$ & $\mathrm{H}$ & 19:30:28.1 & $+18: 20: 53$ & 24.1 & $\mathrm{Y}$ & $\mathrm{N}$ & $\mathrm{N}$ & $\mathrm{N}$ \\
\hline $19282+1742$ & $\mathrm{H}$ & 19:30:30.4 & $+17: 48: 30$ & 0.0 & $\mathrm{~N}$ & - & - & $\mathrm{N}$ \\
\hline $19294+1649$ & $\mathrm{~L}$ & $19: 31: 44.8$ & $+16: 55: 57$ & 0.0 & $\mathrm{~N}$ & - & - & $\mathrm{N}$ \\
\hline $19295+1637$ & $\mathrm{~L}$ & 19:31:50.9 & $+16: 43: 29$ & 0.0 & $\mathrm{~N}$ & - & - & $\mathrm{N}$ \\
\hline $19325+1925$ & $\mathrm{H}$ & $19: 34: 45.9$ & $+19: 31: 41$ & 0.0 & $\mathrm{~N}$ & - & - & $\mathrm{N}$ \\
\hline $19332+2028$ & $\mathrm{~L}$ & $19: 35: 25.4$ & $+20: 34: 56$ & 0.0 & $\mathrm{~N}$ & - & - & $\mathrm{N}$ \\
\hline
\end{tabular}


Table B.1. continued.

\begin{tabular}{|c|c|c|c|c|c|c|c|c|}
\hline IRAS name & type & RA (J2000) & Dec (J2000) & $\begin{array}{c}V_{\mathrm{LSR}} \\
\mathrm{km} \mathrm{s}^{-1}\end{array}$ & $6 \mathrm{GHz}$ & $\begin{array}{l}\mathrm{CH}_{3} \mathrm{OH} \\
44 \mathrm{GHz}\end{array}$ & $95 \mathrm{GHz}$ & $\begin{array}{c}\mathrm{H}_{2} \mathrm{O}^{p} \\
22 \mathrm{GHz}\end{array}$ \\
\hline $19343+2026$ & $\mathrm{~L}$ & $19: 36: 30.2$ & $+20: 33: 08$ & 0.0 & $\mathrm{~N}$ & - & - & $\mathrm{N}$ \\
\hline $19368+2239$ & $\mathrm{H}$ & 19:38:58.1 & $+22: 46: 32$ & 36.4 & $\mathrm{~N}$ & - & - & $\mathrm{N}$ \\
\hline $19374+2352$ & $\mathrm{H}$ & 19:39:33.2 & $+23: 59: 55$ & 36.9 & $\mathrm{~N}$ & $\mathrm{~N}$ & $\mathrm{~N}$ & Y \\
\hline $19383+2711$ & $\mathrm{H}$ & 19:40:22.1 & $+27: 18: 34$ & 0.0 & $\mathrm{~N}$ & - & - & $\mathrm{N}$ \\
\hline $19388+2357$ & $\mathrm{H}$ & $19: 40: 59.3$ & $+24: 04: 39$ & 34.6 & Y & $Y$ & $\mathrm{~N}$ & Y \\
\hline $19423+2541$ & $\mathrm{H}$ & $19: 44: 23.4$ & $+25: 48: 40$ & 0.0 & $\mathrm{~N}$ & - & - & $\mathrm{N}$ \\
\hline $19458+2442$ & $\mathrm{~L}$ & $19: 47: 59.7$ & $+24: 50: 19$ & 0.0 & $\mathrm{~N}$ & - & - & $\mathrm{N}$ \\
\hline $19462+2759$ & $\mathrm{H}$ & 19:48:14.0 & $+28: 07: 23$ & 0.0 & $\mathrm{~N}$ & - & - & $\mathrm{N}$ \\
\hline $19499+2613$ & $\mathrm{H}$ & 19:52:01.4 & $+26: 21: 10$ & 0.0 & $\mathrm{~N}$ & - & - & $\mathrm{N}$ \\
\hline $19542+3004$ & $\mathrm{~L}$ & 19:56:13.2 & $+30: 12: 56$ & 0.0 & $\mathrm{~N}$ & - & - & $\mathrm{N}$ \\
\hline $19560+3135$ & $\mathrm{H}$ & 19:58:03.3 & $+31: 44: 06$ & 0.0 & $\mathrm{~N}$ & - & - & $\mathrm{N}$ \\
\hline $19592+3302$ & $\mathrm{H}$ & 20:01:09.8 & $+33: 11: 08$ & 0.0 & $\mathrm{~N}$ & - & - & $\mathrm{N}$ \\
\hline $20028+2903$ & $\mathrm{~L}$ & 20:04:53.3 & $+29: 11: 37$ & 0.0 & $\mathrm{~N}$ & - & - & $\mathrm{N}$ \\
\hline $20050+2720$ & $\mathrm{H}$ & 20:07:06.7 & $+27: 28: 53$ & 6.4 & $\mathrm{~N}$ & $Y$ & $\mathrm{~N}$ & Y \\
\hline $20051+3435$ & $\mathrm{H}$ & 20:07:03.8 & $+34: 44: 34$ & 0.0 & $\mathrm{~N}$ & - & - & $\mathrm{N}$ \\
\hline $20056+3350$ & $\mathrm{H}$ & $20: 07: 31.5$ & $+33: 59: 39$ & 9.4 & $\mathrm{~N}$ & $\mathrm{~N}$ & $\mathrm{~N}$ & Y \\
\hline $20062+3550$ & $\mathrm{H}$ & 20:08:09.7 & $+35: 59: 20$ & 0.6 & Y & $Y$ & $\mathrm{~N}$ & Y \\
\hline $20081+2720$ & $\mathrm{H}$ & 20:10:11.4 & $+27: 29: 06$ & 0.0 & $\mathrm{~N}$ & - & - & $\mathrm{N}$ \\
\hline $20099+3640$ & $\mathrm{~L}$ & 20:11:46.4 & $+36: 49: 37$ & -36.4 & $\mathrm{~N}$ & $\mathrm{~N}$ & $\mathrm{~N}$ & $\mathrm{~N}$ \\
\hline $20103+3633$ & $\mathrm{H}$ & 20:12:13.9 & $+36: 42: 58$ & 0.0 & $\mathrm{~N}$ & - & - & $\mathrm{N}$ \\
\hline $20106+3545$ & $\mathrm{~L}$ & $20: 12: 31.3$ & $+35: 54: 46$ & 7.8 & $\mathrm{~N}$ & $\mathrm{~N}$ & $\mathrm{~N}$ & $\mathrm{~N}$ \\
\hline $20126+4104$ & $\mathrm{H}$ & $20: 14: 26.0$ & $+41: 13: 32$ & -3.9 & $\mathrm{Y}$ & Y & $Y$ & Y \\
\hline $20149+3440$ & $\mathrm{~L}$ & $20: 16: 50.4$ & $+34: 49: 22$ & 0.0 & $\mathrm{~N}$ & - & - & $\mathrm{N}$ \\
\hline $20153+3850^{a}$ & $\mathrm{~L}$ & 20:17:07.6 & $+38: 59: 25$ & 0.0 & $\mathrm{~N}$ & - & - & $\mathrm{N}^{b}$ \\
\hline $20160+3636^{a}$ & $\mathrm{H}$ & $20: 17: 56.1$ & $+36: 45: 33$ & 0.0 & $\mathrm{~N}$ & - & - & $\mathrm{N}^{b}$ \\
\hline $20173+3714$ & $\mathrm{~L}$ & 20:19:10.4 & $+37: 23: 31$ & 0.0 & $\mathrm{~N}$ & - & - & $\mathrm{N}$ \\
\hline $20180+3558$ & $\mathrm{~L}$ & 20:19:58.0 & $+36: 07: 37$ & 0.0 & $\mathrm{~N}$ & - & - & $\mathrm{N}$ \\
\hline $20188+3928$ & $\mathrm{H}$ & $20: 20: 39.3$ & $+39: 37: 52$ & 1.5 & $\mathrm{~N}$ & $Y$ & $\mathrm{~N}$ & Y \\
\hline $20190+4102$ & $\mathrm{~L}$ & $20: 20: 47.9$ & $+41: 12: 08$ & 0.0 & $\mathrm{~N}$ & - & - & $\mathrm{N}$ \\
\hline $20205+3948$ & $\mathrm{H}$ & $20: 22: 21.8$ & $+39: 58: 04$ & 0.0 & $\mathrm{~N}$ & - & - & $\mathrm{N}$ \\
\hline $20216+4107$ & $\mathrm{H}$ & $20: 23: 23.8$ & $+41: 17: 40$ & 0.0 & $\mathrm{~N}$ & - & - & $\mathrm{N}$ \\
\hline $20217+3947$ & $\mathrm{~L}$ & $20: 23: 31.7$ & $+39: 57: 23$ & -0.9 & $\mathrm{~N}$ & $\mathrm{~N}$ & $\mathrm{~N}$ & $\mathrm{~N}$ \\
\hline $20220+3728$ & $\mathrm{H}$ & $20: 23: 55.6$ & $+37: 38: 10$ & -2.7 & $\mathrm{~N}$ & - & - & $\mathrm{N}$ \\
\hline $20222+3541$ & $\mathrm{~L}$ & $20: 24: 10.9$ & $+35: 51: 37$ & 0.0 & $\mathrm{~N}$ & - & - & $\mathrm{N}$ \\
\hline $20227+4154$ & $\mathrm{H}$ & $20: 24: 31.4$ & $+42: 04: 17$ & 5.9 & $\mathrm{~N}$ & $\mathrm{~N}$ & $\mathrm{~N}$ & $\mathrm{Y}$ \\
\hline $20228+4215^{a}$ & $\mathrm{~L}$ & $20: 24: 34.4$ & $+42: 25: 01$ & 0.0 & $\mathrm{~N}$ & - & - & $\mathbf{N}^{b}$ \\
\hline $20243+3853$ & $\mathrm{H}$ & $20: 26: 10.8$ & $+39: 03: 29$ & 0.0 & $\mathrm{~N}$ & - & - & $\mathrm{N}$ \\
\hline $20261+3825$ & $\mathrm{~L}$ & 20:28:01.9 & $+38: 35: 50$ & 0.0 & $\mathrm{~N}$ & - & - & $\mathrm{N}$ \\
\hline $20264+4042$ & $\mathrm{H}$ & $20: 28: 12.3$ & $+40: 52: 28$ & 0.0 & $\mathrm{~N}$ & - & - & $\mathrm{N}$ \\
\hline $20277+3851$ & $\mathrm{H}$ & $20: 29: 36.7$ & $+39: 01: 17$ & 0.0 & $\mathrm{~N}$ & - & - & $\mathrm{N}$ \\
\hline $20278+3521$ & $\mathrm{~L}$ & $20: 29: 46.9$ & $+35: 31: 39$ & -4.5 & $\mathrm{~N}$ & $\mathrm{~N}$ & $\mathrm{~N}$ & $\mathrm{~N}$ \\
\hline $20281+4038$ & $\mathrm{H}$ & 20:29:54.7 & $+40: 48: 52$ & 0.0 & $\mathrm{~N}$ & - & - & $\mathrm{N}$ \\
\hline $20286+4105$ & $\mathrm{H}$ & $20: 30: 27.9$ & $+41: 15: 48$ & -3.8 & $\mathrm{~N}$ & - & - & Y \\
\hline $20293+4007$ & $\mathrm{~L}$ & 20:31:07.9 & $+40: 17: 23$ & 0.0 & $\mathrm{~N}$ & - & - & $\mathrm{N}$ \\
\hline $20306+4005$ & $\mathrm{H}$ & $20: 32: 28.7$ & $+40: 16: 05$ & 0.0 & $\mathrm{~N}$ & - & - & $\mathrm{N}$ \\
\hline $20306+3749$ & $\mathrm{H}$ & $20: 32: 34.4$ & $+37: 59: 35$ & 0.0 & $\mathrm{~N}$ & - & - & $\mathrm{N}$ \\
\hline $20319+3958$ & $\mathrm{H}$ & 20:33:49.4 & $+40: 08: 44$ & 0.0 & $\mathrm{~N}$ & - & - & $\mathrm{N}$ \\
\hline $20321+4112$ & $\mathrm{H}$ & 20:33:55.6 & $+41: 22: 43$ & 0.0 & $\mathrm{~N}$ & - & - & $\mathrm{N}$ \\
\hline $20327+4120$ & $\mathrm{~L}$ & 20:34:31.1 & $+41: 30: 44$ & 0.0 & $\mathrm{~N}$ & - & - & $\mathrm{N}$ \\
\hline $20332+4124$ & $\mathrm{H}$ & 20:35:00.5 & $+41: 34: 48$ & 0.0 & $\mathrm{~N}$ & - & - & $\mathrm{N}$ \\
\hline $20333+4102$ & $\mathrm{~L}$ & 20:35:09.5 & $+41: 13: 18$ & 8.4 & $\mathrm{~N}$ & - & - & $\mathrm{N}$ \\
\hline $20337+4104$ & $\mathrm{~L}$ & $20: 35: 34.7$ & $+41: 15: 21$ & 0.0 & $\mathrm{~N}$ & - & - & $\mathrm{N}$ \\
\hline $20343+4129$ & $\mathrm{H}$ & 20:36:07.1 & +41:40:01 & 0.0 & $\mathrm{~N}$ & - & - & $\mathrm{N}$ \\
\hline $20350+4126$ & $\mathrm{H}$ & $20: 36: 52.5$ & $+41: 36: 33$ & 0.0 & $\mathrm{Y}$ & - & - & $\mathrm{N}$ \\
\hline $20406+4555$ & $\mathrm{~L}$ & 20:42:21.6 & $+46: 05: 53$ & 0.0 & $\mathrm{~N}$ & - & - & $\mathrm{N}$ \\
\hline $20444+4629$ & $\mathrm{H}$ & 20:46:08.2 & $+46: 40: 41$ & -4.1 & $\mathrm{~N}$ & $\mathrm{~N}$ & $\mathrm{~N}$ & $\mathrm{~N}$ \\
\hline $20446+4613$ & $\mathrm{~L}$ & $20: 46: 17.3$ & $+46: 24: 38$ & 0.0 & $\mathrm{~N}$ & - & - & $\mathrm{N}$ \\
\hline $21020+4939^{a}$ & $\mathrm{~L}$ & 21:03:42.2 & $+49: 51: 53$ & 0.0 & $\mathrm{~N}$ & - & - & $\mathrm{N}^{w}$ \\
\hline $21036+4927^{a}$ & $\mathrm{H}$ & 21:05:15.6 & $+49: 40: 01$ & 0.0 & $\mathrm{~N}$ & - & - & $\mathrm{N}^{w}$ \\
\hline $21046+5110$ & $\mathrm{~L}$ & 21:06:16.3 & $+51: 22: 13$ & 0.0 & $\mathrm{~N}$ & - & - & $\mathrm{N}$ \\
\hline $21078+5211$ & $\mathrm{H}$ & 21:09:25.2 & $+52: 23: 44$ & -6.1 & $\mathrm{~N}$ & $\mathrm{~N}$ & $\mathrm{~N}$ & $\mathrm{Y}$ \\
\hline $21080+4758$ & $\mathrm{~L}$ & 21:09:46.5 & $+48: 10: 59$ & 0.0 & $\mathrm{~N}$ & - & - & $\mathrm{N}$ \\
\hline $21202+5157$ & $\mathrm{H}$ & $21: 21: 53.2$ & $+52: 10: 44$ & 0.0 & $\mathrm{~N}$ & - & - & $\mathrm{N}$ \\
\hline $21270+5423^{a}$ & $\mathrm{~L}$ & $21: 28: 42.0$ & $+54: 36: 51$ & 0.0 & $\mathrm{~N}$ & - & - & $\mathrm{N}^{w}$ \\
\hline $21306+5540^{a}$ & $\mathrm{H}$ & 21:32:11.6 & $+55: 53: 24$ & 0.0 & Y & - & - & $\mathrm{Y}^{v}$ \\
\hline
\end{tabular}


Table B.1. continued.

\begin{tabular}{|c|c|c|c|c|c|c|c|c|}
\hline IRAS name & type & RA (J2000) & Dec (J2000) & $\begin{array}{c}V_{\mathrm{LSR}} \\
\mathrm{km} \mathrm{s}^{-1}\end{array}$ & $6 \mathrm{GHz}$ & $\begin{array}{l}\mathrm{CH}_{3} \mathrm{OH} \\
44 \mathrm{GHz}\end{array}$ & $95 \mathrm{GHz}$ & $\begin{array}{c}\mathrm{H}_{2} \mathrm{O}^{p} \\
22 \mathrm{GHz}\end{array}$ \\
\hline $21307+5049$ & $\mathrm{~L}$ & $21: 32: 31.5$ & $+51: 02: 22$ & -46.7 & $\mathrm{~N}$ & $\mathrm{~N}$ & $\mathrm{~N}$ & $\mathrm{Y}$ \\
\hline $21336+5333$ & $\mathrm{H}$ & $21: 35: 21.0$ & $+53: 47: 12$ & 0.0 & $\mathrm{~N}$ & - & - & $\mathrm{N}$ \\
\hline $21391+5802$ & $\mathrm{H}$ & $21: 40: 42.3$ & $+58: 16: 10$ & 0.4 & $\mathrm{~N}$ & $\mathrm{Y}$ & Y & Y \\
\hline $21418+6552^{a}$ & $\mathrm{H}$ & $21: 43: 02.3$ & $+66: 06: 29$ & 0.0 & $\mathrm{~N}$ & - & - & $\mathrm{Y}^{v}$ \\
\hline $21418+5403^{a}$ & $\mathrm{H}$ & $21: 43: 29.8$ & $+54: 16: 56$ & 0.0 & $\mathrm{~N}$ & - & - & $\mathrm{N}^{w}$ \\
\hline $21519+5613$ & $\mathrm{H}$ & $21: 53: 39.2$ & $+56: 27: 46$ & -63.2 & $\mathrm{~N}$ & - & - & $\mathrm{N}$ \\
\hline $21526+5728$ & $\mathrm{H}$ & $21: 54: 18.4$ & $+57: 42: 51$ & 0.0 & $\mathrm{~N}$ & - & - & $\mathrm{N}$ \\
\hline $21548+5747$ & $\mathrm{~L}$ & $21: 56: 29.9$ & $+58: 01: 35$ & 0.0 & $\mathrm{~N}$ & - & - & $\mathrm{N}$ \\
\hline $22147+5948$ & $\mathrm{~L}$ & $22: 16: 28.6$ & $+60: 03: 49$ & 0.0 & $\mathrm{~N}$ & - & - & $\mathrm{N}$ \\
\hline $22172+5549$ & $\mathrm{~L}$ & 22:19:09.0 & $+56: 04: 45$ & -43.8 & $\mathrm{~N}$ & $\mathrm{~N}$ & $\mathrm{~N}$ & $\mathrm{~N}$ \\
\hline $22187+5559$ & $\mathrm{~L}$ & $22: 20: 34.9$ & $+56: 14: 40$ & 0.0 & $Y$ & - & - & $\mathrm{N}$ \\
\hline $22198+6336$ & $\mathrm{H}$ & $22: 21: 27.6$ & $+63: 51: 42$ & -11.1 & $\mathrm{~N}$ & $\mathrm{~N}$ & $\mathrm{~N}$ & $\mathrm{Y}$ \\
\hline $22267+6244$ & $\mathrm{H}$ & $22: 28: 29.3$ & $+62: 59: 44$ & -1.5 & $\mathrm{~N}$ & $\mathrm{~N}$ & $\mathrm{~N}$ & $\mathrm{~N}$ \\
\hline $22272+6358$ & $\mathrm{H}$ & $22: 28: 52.2$ & $+64: 13: 43$ & -9.9 & Y & $\mathrm{N}$ & $\mathrm{N}$ & $\mathrm{N}$ \\
\hline $22305+5803$ & $\mathrm{H}$ & $22: 32: 24.3$ & $+58: 18: 58$ & -52.1 & $\mathrm{~N}$ & - & - & $\mathrm{Y}$ \\
\hline $22344+5909$ & $\mathrm{~L}$ & $22: 36: 20.6$ & $+59: 24: 57$ & 0.0 & $\mathrm{~N}$ & - & - & $\mathrm{N}$ \\
\hline $22457+5751$ & $\mathrm{~L}$ & $22: 47: 46.5$ & $+58: 07: 19$ & 0.0 & $\mathrm{~N}$ & - & - & $\mathrm{N}$ \\
\hline $22475+5939^{a}$ & $\mathrm{H}$ & $22: 49: 29.5$ & $+59: 54: 57$ & 0.0 & $\mathrm{~N}$ & - & - & $\mathrm{Y}^{v}$ \\
\hline $22506+5944$ & $\mathrm{H}$ & $22: 52: 38.6$ & $+60: 00: 56$ & -51.5 & $Y$ & $Y$ & $Y^{m}$ & $\mathrm{Y}$ \\
\hline $22539+5758^{a}$ & $\mathrm{H}$ & $22: 56: 00.0$ & $+58: 14: 46$ & 0.0 & $\mathrm{~N}$ & - & - & $\mathbf{N}^{v}$ \\
\hline $22542+5815^{a}$ & $\mathrm{~L}$ & $22: 56: 17.0$ & $+58: 31: 13$ & 0.0 & $\mathrm{~N}$ & - & - & $\mathbf{N}^{v}$ \\
\hline $22543+6145^{a}$ & $\mathrm{H}$ & $22: 56: 19.1$ & $+62: 01: 57$ & 0.0 & Y & - & - & $\mathrm{Y}^{v}$ \\
\hline $22551+6221$ & $\mathrm{H}$ & $22: 57: 05.2$ & $+62: 37: 44$ & 0.0 & $\mathrm{~N}$ & - & - & $\mathrm{N}$ \\
\hline $22566+5830^{a}$ & $\mathrm{H}$ & $22: 58: 41.3$ & $+58: 46: 57$ & 0.0 & $\mathrm{~N}$ & - & - & $\mathrm{Y}^{v}$ \\
\hline $22570+5912$ & $\mathrm{H}$ & $22: 59: 06.4$ & $+59: 28: 28$ & 0.0 & $\mathrm{~N}$ & - & - & $\mathrm{N}$ \\
\hline $23026+5948$ & $\mathrm{~L}$ & $23: 04: 45.7$ & $+60: 04: 35$ & -51.1 & $\mathrm{~N}$ & $\mathrm{~N}$ & $\mathrm{~N}$ & $\mathrm{~N}$ \\
\hline $23042+6000$ & $\mathrm{~L}$ & $23: 06: 21.2$ & $+60: 16: 16$ & 0.0 & $\mathrm{~N}$ & $\mathrm{~N}$ & $\mathrm{~N}$ & $\mathrm{~N}$ \\
\hline $23134+6131$ & $\mathrm{~L}$ & $23: 15: 34.5$ & $+61: 47: 41$ & 0.0 & $\mathrm{~N}$ & $\mathrm{~N}$ & $\mathrm{~N}$ & $\mathrm{~N}$ \\
\hline $23140+6121$ & $\mathrm{~L}$ & $23: 16: 11.7$ & $+61: 37: 45$ & -51.5 & $\mathrm{~N}$ & $\mathrm{~N}$ & $\mathrm{~N}$ & $\mathrm{~N}$ \\
\hline $23146+5954$ & $\mathrm{~L}$ & $23: 16: 48.9$ & $+60: 10: 46$ & 0.0 & $\mathrm{~N}$ & - & - & $\mathrm{N}$ \\
\hline $23152+6034$ & $\mathrm{~L}$ & $23: 17: 25.8$ & $+60: 50: 45$ & 0.0 & $\mathrm{~N}$ & - & - & $\mathrm{N}$ \\
\hline $23314+6033$ & $\mathrm{~L}$ & $23: 33: 44.4$ & $+60: 50: 30$ & -45.4 & $\mathrm{~N}$ & $\mathrm{~N}$ & $\mathrm{~N}$ & $\mathrm{~N}$ \\
\hline $23330+6437$ & $\mathrm{~L}$ & $23: 35: 23.7$ & $+64: 54: 31$ & 0.0 & $\mathrm{~N}$ & - & - & $\mathrm{N}$ \\
\hline $23385+6053$ & $\mathrm{~L}$ & $23: 40: 53.2$ & $+61: 10: 21$ & -50.0 & $\mathrm{~N}$ & $\mathrm{Y}$ & $\mathrm{N}$ & $\mathrm{Y}$ \\
\hline $23448+6010$ & $\mathrm{~L}$ & $23: 47: 20.2$ & $+60: 27: 21$ & 0.0 & $\mathrm{~N}$ & - & - & $\mathrm{N}$ \\
\hline $23504+6012^{a}$ & $\mathrm{~L}$ & $23: 52: 58.2$ & $+60: 28: 45$ & 0.0 & $\mathrm{~N}$ & - & - & $\mathbf{N}^{w}$ \\
\hline $23507+6230$ & $\mathrm{~L}$ & $23: 53: 12.9$ & $+62: 47: 00$ & 0.0 & $\mathrm{~N}$ & - & - & $\mathrm{N}$ \\
\hline $23545+6508$ & $\mathrm{H}$ & $23: 57: 05.2$ & $+65: 25: 11$ & -18.4 & $\mathrm{~N}$ & - & - & $\mathrm{N}$ \\
\hline
\end{tabular}

Notes. The new detections are in italics. ${ }^{(p)}$ Observed by Palla et al. (1991) with the Medicina 32-m telescope, except when differently specified. ${ }^{(a)}$ Rejected by Palla et al. (1991) because associated with radio continuum. ${ }^{(w)}$ Observed by Wouterloot et al. (1993). ${ }^{(v)}$ Observed by Valdettaro et al. (2001). ${ }^{(m)}$ Marginal detection at $\sim 3 \sigma .{ }^{(h)}$ Observed by Henning et al. (1992). ${ }^{(b)}$ Observed with the Medicina 32-m telescope (unpublished data). 
F. Fontani et al.: Methanol masers in high-mass star forming regions

Table B.2. Parameters of the $6 \mathrm{GHz} \mathrm{CH} \mathrm{CH}_{3} \mathrm{OH}$ maser (Class II) detected in high sources with the Effelsberg 100-m telescope.

\begin{tabular}{|c|c|c|c|c|c|}
\hline Source & $\begin{array}{c}V_{\mathrm{LSR}^{a}} \\
\left(\mathrm{~km} \mathrm{~s}^{-1}\right)\end{array}$ & $\begin{array}{c}\int F_{\gamma} \mathrm{d} V \\
\left(\mathrm{Jy} \mathrm{km} \mathrm{s}{ }^{-1}\right)\end{array}$ & $\begin{array}{c}V \\
\left(\mathrm{~km} \mathrm{~s}^{-1}\right)\end{array}$ & $\begin{array}{c}\Delta V \\
\left(\mathrm{~km} \mathrm{~s}^{-1}\right)\end{array}$ & $\begin{array}{c}F_{\text {peak }} \\
(\mathrm{Jy})\end{array}$ \\
\hline \multirow[t]{2}{*}{$00338+6312^{*}$} & $-17.5^{f}$ & $6.4 \pm 0.1$ & $-23.030 \pm 0.001$ & $0.287 \pm 0.003$ & 21.0 \\
\hline & & $2.8 \pm 0.2$ & $-22.64 \pm 0.02$ & $0.74 \pm 0.04$ & 3.62 \\
\hline \multirow[t]{4}{*}{$05274+3345$} & -3.8 & $2.40 \pm 0.04$ & $0.324 \pm 0.002$ & $0.331 \pm 0.006$ & 6.81 \\
\hline & & $10.07 \pm 0.04$ & $1.244 \pm 0.003$ & $0.584 \pm 0.004$ & 16.2 \\
\hline & & $16.59 \pm 0.04$ & $1.609 \pm 0.0005$ & $0.349 \pm 0.003$ & 44.6 \\
\hline & & $1.15 \pm 0.03$ & $2.140 \pm 0.003$ & $0.202 \pm 0.005$ & 5.35 \\
\hline \multirow[t]{4}{*}{$05358+3543 *$} & $-17.6^{d}$ & $18 \pm 1$ & $-13.8 \pm 0.1$ & $0.5 \pm 0.1$ & 34.4 \\
\hline & & $15 \pm 1$ & $-13.2 \pm 0.1$ & $0.3 \pm 0.1$ & 45.7 \\
\hline & & $19 \pm 1$ & $-12.8 \pm 0.1$ & $0.3 \pm 0.1$ & 51.8 \\
\hline & & $1.5 \pm 1$ & $-11.5 \pm 0.1$ & $3.0 \pm 0.1$ & 0.47 \\
\hline \multirow[t]{4}{*}{$05480+2545$} & $-9.3^{b}$ & $0.98 \pm 0.03$ & $-15.250 \pm 0.004$ & $0.238 \pm 0.009$ & 3.88 \\
\hline & & $3.09 \pm 0.04$ & $-14.730 \pm 0.003$ & $0.426 \pm 0.007$ & 6.81 \\
\hline & & $0.27 \pm 0.03$ & $-13.99 \pm 0.02$ & $0.30 \pm 0.05$ & 0.84 \\
\hline & & $6.15 \pm 0.04$ & $-4.8940 \pm 0.0001$ & $0.340 \pm 0.003$ & 17.0 \\
\hline \multirow{2}{*}{$06055+2039 *$} & $8.8^{c}$ & $0.2 \pm 0.02$ & $3.9 \pm 0.02$ & $0.38 \pm 0.06$ & 0.5 \\
\hline & & $0.78 \pm 0.02$ & $5.496 \pm 0.006$ & $0.47 \pm 0.02$ & 1.57 \\
\hline \multirow[t]{3}{*}{$06056+2131$} & 2.6 & $3.7 \pm 0.2$ & $8.8 \pm 0.1$ & $0.3 \pm 0.1$ & 12.7 \\
\hline & & $2.2 \pm 0.2$ & $9.6 \pm 0.1$ & $0.3 \pm 0.1$ & 7.26 \\
\hline & & $0.7 \pm 0.2$ & $10.6 \pm 0.1$ & $1.1 \pm 0.1$ & 0.605 \\
\hline \multirow{4}{*}{$06058+2138^{*}$} & $3.1^{c}$ & $4.1 \pm 0.2$ & $8.470 \pm 0.009$ & $0.43 \pm 0.03$ & 9.10 \\
\hline & & $5.0 \pm 0.1$ & $9.446 \pm 0.001$ & $0.386 \pm 0.008$ & 12.2 \\
\hline & & $373.0 \pm 0.2$ & $10.590 \pm 0.001$ & $0.784 \pm 0.001$ & 447 \\
\hline & & $17.7 \pm 0.1$ & $11.45 \pm 0.01$ & $0.212 \pm 0.002$ & 78.7 \\
\hline \multirow[t]{3}{*}{$06061+2151$} & -0.6 & $0.51 \pm 0.02$ & $-5.564 \pm 0.003$ & $0.232 \pm 0.008$ & 2.08 \\
\hline & & $0.17 \pm 0.03$ & $-5.05 \pm 0.06$ & $0.7 \pm 0.2$ & 0.227 \\
\hline & & $0.30 \pm 0.02$ & $10.63 \pm 0.03$ & $0.74 \pm 0.07$ & 0.380 \\
\hline \multirow{3}{*}{$06117+1350^{*}$} & $17.9^{c}$ & $2.2 \pm 0.8$ & $14.6 \pm 0.1$ & $0.2 \pm 0.1$ & 9.5 \\
\hline & & $25.0 \pm 0.8$ & $15.1 \pm 0.1$ & $0.5 \pm 0.1$ & 47.8 \\
\hline & & $4.6 \pm 0.8$ & $15.7 \pm 0.1$ & $0.5 \pm 0.1$ & 8.2 \\
\hline \multirow[t]{2}{*}{$17571-2328$} & - & $0.85 \pm 0.01$ & $143.80 \pm 0.03$ & $1.16 \pm 0.05$ & 0.686 \\
\hline & & $0.29 \pm 0.03$ & $147.30 \pm 0.02$ & $0.37 \pm 0.05$ & 0.731 \\
\hline \multirow{12}{*}{$17589-2312$} & $21.1^{c}$ & $1.5 \pm 0.5$ & $13.1 \pm 0.1$ & $1.0 \pm 0.1$ & 1.44 \\
\hline & & $7.1 \pm 0.5$ & $14.7 \pm 0.1$ & $0.4 \pm 0.1$ & 19.1 \\
\hline & & $9.6 \pm 0.5$ & $15.2 \pm 0.1$ & $0.2 \pm 0.1$ & 39.3 \\
\hline & & $54.7 \pm 0.5$ & $16.0 \pm 0.1$ & $0.8 \pm 0.1$ & 62.5 \\
\hline & & $2.21 \pm 0.06$ & $17.430 \pm 0.006$ & $0.48 \pm 0.02$ & 4.30 \\
\hline & & $2.59 \pm 0.04$ & $18.7000 \pm 0.0008$ & $0.239 \pm 0.005$ & 10.2 \\
\hline & & $3.80 \pm 0.05$ & $19.540 \pm 0.003$ & $0.436 \pm 0.008$ & 8.19 \\
\hline & & $1.08 \pm 0.07$ & $24.60 \pm 0.04$ & $1.19 \pm 0.06$ & 0.847 \\
\hline & & $15.60 \pm 0.07$ & $25.4500 \pm 0.0008$ & $0.569 \pm 0.002$ & 25.8 \\
\hline & & $26.07 \pm 0.05$ & $26.4800 \pm 0.0009$ & $0.937 \pm 0.002$ & 26.1 \\
\hline & & $10.0 \pm 0.4$ & $28.07 \pm 0.02$ & $1.27 \pm 0.04$ & 7.37 \\
\hline & & $7.8 \pm 0.2$ & $28.630 \pm 0.003$ & $0.422 \pm 0.007$ & 17.2 \\
\hline \multirow[t]{9}{*}{$18048-2019$} & 49.1 & $15.3 \pm 0.6$ & $41.40 \pm 0.110$ & $0.6142 \pm 0.110$ & 23.3 \\
\hline & & $17.7 \pm 0.6$ & $42.1 \pm 0.1$ & $0.6 \pm 0.1$ & 27.3 \\
\hline & & $5.9 \pm 0.6$ & $43.2 \pm 0.1$ & $0.4 \pm 0.1$ & 15.5 \\
\hline & & $0.7 \pm 0.6$ & $44.2 \pm 0.1$ & $1.0 \pm 0.1$ & 0.629 \\
\hline & & $4.1 \pm 0.4$ & $45.8 \pm 0.1$ & $1.9 \pm 0.1$ & 2.03 \\
\hline & & $5.6 \pm 0.4$ & $46.8 \pm 0.1$ & $0.8 \pm 0.1$ & 6.67 \\
\hline & & $5.2 \pm 0.4$ & $47.1 \pm 0.1$ & $0.3 \pm 0.1$ & 14.6 \\
\hline & & $1.4 \pm 0.4$ & $48.1 \pm 0.1$ & $0.7 \pm 0.1$ & 1.82 \\
\hline & & $1.0 \pm 0.4$ & $50.4 \pm 0.1$ & $1.0 \pm 0.1$ & 1.00 \\
\hline \multirow[t]{12}{*}{$18089-1732$} & 32.9 & $2.8 \pm 0.1$ & $29.59 \pm 0.08$ & $3.4 \pm 0.2$ & 0.774 \\
\hline & & $0.13 \pm 0.01$ & $29.210 \pm 0.004$ & $0.111 \pm 0.003$ & 1.07 \\
\hline & & $0.94 \pm 0.03$ & $30.210 \pm 0.003$ & $0.270 \pm 0.009$ & 3.26 \\
\hline & & $3.3 \pm 0.7$ & $31.9 \pm 0.1$ & $0.7 \pm 0.1$ & 4.50 \\
\hline & & $4.7 \pm 0.7$ & $32.8 \pm 0.1$ & $0.5 \pm 0.1$ & 9.18 \\
\hline & & $24.7 \pm 0.7$ & $33.7 \pm 0.1$ & $0.5 \pm 0.1$ & 50.3 \\
\hline & & $3.8 \pm 0.7$ & $34.7 \pm 0.1$ & $0.4 \pm 0.1$ & 8.22 \\
\hline & & $1.9 \pm 0.7$ & $36.5 \pm 0.1$ & $0.5 \pm 0.1$ & 3.87 \\
\hline & 32.9 & $5.3 \pm 0.7$ & $37.9 \pm 0.1$ & $1.1 \pm 0.1$ & 4.61 \\
\hline & & $5.8 \pm 0.7$ & $38.7 \pm 0.1$ & $0.3 \pm 0.1$ & 17.2 \\
\hline & & $27.1 \pm 0.7$ & $39.2 \pm 0.1$ & $0.5 \pm 0.1$ & 55.4 \\
\hline & & $3.6 \pm 0.7$ & $42.4 \pm 0.1$ & $10.4 \pm 0.1$ & 0.321 \\
\hline
\end{tabular}


A\&A 517, A56 (2010)

Table B.2. continued.

\begin{tabular}{|c|c|c|c|c|c|}
\hline Source & $\begin{array}{c}V_{\mathrm{LSR}}{ }^{a} \\
\left(\mathrm{~km} \mathrm{~s}^{-1}\right)\end{array}$ & $\begin{array}{c}\int_{(\mathrm{Jy} \mathrm{km} \mathrm{s}} F_{v} \mathrm{~d} V \\
\left.\mathrm{~km} \mathrm{~s}^{-1}\right)\end{array}$ & $\begin{array}{c}V \\
\left(\mathrm{~km} \mathrm{~s}^{-1}\right)\end{array}$ & $\begin{array}{c}\Delta V \\
\left(\mathrm{~km} \mathrm{~s}^{-1}\right)\end{array}$ & $\begin{array}{l}F_{\text {peak }} \\
(\mathrm{Jy})\end{array}$ \\
\hline \multirow[t]{6}{*}{$18102-1800$} & $21.1^{d}$ & $3.8 \pm 0.1$ & $21.6 \pm 0.1$ & $0.5 \pm 0.1$ & 7.05 \\
\hline & & $1.5 \pm 0.1$ & $23.1 \pm 0.1$ & $0.4 \pm 0.1$ & 3.09 \\
\hline & & $2.9 \pm 0.1$ & $24.0 \pm 0.1$ & $0.6 \pm 0.1$ & 4.23 \\
\hline & & $1.40 \pm 0.04$ & $25.020 \pm 0.006$ & $0.49 \pm 0.02$ & 2.69 \\
\hline & & $1.11 \pm 0.04$ & $25.640 \pm 0.007$ & $0.46 \pm 0.02$ & 2.28 \\
\hline & & $0.19 \pm 0.03$ & $27.22 \pm 0.03$ & $0.51 \pm 0.1$ & 0.35 \\
\hline \multirow[t]{11}{*}{ 18134-1942 } & 10.5 & $2.28 \pm 0.08$ & $4.877 \pm 0.004$ & $0.28 \pm 0.01$ & 7.56 \\
\hline & & $42 \pm 3$ & $6.4 \pm 0.1$ & $1.1 \pm 0.1$ & 35.0 \\
\hline & & $37 \pm 3$ & $6.6 \pm 0.1$ & $0.3 \pm 0.1$ & 107. \\
\hline & & $40 \pm 3$ & $7.7 \pm 0.1$ & $0.4 \pm 0.1$ & 83.2 \\
\hline & & $8 \pm 3$ & $8.3 \pm 0.1$ & $0.5 \pm 0.1$ & 16.7 \\
\hline & & $14 \pm 3$ & $8.8 \pm 0.1$ & $0.4 \pm 0.1$ & 31.1 \\
\hline & & $3 \pm 3$ & $13.3 \pm 0.1$ & $0.5 \pm 0.1$ & 5.64 \\
\hline & & $1.6 \pm 0.3$ & $14.4 \pm 0.1$ & $0.5 \pm 0.1$ & 3.01 \\
\hline & & $7.3 \pm 0.4$ & $14.7 \pm 0.1$ & $0.4 \pm 0.1$ & 16.4 \\
\hline & & $2.5 \pm 0.4$ & $15.4 \pm 0.1$ & $0.4 \pm 0.1$ & 5.26 \\
\hline & & $1.3 \pm 0.4$ & $16.1 \pm 0.1$ & $0.4 \pm 0.1$ & 3.20 \\
\hline \multirow[t]{3}{*}{ 18151-1208 } & 32.8 & $11.75 \pm 0.09$ & $27.630 \pm 0.002$ & $0.323 \pm 0.003$ & 34.1 \\
\hline & & $31.16 \pm 0.08$ & $28.000 \pm 0.003$ & $0.258 \pm 0.007$ & 113. \\
\hline & & $0.57 \pm 0.05$ & $28.990 \pm 0.007$ & $0.30 \pm 0.03$ & 1.78 \\
\hline $18159-1648$ & 22.1 & $0.20 \pm 0.04$ & $22.7 \pm 0.1$ & $1.2 \pm 0.4$ & 0.154 \\
\hline \multirow[t]{5}{*}{ 18236-1205 } & 26.2 & $0.9 \pm 0.2$ & $25.1 \pm 0.1$ & $1.1 \pm 0.1$ & 0.746 \\
\hline & & $1.8 \pm 0.2$ & $25.2 \pm 0.1$ & $0.5 \pm 0.1$ & 3.37 \\
\hline & & $3.6 \pm 0.2$ & $27.2 \pm 0.1$ & $0.5 \pm 0.1$ & 6.19 \\
\hline & & $3.0 \pm 0.2$ & $28.7 \pm 0.1$ & $0.5 \pm 0.1$ & 5.98 \\
\hline & & $0.3 \pm 0.2$ & $29.9 \pm 0.1$ & $0.9 \pm 0.1$ & 0.341 \\
\hline \multirow[t]{2}{*}{$18247-1147$} & 55.9 & $0.34 \pm 0.02$ & $116.300 \pm 0.005$ & $0.23 \pm 0.01$ & 1.38 \\
\hline & & $0.31 \pm 0.02$ & $123.00 \pm 0.02$ & $0.39 \pm 0.04$ & 0.756 \\
\hline \multirow[t]{4}{*}{$18265-1517$} & $19.0^{b}$ & $8.83 \pm 0.06$ & $14.900 \pm 0.003$ & $0.256 \pm 0.002$ & 32.4 \\
\hline & & $1.44 \pm 0.09$ & $15.55 \pm 0.02$ & $0.53 \pm 0.04$ & 2.55 \\
\hline & & $6.02 \pm 0.06$ & $17.250 \pm 0.002$ & $0.324 \pm 0.004$ & 17.4 \\
\hline & & $2.33 \pm 0.06$ & $18.660 \pm 0.005$ & $0.38 \pm 0.01$ & 5.82 \\
\hline \multirow[t]{4}{*}{ 18316-0602 } & 42.2 & $0.5 \pm 0.4$ & $38.5 \pm 0.1$ & $0.4 \pm 0.1$ & 1.41 \\
\hline & & $4.0 \pm 0.4$ & $41.0 \pm 0.1$ & $0.9 \pm 0.1$ & 4.04 \\
\hline & & $39.3 \pm 0.4$ & $41.8 \pm 0.1$ & $0.3 \pm 0.1$ & 118. \\
\hline & & $0.7 \pm 0.4$ & $42.5 \pm 0.1$ & $0.4 \pm 0.1$ & 1.87 \\
\hline \multirow[t]{6}{*}{$18317-0845$} & 62.4 & $0.22 \pm 0.03$ & $59.67 \pm 0.05$ & $0.7 \pm 0.1$ & 0.304 \\
\hline & & $0.27 \pm 0.04$ & $63.15 \pm 0.03$ & $0.48 \pm 0.06$ & 0.537 \\
\hline & & $0.60 \pm 0.07$ & $63.890 \pm 0.005$ & $0.28 \pm 0.02$ & 1.99 \\
\hline & & $3.5 \pm 0.1$ & $64.39 \pm 0.01$ & $0.96 \pm 0.04$ & 3.39 \\
\hline & & $0.49 \pm 0.05$ & $65.020 \pm 0.005$ & $0.26 \pm 0.02$ & 1.75 \\
\hline & & $0.18 \pm 0.02$ & $65.77 \pm 0.01$ & $0.22 \pm 0.02$ & 0.771 \\
\hline \multirow[t]{4}{*}{ 18372-0541 } & 22.8 & $0.95 \pm 0.04$ & $18.25 \pm 0.01$ & $0.54 \pm 0.02$ & 1.65 \\
\hline & & $2.81 \pm 0.03$ & $22.900 \pm 0.001$ & $0.296 \pm 0.004$ & 8.91 \\
\hline & & $2.8 \pm 0.1$ & $24.06 \pm 0.02$ & $1.00 \pm 0.06$ & 2.67 \\
\hline & & $3.7 \pm 0.1$ & $24.860 \pm 0.003$ & $0.433 \pm 0.007$ & 8.11 \\
\hline \multirow[t]{3}{*}{$18408-0353$} & $102.1^{b}$ & $0.20 \pm 0.04$ & $100.00 \pm 0.06$ & $0.7 \pm 0.2$ & 0.293 \\
\hline & & $0.11 \pm 0.03$ & $105.30 \pm 0.03$ & $0.3 \pm 0.1$ & 0.334 \\
\hline & & $0.57 \pm 0.02$ & $106.400 \pm 0.003$ & $0.238 \pm 0.009$ & 2.24 \\
\hline \multirow[t]{6}{*}{$18488+0000$} & 83.2 & $2.7 \pm 0.3$ & $90.2 \pm 0.1$ & $0.6 \pm 0.1$ & 4.17 \\
\hline & & $1.7 \pm 0.3$ & $90.9 \pm 0.1$ & $0.4 \pm 0.1$ & 3.78 \\
\hline & & $0.6 \pm 0.3$ & $91.4 \pm 0.1$ & $0.2 \pm 0.1$ & 2.69 \\
\hline & & $6.3 \pm 0.3$ & $91.9 \pm 0.1$ & $0.4 \pm 0.1$ & 13.8 \\
\hline & & $0.27 \pm 0.02$ & $94.190 \pm 0.007$ & $0.24 \pm 0.02$ & 1.07 \\
\hline & & $0.12 \pm 0.02$ & $94.69 \pm 0.02$ & $0.25 \pm 0.04$ & 0.478 \\
\hline
\end{tabular}


F. Fontani et al.: Methanol masers in high-mass star forming regions

Table B.2. continued.

\begin{tabular}{|c|c|c|c|c|c|}
\hline Source & $\begin{array}{c}V_{\mathrm{LSR}}{ }^{a} \\
\left(\mathrm{~km} \mathrm{~s}^{-1}\right)\end{array}$ & $\begin{array}{c}\int F_{\nu} \mathrm{d} V \\
\left(\mathrm{Jy} \mathrm{km} \mathrm{s}{ }^{-1}\right)\end{array}$ & $\begin{array}{c}V \\
\left(\mathrm{~km} \mathrm{~s}^{-1}\right)\end{array}$ & $\begin{array}{c}\Delta V \\
\left(\mathrm{~km} \mathrm{~s}^{-1}\right)\end{array}$ & $\begin{array}{c}F_{\text {peak }} \\
(\mathrm{Jy})\end{array}$ \\
\hline \multirow[t]{4}{*}{$18507+0121$} & 57.1 & $8.62 \pm 0.02$ & $55.660 \pm 0.003$ & $0.394 \pm 0.003$ & 20.6 \\
\hline & & $0.17 \pm 0.01$ & $57.860 \pm 0.003$ & $0.20 \pm 0.01$ & 0.766 \\
\hline & & $0.93 \pm 0.08$ & $59.9 \pm 0.1$ & $0.4 \pm 0.1$ & 2.05 \\
\hline & & $1.8 \pm 0.08$ & $62.5 \pm 0.1$ & $0.6 \pm 0.1$ & 2.73 \\
\hline \multirow[t]{7}{*}{$18517+0437$} & 43.7 & $1.4 \pm 0.1$ & $39.64 \pm 0.03$ & $1.0 \pm 0.1$ & 1.33 \\
\hline & & $138.1 \pm 0.3$ & $41.180 \pm 0.003$ & $0.524 \pm 0.003$ & 248. \\
\hline & & $1.56 \pm 0.2$ & $42.75 \pm 0.04$ & $0.8 \pm 0.1$ & 1.88 \\
\hline & & $3.2 \pm 0.2$ & $45.34 \pm 0.05$ & $1.7 \pm 0.1$ & 1.81 \\
\hline & & $1.67 \pm 0.08$ & $45.910 \pm 0.004$ & $0.23 \pm 0.01$ & 6.74 \\
\hline & & $0.69 \pm 0.08$ & $48.22 \pm 0.02$ & $0.40 \pm 0.06$ & 1.62 \\
\hline & & $2.35 \pm 0.08$ & $51.26 \pm 0.01$ & $0.50 \pm 0.02$ & 4.38 \\
\hline $18532+0047$ & 58.6 & $0.23 \pm 0.02$ & $61.89 \pm 0.02$ & $0.48 \pm 0.05$ & 0.449 \\
\hline \multirow[t]{8}{*}{$18566+0408$} & 85.1 & $0.12 \pm 0.02$ & $78.41 \pm 0.02$ & $0.26 \pm 0.05$ & 0.447 \\
\hline & & $0.31 \pm 0.02$ & $79.19 \pm 0.01$ & $0.33 \pm 0.03$ & 0.882 \\
\hline & & $1.12 \pm 0.02$ & $79.680 \pm 0.004$ & $0.37 \pm 0.01$ & 2.80 \\
\hline & & $1.56 \pm 0.07$ & $83.7 \pm 0.1$ & $0.3 \pm 0.1$ & 4.72 \\
\hline & & $1.39 \pm 0.07$ & $84.3 \pm 0.1$ & $0.6 \pm 0.1$ & 2.09 \\
\hline & & $0.96 \pm 0.07$ & $84.9 \pm 0.1$ & $0.3 \pm 0.1$ & 2.65 \\
\hline & & $1.31 \pm 0.07$ & $86.3 \pm 0.1$ & $0.6 \pm 0.1$ & 2.18 \\
\hline & & $0.23 \pm 0.07$ & $87.7 \pm 0.1$ & $0.7 \pm 0.1$ & 0.302 \\
\hline \multirow[t]{5}{*}{$19230+1341$} & 39.6 & $6.69 \pm 0.01$ & $35.800 \pm 0.001$ & $0.658 \pm 0.003$ & 9.56 \\
\hline & & $16.10 \pm 0.05$ & $36.900 \pm 0.001$ & $0.867 \pm 0.003$ & 17.4 \\
\hline & & $1.00 \pm 0.03$ & $38.390 \pm 0.003$ & $0.32 \pm 0.01$ & 2.97 \\
\hline & & $3.43 \pm 0.05$ & $39.180 \pm 0.005$ & $0.93 \pm 0.02$ & 3.47 \\
\hline & & $0.95 \pm 0.03$ & $40.65 \pm 0.01$ & $0.74 \pm 0.03$ & 1.20 \\
\hline $19282+1814$ & 24.1 & $1.55 \pm 0.02$ & $18.860 \pm 0.004$ & $0.513 \pm 0.008$ & 2.83 \\
\hline \multirow[t]{5}{*}{$19388+2357$} & 34.6 & $3.3 \pm 0.4$ & $36.4 \pm 0.1$ & $0.7 \pm 0.1$ & 4.18 \\
\hline & & $3.5 \pm 0.4$ & $37.2 \pm 0.1$ & $0.5 \pm 0.1$ & 6.75 \\
\hline & & $8.8 \pm 0.4$ & $38.2 \pm 0.1$ & $0.4 \pm 0.1$ & 23.0 \\
\hline & & $0.4 \pm 0.4$ & $38.7 \pm 0.1$ & $0.2 \pm 0.1$ & 1.63 \\
\hline & & $1.1 \pm 0.4$ & $39.6 \pm 0.1$ & $0.4 \pm 0.1$ & 2.90 \\
\hline \multirow{4}{*}{$20062+3550$} & 0.6 & $0.49 \pm 0.05$ & $-3.0 \pm 0.1$ & $0.5 \pm 0.1$ & 0.883 \\
\hline & & $0.48 \pm 0.05$ & $-2.6 \pm 0.1$ & $0.3 \pm 0.1$ & 1.57 \\
\hline & & $1.47 \pm 0.05$ & $5.9 \pm 0.1$ & $0.4 \pm 0.1$ & 3.75 \\
\hline & 0.6 & $0.83 \pm 0.05$ & $6.6 \pm 0.1$ & $0.4 \pm 0.1$ & 1.92 \\
\hline \multirow[t]{6}{*}{$20126+4104$} & -3.9 & $1.49 \pm 0.03$ & $-8.393 \pm 0.005$ & $0.56 \pm 0.02$ & 2.52 \\
\hline & & $4.6 \pm 0.9$ & $-7.7 \pm 0.1$ & $0.4 \pm 0.1$ & 11.0 \\
\hline & & $4.9 \pm 0.9$ & $-6.5 \pm 0.1$ & $0.5 \pm 0.1$ & 9.09 \\
\hline & & $18.5 \pm 0.9$ & $-6.6 \pm 0.1$ & $1.3 \pm 0.1$ & 13.4 \\
\hline & & $12.2 \pm 0.9$ & $-6.2 \pm 0.1$ & $0.3 \pm 0.1$ & 41.4 \\
\hline & & $1.2 \pm 0.9$ & $-4.9 \pm 0.1$ & $0.4 \pm 0.1$ & 2.68 \\
\hline \multirow[t]{2}{*}{$20350+4126$} & $-2.5^{b}$ & $0.20 \pm 0.03$ & $-10.93 \pm 0.08$ & $0.9 \pm 0.2$ & 0.206 \\
\hline & & $0.09 \pm 0.02$ & $-4.07 \pm 0.04$ & $0.31 \pm 0.07$ & 0.268 \\
\hline \multirow[t]{5}{*}{$21306+5540^{*}$} & $-71.1^{f}$ & $0.13 \pm 0.02$ & $-78.27 \pm 0.05$ & $0.6 \pm 0.1$ & 0.22 \\
\hline & & $0.38 \pm 0.02$ & $-73.33 \pm 0.01$ & $0.36 \pm 0.02$ & 1.01 \\
\hline & & $0.49 \pm 0.03$ & $-71.04 \pm 0.02$ & $0.69 \pm 0.06$ & 0.66 \\
\hline & & $0.47 \pm 0.03$ & $-69.90 \pm 0.01$ & $0.46 \pm 0.04$ & 0.95 \\
\hline & & $0.20 \pm 0.03$ & $-68.66 \pm 0.08$ & $1.0 \pm 0.2$ & 0.2 \\
\hline \multirow[t]{4}{*}{$22272+6358$} & -9.9 & $0.46 \pm 0.02$ & $-12.880 \pm 0.008$ & $0.30 \pm 0.02$ & 1.43 \\
\hline & & $0.37 \pm 0.02$ & $-12.40 \pm 0.02$ & $0.41 \pm 0.03$ & 0.853 \\
\hline & & $20.78 \pm 0.02$ & $-11.010 \pm 0.003$ & $0.367 \pm 0.003$ & 53.1 \\
\hline & & $6.03 \pm 0.02$ & $-10.270 \pm 0.001$ & $0.372 \pm 0.002$ & 15.2 \\
\hline \multirow[t]{2}{*}{$22506+5944$} & -51.5 & $0.17 \pm 0.04$ & $-55.6 \pm 0.1$ & $0.9 \pm 0.3$ & 0.172 \\
\hline & & $0.81 \pm 0.02$ & $-53.880 \pm 0.006$ & $0.44 \pm 0.01$ & 1.72 \\
\hline \multirow[t]{5}{*}{$22543+6145^{*}$} & $-11.1^{c}$ & $71 \pm 1$ & $-4.7 \pm 0.1$ & $0.6 \pm 0.1$ & 147 \\
\hline & & $129 \pm 1$ & $-4.1 \pm 0.1$ & $0.3 \pm 0.1$ & 361 \\
\hline & & $101 \pm 1$ & $-3.8 \pm 0.1$ & $0.2 \pm 0.1$ & 394 \\
\hline & & $156 \pm 1$ & $-2.5 \pm 0.1$ & $0.5 \pm 0.1$ & 296 \\
\hline & & $30 \pm 1$ & $-1.8 \pm 0.1$ & $0.3 \pm 0.1$ & 92 \\
\hline
\end{tabular}

Notes. ${ }^{(*)}$ Sources rejected by Palla et al. (1991); ${ }^{(a)}$ from Molinari et al. (1996) except when differently specified; ${ }^{(b)}$ from NH observations performed with the Nobeyama $45-\mathrm{m}$ telescope simultaneously to the $\mathrm{CH}_{3} \mathrm{OH}$ maser observations; ${ }^{(c)}$ from CS (2-1) observations, Bronfman et al. (1996); ${ }^{(d)}$ from Sridharan et al. (2002); ${ }^{(e)}$ from Richards et al. (1987); ${ }^{(f)}$ from Sunada et al. (2007) and references therein. 
Table B.3. Same as Table B. 2 for low sources.

\begin{tabular}{|c|c|c|c|c|c|}
\hline Source & $\begin{array}{c}V_{\mathrm{LSR}}{ }^{a} \\
\left(\mathrm{~km} \mathrm{~s}^{-1}\right)\end{array}$ & $\begin{array}{c}\int F_{v} \mathrm{~d} V \\
\left(\mathrm{Jy} \mathrm{km} \mathrm{s}{ }^{-1}\right)\end{array}$ & $\begin{array}{c}V \\
\left(\mathrm{~km} \mathrm{~s}^{-1}\right)\end{array}$ & $\begin{array}{c}\Delta V \\
\left(\mathrm{~km} \mathrm{~s}^{-1}\right)\end{array}$ & $\begin{array}{c}F_{\text {peak }} \\
(\mathrm{Jy})\end{array}$ \\
\hline $05137+3919$ & -25.4 & $0.21 \pm 0.06$ & $-16.2 \pm 0.1$ & $0.6 \pm 0.2$ & 0.3 \\
\hline \multirow[t]{4}{*}{$06099+1800^{*}$} & $7.1^{f}$ & $1.8 \pm 0.9$ & $1.9 \pm 0.1$ & $0.6 \pm 0.1$ & 2.8 \\
\hline & & $5.1 \pm 0.9$ & $4.0 \pm 0.1$ & $0.3 \pm 0.1$ & 15.9 \\
\hline & & $28.7 \pm 0.9$ & $4.6 \pm 0.1$ & $0.4 \pm 0.1$ & 63.6 \\
\hline & & $15.6 \pm 0.9$ & $5.4 \pm 0.1$ & $0.4 \pm 0.1$ & 35.4 \\
\hline $17450-2742$ & -16.9 & $0.39 \pm 0.02$ & $-12.15 \pm 0.01$ & $0.37 \pm 0.03$ & 0.986 \\
\hline \multirow[t]{13}{*}{$18024-2119$} & 0.5 & $25 \pm 4$ & $-5.33 \pm 0.03$ & $0.42 \pm 0.08$ & 56.0 \\
\hline & & $67 \pm 3$ & $-4.29 \pm 0.07$ & $0.8 \pm 0.2$ & 78.9 \\
\hline & & $28 \pm 2$ & $-3.81 \pm 0.02$ & $0.32 \pm 0.05$ & 83.9 \\
\hline & & $39 \pm 2$ & $-3.22 \pm 0.03$ & $0.50 \pm 0.07$ & 73.4 \\
\hline & & $27 \pm 2$ & $-5.3 \pm 0.1$ & $0.5 \pm 0.1$ & 55.4 \\
\hline & & $48 \pm 2$ & $-4.4 \pm 0.1$ & $0.6 \pm 0.1$ & 74.2 \\
\hline & & $51 \pm 2$ & $-3.8 \pm 0.1$ & $0.5 \pm 0.1$ & 105. \\
\hline & & $33 \pm 2$ & $-3.2 \pm 0.1$ & $0.4 \pm 0.1$ & 76.5 \\
\hline & & $5 \pm 2$ & $-2.6 \pm 0.1$ & $0.6 \pm 0.1$ & 8.65 \\
\hline & & $6.2 \pm 0.3$ & $-0.827 \pm 0.004$ & $0.86 \pm 0.06$ & 6.75 \\
\hline & & $10.7 \pm 0.2$ & $-9.90 .09 \pm 0.006$ & $0.62 \pm 0.01$ & 16.1 \\
\hline & & $54.3 \pm 0.3$ & $1.891 \pm 0.004$ & $1.066 \pm 0.009$ & 47.9 \\
\hline & & $24.4 \pm 0.1$ & $2.69 \pm 0.01$ & $1.29 \pm 0.03$ & 17.7 \\
\hline \multirow[t]{6}{*}{$18144-1723$} & 47.3 & $1.40 \pm 0.04$ & $47.510 \pm 0.005$ & $0.43 \pm 0.01$ & 3.04 \\
\hline & & $8.95 \pm 0.04$ & $49.020 \pm 0.003$ & $0.464 \pm 0.003$ & 18.1 \\
\hline & & $6.35 \pm 0.04$ & $49.600 \pm 0.003$ & $0.355 \pm 0.003$ & 16.8 \\
\hline & & $2.18 \pm 0.03$ & $50.330 \pm 0.004$ & $0.464 \pm 0.007$ & 4.42 \\
\hline & & $12.51 \pm 0.03$ & $51.090 \pm 0.003$ & $0.479 \pm 0.003$ & 24.5 \\
\hline & & $1.50 \pm 0.02$ & $51.900 \pm 0.003$ & $0.344 \pm 0.006$ & 4.10 \\
\hline \multirow[t]{2}{*}{$18181-1534$} & $-5.8^{b}$ & $1.61 \pm 0.03$ & $-3.740 \pm 0.002$ & $0.296 \pm 0.006$ & 5.1 \\
\hline & & $20.06 \pm 0.03$ & $-2.999 \pm 0.003$ & $0.399 \pm 0.003$ & 47.2 \\
\hline \multirow[t]{2}{*}{$18224-1228$} & $48.8^{b}$ & $2.14 \pm 0.02$ & $38.700 \pm 0.002$ & $0.394 \pm 0.005$ & 5.1 \\
\hline & & $0.08 \pm 0.01$ & $39.60 \pm 0.02$ & $0.19 \pm 0.04$ & 0.401 \\
\hline \multirow[t]{11}{*}{ 18278-1009 } & 93.7 & $0.07 \pm 0.02$ & $108.70 \pm 0.02$ & $0.19 \pm 0.09$ & 0.35 \\
\hline & & $0.45 \pm 0.02$ & $109.800 \pm 0.007$ & $0.35 \pm 0.02$ & 1.19 \\
\hline & & $0.46 \pm 0.02$ & $110.900 \pm 0.005$ & $0.30 \pm 0.01$ & 1.46 \\
\hline & & $1.7 \pm 0.2$ & $115.9 \pm 0.1$ & $1.1 \pm 0.1$ & 1.48 \\
\hline & & $2.5 \pm 0.2$ & $116.5 \pm 0.1$ & $0.5 \pm 0.1$ & 4.46 \\
\hline & & $5.4 \pm 0.2$ & $117.2 \pm 0.1$ & $0.5 \pm 0.1$ & 9.98 \\
\hline & & $1.1 \pm 0.2$ & $117.9 \pm 0.1$ & $0.4 \pm 0.1$ & 2.50 \\
\hline & 93.7 & $0.4 \pm 0.2$ & $118.4 \pm 0.1$ & $0.3 \pm 0.1$ & 1.13 \\
\hline & & $1.24 \pm 0.02$ & $119.000 \pm 0.003$ & $0.405 \pm 0.009$ & 2.88 \\
\hline & & $0.86 \pm 0.04$ & $119.600 \pm 0.007$ & $0.39 \pm 0.02$ & 2.08 \\
\hline & & $0.22 \pm 0.04$ & $120.20 \pm 0.05$ & $0.5 \pm 0.1$ & 0.381 \\
\hline \multirow[t]{5}{*}{ 18441-0134 } & $57.6^{b}$ & $0.22 \pm 0.07$ & $78.0 \pm 0.1$ & $0.2 \pm 0.1$ & 1.02 \\
\hline & & $2.05 \pm 0.07$ & $79.2 \pm 0.1$ & $0.8 \pm 0.1$ & 2.54 \\
\hline & & $3.53 \pm 0.07$ & $80.9 \pm 0.1$ & $1.1 \pm 0.1$ & 3.04 \\
\hline & & $0.36 \pm 0.02$ & $83.080 \pm 0.005$ & $0.26 \pm 0.01$ & 1.31 \\
\hline & & $0.35 \pm 0.02$ & $83.870 \pm 0.009$ & $0.35 \pm 0.02$ & 0.946 \\
\hline $18511+0146$ & 56.8 & $0.12 \pm 0.02$ & $59.74 \pm 0.03$ & $0.42 \pm 0.08$ & 0.27626 \\
\hline \multirow[t]{8}{*}{$18527+0301$} & 76.0 & $3.6 \pm 0.3$ & $70.3 \pm 0.1$ & $0.6 \pm 0.1$ & 5.78 \\
\hline & & $2.0 \pm 0.3$ & $71.9 \pm 0.1$ & $0.6 \pm 0.1$ & 3.00 \\
\hline & & $10.1 \pm 0.3$ & $72.8 \pm 0.1$ & $0.7 \pm 0.1$ & 14.4 \\
\hline & & $9.1 \pm 0.3$ & $74.3 \pm 0.1$ & $0.5 \pm 0.1$ & 18.2 \\
\hline & & $0.8 \pm 0.3$ & $76.1 \pm 0.1$ & $0.4 \pm 0.1$ & 2.02 \\
\hline & & $1.06 \pm 0.08$ & $81.4 \pm 0.1$ & $0.6 \pm 0.1$ & 1.55 \\
\hline & & $1.32 \pm 0.08$ & $82.1 \pm 0.1$ & $0.4 \pm 0.1$ & 3.29 \\
\hline & & $2.64 \pm 0.08$ & $83.9 \pm 0.1$ & $0.7 \pm 0.1$ & 3.78 \\
\hline $19012+0505$ & 40.4 & $0.32 \pm 0.04$ & $31.95 \pm 0.06$ & $1.2 \pm 0.2$ & 0.243 \\
\hline \multirow[t]{6}{*}{$19092+0841$} & 58.0 & $3.7 \pm 0.09$ & $54.8 \pm 0.1$ & $0.6 \pm 0.1$ & 6.31 \\
\hline & & $0.56 \pm 0.09$ & $55.5 \pm 0.1$ & $0.4 \pm 0.1$ & 1.49 \\
\hline & & $0.61 \pm 0.09$ & $56.2 \pm 0.1$ & $0.4 \pm 0.1$ & 1.34 \\
\hline & & $0.84 \pm 0.09$ & $56.8 \pm 0.1$ & $0.6 \pm 0.1$ & 1.24 \\
\hline & & $0.16 \pm 0.09$ & $58.1 \pm 0.1$ & $0.3 \pm 0.1$ & 0.539 \\
\hline & & $1.67 \pm 0.04$ & $62.440 \pm 0.009$ & $0.96 \pm 0.03$ & 1.63 \\
\hline
\end{tabular}


F. Fontani et al.: Methanol masers in high-mass star forming regions

Table B.3. continued.

\begin{tabular}{cccccc}
\hline \hline Source & $\begin{array}{c}V_{\mathrm{LSR}}{ }^{a} \\
\left(\mathrm{~km} \mathrm{~s}^{-1}\right)\end{array}$ & $\begin{array}{c}\int F_{v} \mathrm{~d} V \\
\left(\mathrm{Jy} \mathrm{km} \mathrm{s}^{-1}\right)\end{array}$ & $\begin{array}{c}V \\
\left(\mathrm{~km} \mathrm{~s}^{-1}\right)\end{array}$ & $\begin{array}{c}\Delta V \\
\left(\mathrm{~km} \mathrm{~s}^{-1}\right)\end{array}$ & $\begin{array}{c}F_{\text {peak }} \\
(\mathrm{Jy})\end{array}$ \\
\hline $19120+1148$ & 55.0 & $0.16 \pm 0.02$ & $57.96 \pm 0.04$ & $0.6 \pm 0.1$ & 0.251 \\
& & $0.21 \pm 0.02$ & $59.00 \pm 0.01$ & $0.39 \pm 0.05$ & 0.519 \\
$19186+1440$ & & $0.15 \pm 0.03$ & $62.11 \pm 0.09$ & $1.0 \pm 0.2$ & 0.141 \\
& & $0.47 \pm 0.02$ & $-26.670 \pm 0.007$ & $0.33 \pm 0.02$ & 1.33 \\
& & $1.37 \pm 0.03$ & $-25.800 \pm 0.008$ & $0.79 \pm 0.02$ & 1.62 \\
& & $0.18 \pm 0.05$ & $-23.99 \pm 0.08$ & $0.9 \pm 0.5$ & 0.185 \\
& & $0.92 \pm 0.07$ & $-14.86 \pm 0.03$ & $0.78 \pm 0.06$ & 1.11 \\
& & $2.75 \pm 0.06$ & $-14.370 \pm 0.006$ & $0.37 \pm 0.01$ & 1.90 \\
& & $3.15 \pm 0.03$ & $-13.380 \pm 0.003$ & $0.677 \pm 0.008$ & 3.50 \\
$22187+5559$ & $-45.2^{e}$ & $2.97 \pm 0.03$ & $-12.110 \pm 0.003$ & $0.698 \pm 0.006$ & 4.24 \\
& & $0.09 \pm 0.03$ & $-11.44 \pm 0.08$ & $0.6 \pm 0.3$ & 0.133 \\
\hline
\end{tabular}

Table B.4. Parameters of the $44 \mathrm{GHz} \mathrm{CH} 3 \mathrm{OH}$ maser (Class I) detected with the Nobeyama 45-m telescope for both high (the IRAS name begins with $\mathrm{H}$ ) and low (the IRAS name is begins with $\mathrm{L}$ ) sources.

\begin{tabular}{|c|c|c|c|c|c|}
\hline Source ${ }^{a}$ & $\begin{array}{c}V_{\mathrm{LSR}} \\
\left(\mathrm{km} \mathrm{s}^{-1}\right)\end{array}$ & 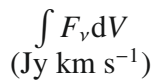 & $\begin{array}{c}V \\
\left(\mathrm{~km} \mathrm{~s}^{-1}\right)\end{array}$ & $\begin{array}{c}\Delta V \\
\left(\mathrm{~km} \mathrm{~s}^{-1}\right)\end{array}$ & $\begin{array}{c}F_{v}^{\text {peak }} \\
(\mathrm{Jy})\end{array}$ \\
\hline H05168+3634 & -15.1 & $1.12 \pm 0.2$ & $-4.9 \pm 0.2$ & $1.3 \pm 0.4$ & 0.80 \\
\hline $\mathrm{H} 05480+2545$ & $-9.3^{b}$ & $3.3 \pm 0.1$ & $-9.79 \pm 0.02$ & $0.77 \pm 0.05$ & 4.08 \\
\hline H06103+3030 & 15.6 & $2.7 \pm 0.6$ & $16.4 \pm 0.7$ & $5 \pm 1.5$ & 0.51 \\
\hline H18089-1732 & 32.9 & $10.9 \pm 0.4$ & $31.94 \pm 0.01$ & $0.86 \pm 0.04$ & 11.8 \\
\hline \multirow[t]{2}{*}{ H18151-1208 } & 32.8 & $2.2 \pm 0.2$ & $30.5 \pm 0.1$ & $1.5 \pm 0.3$ & 1.34 \\
\hline & & $2.0 \pm 0.4$ & $33.8 \pm 0.2$ & $2.1 \pm 0.5$ & 0.89 \\
\hline \multirow[t]{5}{*}{ H18159-1648 } & 22.1 & $4.0 \pm 0.6$ & $13.2 \pm 0.1$ & $0.9 \pm 0.1$ & 3.95 \\
\hline & & $10.9 \pm 0.6$ & $19.5 \pm 0.1$ & $1.0 \pm 0.1$ & 10.01 \\
\hline & & $15.8 \pm 0.6$ & $20.9 \pm 0.1$ & $1.0 \pm 0.1$ & 6.97 \\
\hline & & $31.4 \pm 0.6$ & $22.9 \pm 0.1$ & $0.9 \pm 0.1$ & 32.11 \\
\hline & & $18.5 \pm 0.6$ & $23.9 \pm 0.1$ & $0.6 \pm 0.1$ & 27.9 \\
\hline \multirow[t]{3}{*}{ H18316-0602 } & 42.2 & $6.6 \pm 0.1$ & $42.060 \pm 0.008$ & $0.62 \pm 0.02$ & 9.88 \\
\hline & & $1.6 \pm 0.2$ & $43.10 \pm 0.04$ & $0.70 \pm 0.09$ & 2.07 \\
\hline & & $2.9 \pm 0.4$ & $44.52 \pm 0.09$ & $1.6 \pm 0.3$ & 1.67 \\
\hline \multirow{2}{*}{ H18360-0537 } & 102.3 & $6.7 \pm 0.4$ & $102.4 \pm 0.1$ & $2.83 \pm 0.2$ & 2.23 \\
\hline & & $1.6 \pm 0.4$ & $106.4 \pm 0.3$ & $1.9 \pm 0.7$ & 0.74 \\
\hline H18507+0121 & 57.1 & $10.0 \pm 0.4$ & $60.33 \pm 0.04$ & $1.3 \pm 0.1$ & 7.00 \\
\hline H18517+0437 & 43.7 & $3.1 \pm 0.2$ & $43.97 \pm 0.05$ & $1.1 \pm 0.1$ & 2.70 \\
\hline \multirow[t]{2}{*}{ H19043+0726 } & 58.9 & $2.5 \pm 0.2$ & $58.69 \pm 0.03$ & $0.65 \pm 0.09$ & 3.52 \\
\hline & & $1.1 \pm 0.2$ & $59.89 \pm 0.08$ & $0.7 \pm 0.2$ & 1.31 \\
\hline H19088+0902 & 59.6 & $10 \pm 1$ & $58.67 \pm 0.07$ & $2.2 \pm 0.2$ & 2.0 \\
\hline H19388+2357 & 34.6 & $1.8 \pm 0.4$ & $35.4 \pm 0.2$ & $1.6 \pm 0.4$ & 1.07 \\
\hline H20050+2720 & 6.4 & $2.0 \pm 0.2$ & $6.6 \pm 0.1$ & $1.8 \pm 0.3$ & 1.09 \\
\hline H20062+3550 & 0.6 & $2.5 \pm 0.2$ & $0.60 \pm 0.06$ & $1.0 \pm 0.1$ & 2.36 \\
\hline H20126+4104 & -3.9 & $8.9 \pm 0.4$ & $-2.43 \pm 0.04$ & $2.0 \pm 0.1$ & 4.17 \\
\hline H20188+3928 & 1.5 & $2 \pm 1$ & $3 \pm 1$ & $3 \pm 2$ & 0.76 \\
\hline \multirow[t]{2}{*}{ H21391+5802 } & 0.4 & $4.2 \pm 0.2$ & $-0.49 \pm 0.02$ & $0.73 \pm 0.08$ & 5.33 \\
\hline & & $5.4 \pm 0.4$ & $6.6 \pm 0.1$ & $2.3 \pm 0.3$ & 2.25 \\
\hline \multirow[t]{2}{*}{ H22506+5944 } & -51.5 & $3 \pm 1$ & $-51.3 \pm 0.1$ & $1.6 \pm 0.6$ & 1.81 \\
\hline & & $4 \pm 2$ & $-48 \pm 1$ & $5 \pm 2$ & 0.8 \\
\hline L00420+5530 & -51.20 & $1.6 \pm 0.4$ & $-48.8 \pm 0.3$ & $2.0 \pm 0.5$ & 0.8 \\
\hline L18018-2426 & 10.5 & $241.1 \pm 0.4$ & $11.280 \pm 0.003$ & $0.669 \pm 0.002$ & 339 \\
\hline \multirow[t]{2}{*}{ L18024-2119 } & 0.5 & $10.0 \pm 0.4$ & $0.31 \pm 0.02$ & $1.28 \pm 0.05$ & 7.34 \\
\hline & & $3.1 \pm 0.4$ & $2.7 \pm 0.1$ & $2.3 \pm 0.3$ & 1.4 \\
\hline L18144-1723 & 47.3 & $42.1 \pm 0.2$ & $48.590 \pm 0.005$ & $1.54 \pm 0.01$ & 25.6 \\
\hline L18162-1612 & 61.8 & $5.1 \pm 0.2$ & $62.80 \pm 0.03$ & $0.84 \pm 0.07$ & 3.2 \\
\hline L18396-0431 & 97.3 & $1.0 \pm 0.2$ & $97.6 \pm 0.1$ & $1.0 \pm 0.3$ & 1.0 \\
\hline L19092+0841 & 58.0 & $4.0 \pm 0.4$ & $59.07 \pm 0.4$ & $5.7 \pm 0.7$ & 0.65 \\
\hline L23385+6053 & -50.0 & $2.9 \pm 0.4$ & $-50.6 \pm 0.3$ & $3.2 \pm 0.7$ & 0.9 \\
\hline
\end{tabular}

Notes. ${ }^{(a)}$ "L" and "H" indicate if the source belongs to the low or high sample; ${ }^{(b)}$ from $\mathrm{NH}_{3}$ observations performed with the Nobeyama 45-m telescope. 
A\&A 517, A56 (2010)

Table B.5. Same as Table B.4 for the $95 \mathrm{GHz} \mathrm{CH} 3 \mathrm{OH}$ maser (Class I) detected with the Nobeyama 45-m telescope.

\begin{tabular}{cccccc}
\hline \hline Source $^{a}$ & $\begin{array}{c}V_{\mathrm{LSR}} \\
\left(\mathrm{km} \mathrm{s}^{-1}\right)\end{array}$ & $\begin{array}{c}\int F_{v} \mathrm{~d} V \\
\left(\mathrm{Jy} \mathrm{km} \mathrm{s}^{-1}\right)\end{array}$ & $\begin{array}{c}V \\
\left(\mathrm{~km} \mathrm{~s}^{-1}\right)\end{array}$ & $\begin{array}{c}\Delta V \\
\left(\mathrm{~km} \mathrm{~s}^{-1}\right)\end{array}$ & $\begin{array}{c}F_{v}^{\text {peak }} \\
(\mathrm{Jy})\end{array}$ \\
\hline H05480+2545 & $-9.3^{b}$ & $3.1 \pm 0.6$ & $-10.6 \pm 0.1$ & $1.3 \pm 0.3$ & 2.2 \\
$\mathrm{H} 18089-1732$ & 32.9 & $2.7 \pm 0.4$ & $31.38 \pm 0.02$ & $0.45 \pm 0.05$ & 5.5 \\
& & $14 \pm 2$ & $32.4 \pm 0.2$ & $3.2 \pm 0.4$ & 4.2 \\
$\mathrm{H} 18159-1648$ & 22.1 & $4.7 \pm 0.8$ & $20.1 \pm 0.1$ & $1.6 \pm 0.4$ & 2.7 \\
& & $7.6 \pm 0.6$ & $22.56 \pm 0.06$ & $1.4 \pm 0.1$ & 5.2 \\
$\mathrm{H} 18316-0602$ & 42.2 & $1.1 \pm 0.2$ & $41.63 \pm 0.05$ & $0.5 \pm 0.1$ & 2.1 \\
$\mathrm{H} 18360-0537$ & 102.3 & $13.2 \pm 0.8$ & $102.5 \pm 0.1$ & $4.1 \pm 0.4$ & 4.0 \\
H20126+4104 & -3.9 & $6.0 \pm 0.4$ & $-2.75 \pm 0.08$ & $2.3 \pm 0.2$ & 2.5 \\
$\mathrm{H} 21391+5802$ & 0.4 & $2.5 \pm 0.6$ & $12.1 \pm 0.1$ & $1.2 \pm 0.5$ & 2.0 \\
$\mathrm{H} 22506+5944$ & -51.5 & $5 \pm 1$ & $-47.1 \pm 0.2$ & $2.4 \pm 0.6$ & 2.0 \\
L18018-2426 & 10.5 & $33.5 \pm 0.4$ & $10.800 \pm 0.004$ & $0.622 \pm 0.009$ & 50 \\
L18144-1723 & 47.3 & $26.4 \pm 0.6$ & $47.91 \pm 0.03$ & $2.07 \pm 0.08$ & 12 \\
L18396-0431 & 97.3 & $3.8 \pm 0.4$ & $50.37 \pm 0.08$ & $1.24 \pm 0.2$ & 2.9 \\
& & $14 \pm 2$ & $57.4 \pm 0.6$ & $7 \pm 1$ & 1.9 \\
& & $4 \pm 1$ & $61.5 \pm 0.1$ & $1.3 \pm 0.4$ & 2.5 \\
& & $8.0 \pm 0.8$ & $71.3 \pm 0.2$ & $3.4 \pm 0.6$ & 2.2 \\
& & $1.6 \pm 0.2$ & $130.50 \pm 0.08$ & $0.7 \pm 0.1$ & 2.1 \\
\hline
\end{tabular}

Notes. ${ }^{(a)}$ "L" and "H" indicate if the source belongs to the low or high sample; ${ }^{(b)}$ from $\mathrm{NH}_{3}$ observations performed with the Nobeyama $45-\mathrm{m}$ telescope. 